\title{
DOE/EA- -1202
}

\section{ENVIRONMENTAL ASSESSMENT}

\section{MCCULLOUGH}

TO

RECEIVED

LIBERTY

AUG 061997

FIBER OPTICS

PROJECT

O\&।

PREPARED FOR

U.S. DOE WESTERN AREA POWER ADMINISTRATION

DOE/EA-1202

PREPARED BY

DAMES \& MOORE 



\section{U.S. DEPARTMENT OF ENERGY}

Western Area Power Administration

\section{RECEIVED}

AUG 061997

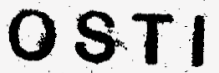

McCullough to Liberty Fiber Optics Project; Clark County, Nevada, San Bernadino County, California, and Mohave, La Paz and Maricopa Counties, Arizona

AGENCY: Western Area Power Administration, DOE.

ACTION: Findings of No Significant Impact

SUMMARY: The U.S. Department of Energy, Western Area Power Administration (Western) proposes to replace an existing overhead static wire with a shield wire that contains optical fibers (OPGW) on transmission lines from McCullough Substation, south of Las Vegas, Nevada, to Liberty Substation near Phoenix, Arizona. The replacement will occur on the McCulloughDavis, Davis-Parker No. 2, and Parker-Liberty No. $1230-\mathrm{kV}$ transmission lines. Western is responsible for the operation and maintenance of the lines.

Western prepared an Environmental Assessment (EA) entitled "McCullough to Liberty Fiber Optics Project" (DOE/EA-1202). The EA contains the analysis of the proposed construction, operation, and maintenance of the OPGW. Based on the analysis in the EA, Western finds that the proposed action is not a major Federal action significantly affecting the quality of the human environment, within the meaning of the National Environmental Policy Act (NEPA) of 1969. The preparation of an environmental impact statement (EIS) is not required, and therefore; Western is issuing this Findings of No Significant Impact (FONSI).

\section{FOR FURTHER INFORMATION CONTACT:}

Mr. J. Tyler Carlson

Regional Manager

Desert Southwest Region

Western Area Power Administration

P.O. Box 6457

Phoenix, AZ 85005 (602) 352-2525 
Additional information and copies of the EA and FONSI are available to all interested persons and the general public from the person named above. For general information on DOE NEPA activities contact:

Ms. Carol M. Borgstrom, Director

Office of NEPA Oversight, EH-42

U.S. Department of Energy

1000 Independence Avenue, SW

Washington DC 20585

(202) $586-4600$ or $(800) 472-2756$.

SUPPLEMENTARY INFORMATION: Western proposes to replace one of the existing overhead static wires along Federal transmission lines with an OPGW. The United States has entered into an arrangement with a commercial telecommunications company to build a system capable of meeting the telecommunications needs of the United States.

Lattice steel structures, supporting the existing 230-kV transmission lines between McCullough Substation in southern Nevada and Liberty Substation in Arizona would be used to support the OPGW. The total length of project would be approximately 250 miles and include the following transmission lines: McCullough-Davis, Davis-Parker No. 2, and Parker-Liberty No. 1 lines. In addition to the OPGW, a total of eight regeneration facilities that would enhance the signal would have to be constructed. Five of these would be located at existing substations and three at other locations along the lines. Regeneration stations would be placed 25 to 45 miles apart along the route. Majority of the construction would take place within the existing Right-Of-Way (ROW) with the exception of three regeneration sites located on U.S. Bureau of Land Management (BLM) land adjacent to the ROW.

The purpose of the proposed action is to provide the United States with increased data transmission capacity to key components of the communication centers of McCullough, Davis Dam, Parker Dam, Harcuvar, Hassayampa Tap, and Liberty substations by an existing connection to Western's Phoenix control center. Fiber optical laterals to Havasu, Bouse Hills, and Hassayampa Pumping Plants of the Central Arizona Project would be included in the project 
design. The project would enhance Western's communication by providing loop closure and increased reliability for the microwave based data link for the Supervisory Control and Data Acquisition system presently used in serving the Colorado River and north to the Mead Substation in Boulder City, Nevada. Overall, this project would increase system reliability and reduce the dependence on a single communication path currently provided by microwave systems.

Several alternatives to the proposed action were considered including: the No Action alternative, alternative locations of regeneration sites, a routing alternative to avoid the Crossman Peak Natural Scenic Area, alternative sources of power for the regeneration stations, and alternatives to using overhead wires.

The No Action alternative would not meet the stated purpose and need for the project.

Three alternative sites for regeneration stations were evaluated: two sites near Topock, Arizona, and a site near Aguila, Arizona. They were rejected because of safety and environmental concerns, including: proximity to several high-pressure gas pipelines, proximity to floodplains, visual resources, and the need for power on site.

In order to avoid the Crossman Peak Natural Scenic Area, an alternative was considered that would place the OPGW on a different transmission line near Lake Havasu. The alternative would involved changing the OPGW from the Davis-Parker No. 2 line to the Davis-Parker No. 1 line, near the Topock Regeneration Station, passing through the city of Lake Havasu and then changing back to the Davis-Parker No. 2 line at Black Mesa Substation. This route was eliminated because of the environmental impacts associated with construction in Lake Havasu City, and the change of ownership of the line segments involved.

Two proposed regeneration sites, Harcuvar and Hassayampa Tap, do not have a power source readily available. The alternatives to obtain power that were evaluated were:

- installing a transformer inside each existing substation, or 
- at Harcuvar regeneration site, installing a distribution line from the Alamo Dam. Access Road for approximately one mile to the regeneration site, and

- at the Hassayampa Tap regeneration site, replacing one of the overhead static wires with an electrical distribution line on the Hassayampa Pumping Plant transmission line to the regeneration site or adding a distribution line to the waist of the existing transmission line structures.

Further engineering work is needed to determine the best power option. None of the alternatives would result in significant impacts, although adding a distribution line at the waist of the structures may slightly increase the potential for bird collisions.

Along the route of the McCullough-Davis and Parker-Liberty No. 1 lines, several other highvoltage transmission lines converge and cross over the lines. In these areas, in order to comply with the National Electric Safety Code, there is no overhead static wire between the structures. The following alternatives were considered for installing the fiber optic wire:

- attaching the OPGW to the structures at other places on the structure and continuing the OPGW overhead, or

- trenching within the existing ROW between each structure where no static wire is present.

For the McCullough-Davis and Parker-Liberty lines, the OPGW would be installed on the structures.

Current residential, institutional, industrial, and recreational land uses in the project area, including the Crossman Peak Natural Scenic Area, would not be affected by the construction, operation or maintenance. The existing rights-of-way and transmission structures would be used for the project's construction. Impacts to the land uses along the route would not be significant. The proposed action would be consistent with the management plans developed by the BLM for the operation and maintenance of transmission lines in the resource areas where they occur. 
Construction of the proposed regeneration stations and electrical distribution lines have been evaluated for visual resources including the Crossman Peak Natural Scenic Area. The visual impacts of the OPGW, regeneration stations and electrical distribution lines would not be significant.

Construction of the proposed action would not impact any significant archaeological or historic sites. For compliance with the National Historic Preservation Act, specifically Section 106, Western consulted with the Arizona, California, and Nevada State Historic Preservation Officers (SHPO) concerning the National Register eligibility of sites within the area of potential impact. All three SHPO's have concurred with Western's determination that no historic properties would be affected by the project. An archaeological monitor will accompany each work crew to survey and approve all areas prior to construction.

The proposed action would result in a minimal loss of desert scrub vegetation from the construction of the regeneration stations and electrical distribution lines. A minimal area of desert scrub vegetation would be temporarily disturbed during the installation and tensioning of the OPGW. All salvageable plants protected by the Arizona Native Plant Law and Nevada Cactus and Yucca Law would be transplanted nearby.

Construction activities of the project would result in a minimal loss, or modification, of wildlife habitat from project implementation. Coordination with the U:S. Fish and Wildlife Service (FWS) regarding the implementation of this project revealed the potential occurrence of listed endangered or threatened species or designated critical habitat. The proposed action would result in no adverse effects on the Yuma clapper rail, bald eagle, peregrine falcon, Southwestern willow flycatcher, razorback sucker, or bonytail chub. However, small areas of designated critical habitat for the Mohave desert tortoise would be permanently committed to the project as a result of the construction of the regeneration sites. Western initiated formal consultation with FWS regarding the Mohave desert tortoise, a threatened species in Nevada and California. The FWS concluded that the proposed action would not jeopardize the continued existence of Federally listed 
threatened and endangered species or critical habitat. Biological monitors will be stationed with each work crew to survey and approve areas in threatened desert tortoise habitat prior to construction; as a result, no significant impacts will occur.

There would be no significant impacts to geology and soils due to construction.

No floodplains or wetlands would be affected by the proposed action.

This project would not directly affect minority and low-income communities; however, the Central Arizona Project that services these communities would be improved.

DETERMINATION: The analysis contained in the EA indicates that the proposed action is not a major Federal action significantly affecting the quality of the human environment, within the meaning of NEPA. Western has determined that preparation of an EIS is not required and is, therefore, issuing this FONSI.

Issued at Golden, Colorado, on

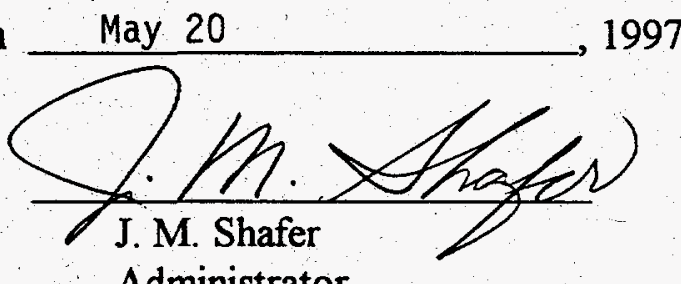

Administrator 


\section{DISCLAMMER}

Portions of this document may be illegible in electronic image products. Images are produced from the best available original docoment. 



\title{
ENVIRONMENTAL ASSESSMENT
}

\section{MCCULLOUGH TO LIBERTY FIBER OPTICS PROJECT}

\author{
Prepared for \\ U.S. Department of Energy \\ Western Area Power Administration \\ DOE/EA - 1202
}

\section{DISCLAIMER}

This report was prepared as an account of work sponsored by an agency of the United States Government. Neither the United States Government nor any agency thereof, nor any of their employees, makes any warranty, express or implied, or assumes any legal liability or responsibility for the accuracy, completeness, or usefulness of any information, apparatus, product, or process disclosed, or represents that its use would not infringe privately owned rights. Reference herein to any specific commercial product, process, or service by trade name, trademark, manufacturer, or otherwise does not necessarily constitute or imply its endorsement, recommendation, or favoring by the United States Government or any agency thereof. The views and opinions of authors expressed herein do not necessarily state or reflect those of the United States Government or any agency thereof. 



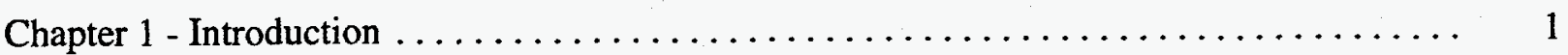

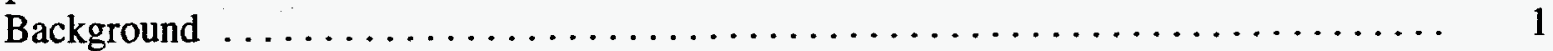

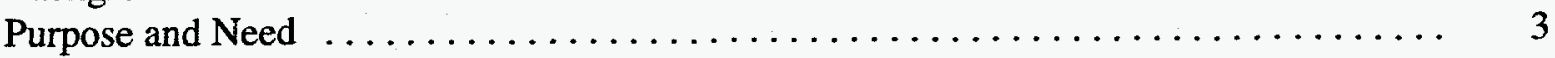

Conformance with Existing Plans, Statutes, or Other Regulations $\ldots \ldots \ldots \ldots \ldots \ldots .4$

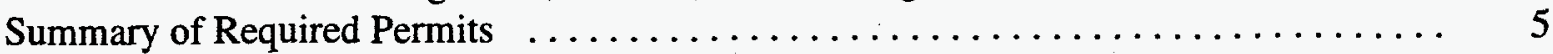

Chapter 2 - Proposed Action and Alternatives $\ldots \ldots \ldots \ldots \ldots \ldots \ldots \ldots \ldots \ldots \ldots \ldots \ldots$

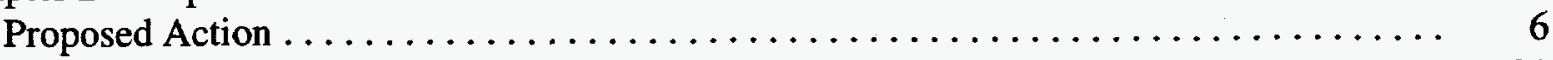

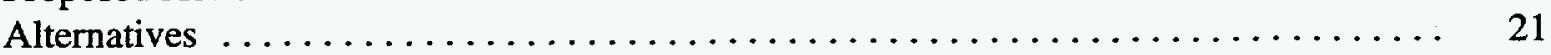

Chapter 3 - Affected Environment and Environmental Consequences $\ldots \ldots \ldots \ldots \ldots \ldots$

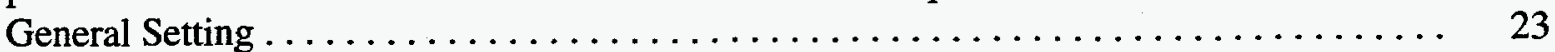

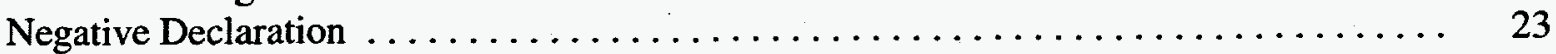

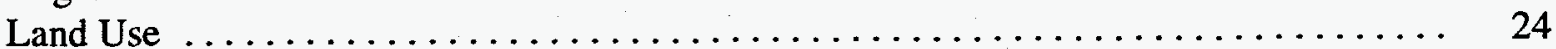

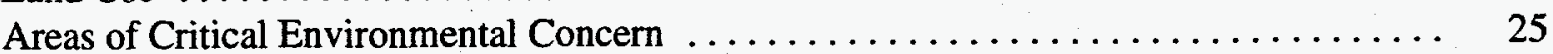

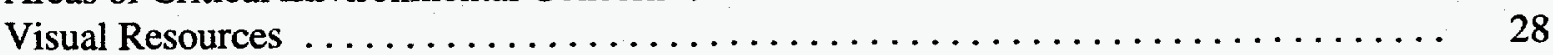

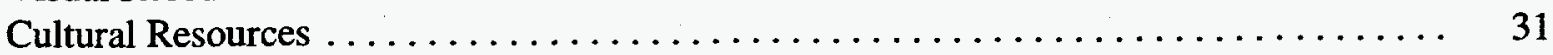

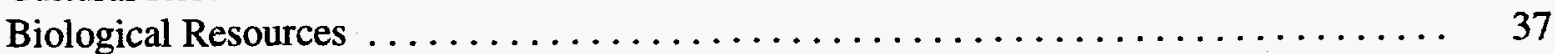

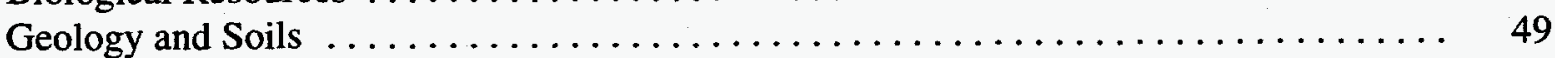

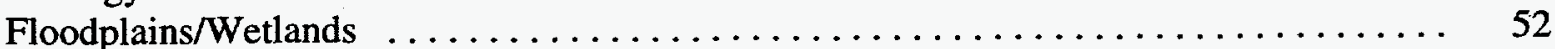

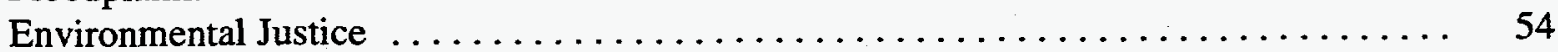

Cumulative Effects . . . . . . . . . . . . . . . . . . . . . . . . . 54

Chapter 4 - List of Preparers $\ldots \ldots \ldots \ldots \ldots \ldots \ldots \ldots \ldots \ldots \ldots \ldots \ldots \ldots \ldots \ldots \ldots$

Chapter 5 - Consultation and Coordination $\ldots \ldots \ldots \ldots \ldots \ldots \ldots \ldots \ldots \ldots \ldots \ldots$

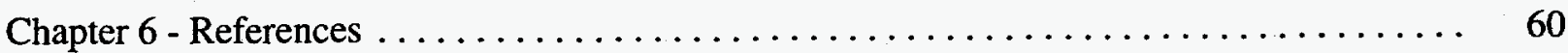

Appendices

A - Temporary Disturbance Area Maps

B - Project Route Maps

C - Cultural Resource Class I Report

D - Biological Assessment

E - Biological Opinion 


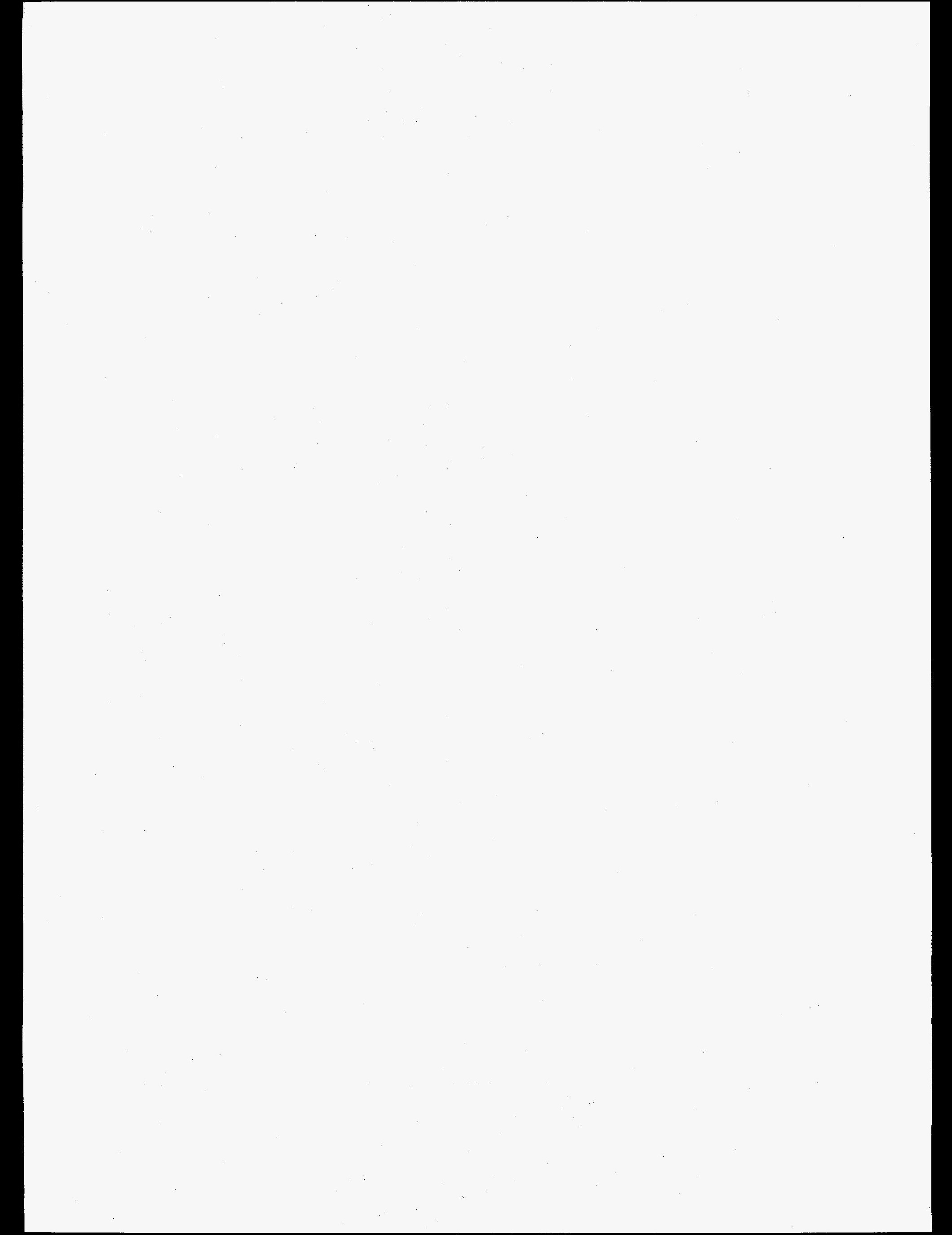




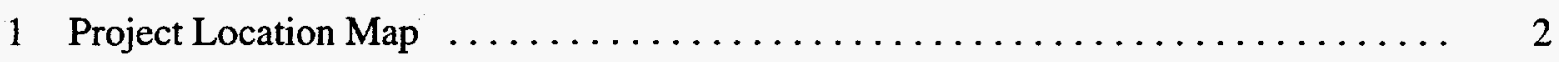

2 Typical Electrical Transmission Line Structure $\ldots \ldots \ldots \ldots \ldots \ldots \ldots \ldots \ldots$

\section{LIST OF TABLES}

1 Summary of Prior Cultural Resource Surveys and Data Recovery Studies for Granite Reef Aqueduct Transmission System

2 Special Status Wildlife Likely to Occur in the Vicinity of the McCullough to Liberty Fiber Optic Project . . . . . . . . . . . . . . . . 


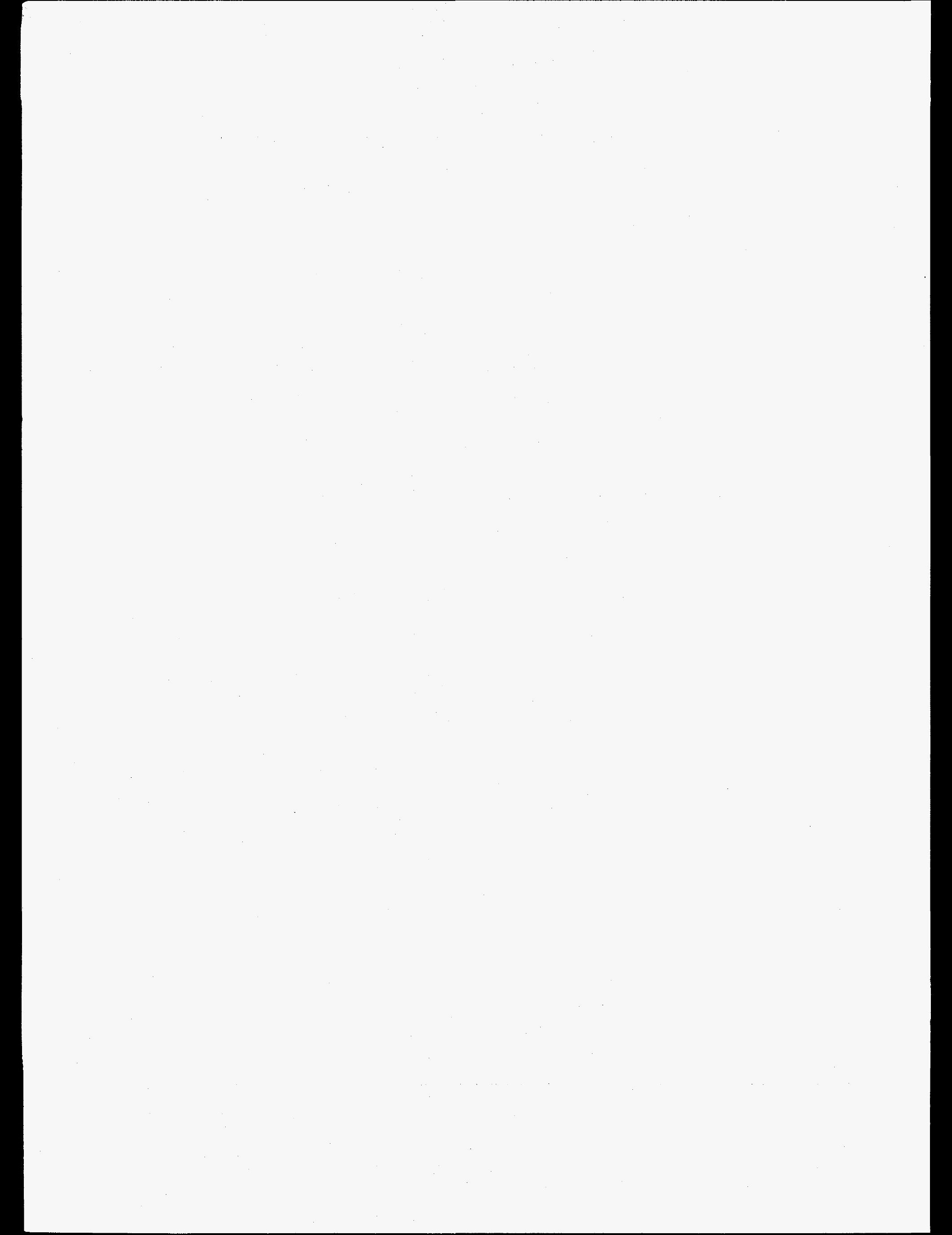




\section{LIST OF ACRONYMS AND ABBREVIATIONS}

ACHP

BA

BLM

DOE

DWMA

EA

ESA

FEMA

FWS

IXC

$\mathrm{kV}$

NEPA

NERC

OPGW

Reclamation

SHPO

VRM

Western
Advisory Council on Historic Preservation

Biological Assessment

U.S. Bureau of Land Management

U.S. Department of Energy

Desert Wildlife Management Area

environmental assessment

Endangered Species Act

Federal Emergency Management Agency

U.S. Fish and Wildlife Service

IXC Carrier Group Inc.

kilovolt

National Environmental Policy Act

National Electric Reliability Council

optical ground wire

U.S. Bureau of Reclamation

State Historic Preservation Officers

Visual Resources Management

Western Area Power Administration 

The U.S. Department of Energy (DOE) Western Area Power Administration (Western) proposes to install, operate, and maintain an optical ground wire (OPGW) and associated ancillary facilities between the Liberty Substation near Phoenix, Arizona and the McCullough Substation near Boulder City, Nevada (Figure 1). The OPGW would replace the static line along existing transmission lines. The United States Government owns the transmission lines and substations that would be affected by the project. This project would connect to existing telecommunication networks at the Liberty and McCullough substations. Reclamation is a cooperating agency in the preparation of this document pursuant to the National Environmental Policy Act of 1969 (NEPA).

\section{BACKGROUND}

New demands for telecommunication services are increasing the pressure on commercial providers to expand their systems and increase capacity. In the United States, legislation such as the Telecommunications Act of 1996 and the Federal Power Act has created unique opportunities for the communications and power utility industries to form partnerships in an attempt to address the new higher demands. The Federal Government, recognizing (1) opportunities that commercial telecommunications networks create for Federal facility systems enhancement; (2) benefits to Western and Reclamation facilities and Central Arizona Project operations that derive from installation of a telecommunications network; and (3) the overall minimization of disturbance to the environment that can be achieved by using established transmission corridors and utility lines, has entered into an arrangement with a commercial provider to build a system within established corridors that meets the telecommunication needs of the Federal Government while satisfying the commercial objectives of the provider. Once in place, the system would provide Western and Reclamation with high-speed data transfer capabilities that will use new technologies supported by fiber optic lines to improve and increase the communication capacity of Federal water and power control facilities. The commercial provider would be permitted to utilize the excess communication capacity for commercial uses. The Federal communications system would operate independent of the non-Federal system. 



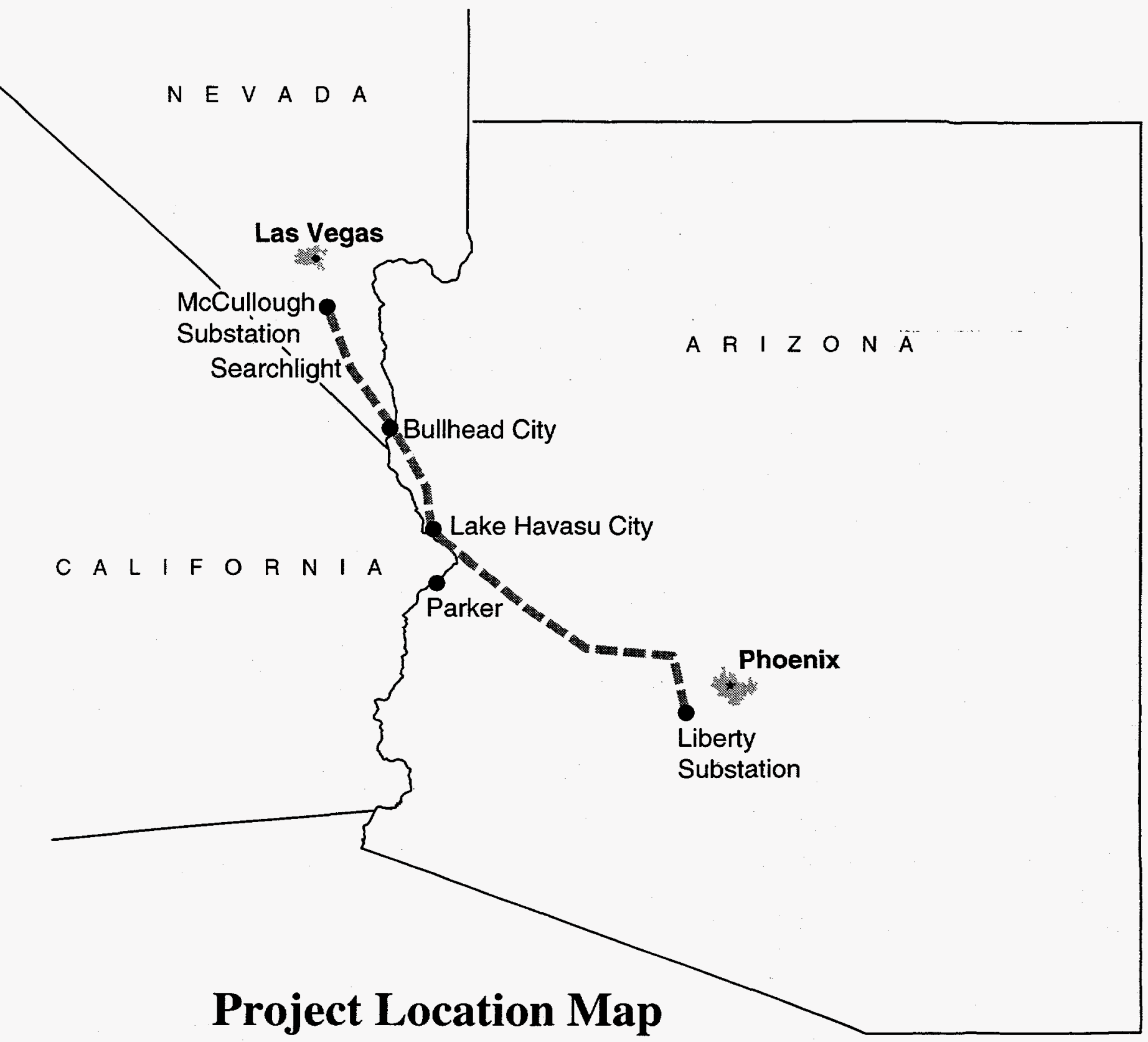

Figure 2 

The commercial provider is IXC Carrier Group Inc. (IXC), a telecommunications company based in Austin, Texas that specializes in fiber optic service for multiple telecommunications companies. IXC is developing a fiber-optic-cabled network from Dallas, Texas, to Los Angeles, California, much of which is already in place or under construction. IXC's network utilizes existing utility corridors and transmission line structures to carry fiber-optic cable for a significant portion of its system. IXC considered various alternative routes between the Phoenix metropolitan area and the Las Vegas metropolitan area. In general, the routes considered traverse a significant amount of public land under Bureau of Land Management (BLM) jurisdiction (where creation of new transmission corridors is restricted). The arrangement with the United States Government permits the use of an existing transmission line corridor and reduces the overall cost and environmental impacts as well. IXC is subject to and must comply with all applicable Federal, state, and local requirements for its system.

This environmental document was prepared in compliance with NEPA and the regulation's implementing procedures, as well as guidance provided by the Council on Environmental Quality (40 CFR 1500-1508) and DOE (10 CFR 1021).

\section{PURPOSE AND NEED}

Western and Reclamation need a more reliable, higher capacity, communication system to tie into their remote facilities.

The purpose of the proposed action is to provide Western and Reclamation with increased data transmission capacity to key components of the communication centers at the McCullough, Davis Dam, Parker Dam, Harcuvar, Hassayampa Tap, and Liberty substations via an existing connection to the Phoenix control center. Additionally, laterals to the Central Arizona Project pumping plants at Havasu, Bouse Hills, and Hassayampa would be included in the proposed action. The project would provide uninterrupted, reliable, high-capacity voice and data transfer communication, with backup, to remote locations along Western's transmission lines and Reclamation's water storage, pumping, and transfer facilities. The project would enhance Western's communication capabilities by providing loop closure 
for the microwave based data link for the Supervisory Control and Data Acquisition system presently used in monitoring the transmission and substation facilities along the Colorado River and north to the Mead Substation in Boulder City, Nevada. It would provide closer integrated and interregional communication for Western and cooperating utilities as required by the Western Systems Coordinating Council and the National Electric Reliability Council (NERC). It would provide primary communication control for Reclamation's water delivery system on the Colorado River from Hoover Dam to Parker Dam, and it would provide urgently needed backup and capacity to the Central Arizona Project Canal system from their Phoenix remote control center. Overall, this project would increase system reliability and reduce the dependence on the single communication path currently provided by microwave systems.

\section{CONFORMANCE WITH EXISTING PLANS, STATUTES, OR OTHER REGULATIONS}

The proposed project would use existing power line structures owned, operated, and maintained by the United States Government. The proposed action would be consistent with the existing use and an enhancement of facilities in accordance with the Western Area Power Administration Engineering and Construction 10 Year Plan, Desert Southwest Region - Physical Year 1996. The project is also in conformance with the affected BLM plans listed below.

- Kingman Resource Area Management Plan and Final Environmental Impact Statement 1993

- Final Yuma District Resource Management Plan and Environmental Impact Statement 1985

- Yuma District Resource Management Plan Amendment 1992

- Phoenix Resource Management Plan and Final Environmental Impact Statement 1988

- Lower Gila North Management Framework Plan, Phoenix, Arizona, BLM District Office 1981

- Draft Stateline Resource Area Management Plan 1992 


\section{SUMMARY OF REQUIRED PERMITS}

\begin{tabular}{|c|c|}
\hline Permitting Agency & Permit/Authorization \\
\hline U.S. Bureau of Land Management & - grant of right-of-way \\
\hline U.S. Bureau of Reclamation & $\begin{array}{l}\text { amendments to existing right-of-way agreements as } \\
\text { required }\end{array}$ \\
\hline Western Area Power Administration & $\begin{array}{l}\text { amendments to existing right-of-way agreements as } \\
\text { required }\end{array}$ \\
\hline Arizona Department of Transportation & - right-of-way encroachment permits - statewide permit \\
\hline Mohave, LaPaz, and Maricopa, Arizona & - county construction permits \\
\hline Clark County, Nevada & - county construction permits \\
\hline San Bernardino, California & - county construction permits \\
\hline U.S. Army Corps of Engineers & $\begin{array}{l}\text { - Section } 10 \text { Rivers and Harbors Act as amended } \\
\text { - letter of authorization }\end{array}$ \\
\hline U.S. Fish and Wildlife Service & $\begin{array}{l}\text { Section } 7 \text { Endangered Species Act as amended; } \\
\text { consultation and biological opinion or letter of concurrence }\end{array}$ \\
\hline $\begin{array}{l}\text { State Historic Preservation Office } \\
\text { (Arizona, California, Nevada) }\end{array}$ & $\begin{array}{l}\text { - Section } 106 \text { National Historic Preservation Act, as } \\
\text { amended; complete consultation }\end{array}$ \\
\hline Advisory Council on Historic Preservation & $\begin{array}{l}\text { Section } 106 \text { National Historic Preservation Act, as } \\
\text { amended; complete consultation }\end{array}$ \\
\hline $\begin{array}{l}\text { U.S. Environmental Protection Agency or } \\
\text { delegated state agency }\end{array}$ & $\begin{array}{l}\text { National Pollutant Discharge Elimination System permit } \\
\text { for construction activities }\end{array}$ \\
\hline
\end{tabular}





\section{CHAPTER 2 - PROPOSED ACTION AND ALTERNATIVES}

\section{PROPOSED ACTION}

The United States owns, operates, and maintains electrical transmission lines connecting the McCullough Substation near Boulder City, Nevada to the Liberty Substation near Phoenix, Arizona (see Figure 1). The proposed action is to replace existing overhead static wire along Reclamation lines with an OPGW (Figure 2). In four locations where power lines cross each other, a static wire is not present for several hundred feet between two or three structures. Alternatives in these areas could involve attaching the OPGW in alternate locations on the existing structures or trenching underground within the existing rightof-way. After evaluating these two options it has been determined that trenching in these locations is not preferable and the intent is to attach the OPGW to the existing structures above ground.

This project may require amendments to the right-of-way agreements originally acquired for the HaydenRhoades Aqueduct (formerly known as the Granite Reef Aqueduct), a feature of the Central Arizona Project transmission system. In addition, a grant of right-of-way would be required from BLM for three regeneration stations and two electrical distribution lines described in detail in the project description as alternatives. The OPGW would use United States Government facilities exclusively and connect the substations at McCullough, Davis Dam, Parker Dam, Harcuvar, Hassayampa Tap, and Liberty. In addition to the new OPGW, a total of eight regeneration facilities would be necessary-five would be located at existing substations and three at other locations along the lines. A regeneration station is a location where the signal carried by the OPGW is enhanced or amplified. Regeneration stations require an area of approximately 100 by 100 feet bounded by a six-foot chain link fence with a 1,000 -square-foot control building. Regeneration stations would be located between 20 and 45 miles apart along the route.

The United States would own the OPGW, the electronics equipment used by the Federal Government, and the ancillary facilities including the regeneration stations. The commercial partner would own and operate their own electronics. The project would not change the size of the right-of-way or the way in which it is maintained, and new road construction would not be necessary as part of this action, 



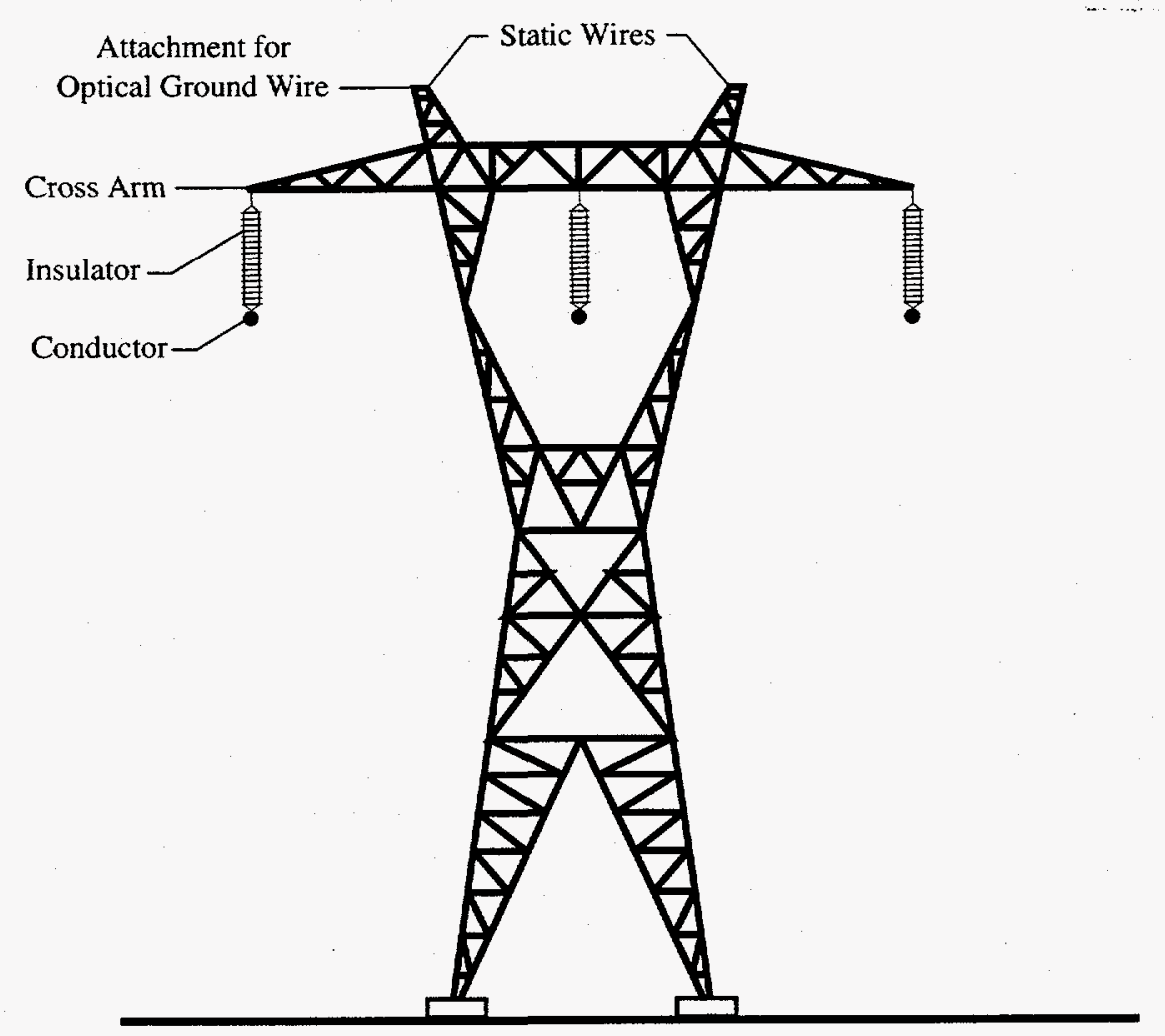

\section{Typical Electrical \\ Transmission Line Structure}

Figure 2 

although some existing access routes would need to be improved to accommodate construction activities. New ground disturbance during construction would be limited to the following areas: (1) seven locations where a maximum 150 - by 150 -foot area would be prepared for 100 - by 100 -foot regeneration station sites; (2) where trenching would be required; (3) where a larger regeneration station (208 by 208 feet) would require a total temporary disturbance area of approximately 250 by 250 feet; and (4) where an electrical distribution line would require the placement of new wooden power poles to supply electricity to two regeneration stations for a total distance of about one mile. Maps showing the locations where temporary disturbance is possible are included in Appendix A.

Permanent new ground disturbance would be limited to the 100 - by 100 -foot site or 208 - by 208 -foot site for each regeneration station respectively, and the area occupied by the wooden poles for the electrical distribution line.

\section{Project Description}

Western proposes to conduct all necessary environmental assessments, permitting, design, construction, and rehabilitation/mitigation for the installation of the OPGW and ancillary facilities on or adjacent to existing electrical transmission line structures.

From end to end the primary or trunk OPGW would be approximately 250 miles, with an additional 32 miles of lateral OPGW (spurs) connecting the trunk line with Reclamation pumping facilities from three locations-Parker Dam, Harcuvar, and Hassayampa Tap substations.

The OPGW is composed of not more than 120 dielectric (i.e., does not conduct electricity) fibers encased in a metal jacket that protects the fibers and serves the purpose of the static line it would replace. The fibers with their protective coatings, including the metal jacket, create a cable approximately one inch in diameter. The cable does not emit any additional noise or electric or magnetic fields. The primary OPGW would be attached at or near the top of each electrical transmission line structure above the electrical conductors (see Figure 2). 
The proposed project would be constructed and operated on property administered by Western and Reclamation, with the exception of three BLM parcels identified for regeneration stations and one location where an electrical distribution line is under consideration as alternative power supply.

The route for the project generally trends southeast from McCullough Substation in Nevada to Liberty Substation west of Phoenix, Arizona. The main trunk of the OPGW would attach to existing 230 kilovolt $(\mathrm{kV})$ transmission line structures connecting the endpoints and would include the following segments:

- McCullough-Davis $230 \mathrm{kV}$ - 62 miles

- Davis-Parker No. 2 230kV - 68 miles

- Parker-Liberty No. $1230 \mathrm{kV}$ - 113 miles

In addition to the main trunk wire, three lateral wires would connect Reclamation pumping plants to the system. These laterals also would attach to existing transmission lines. There are eight regeneration stations proposed along the route, five of which are within or adjacent to existing substations. The OPGW would for the most part replace the existing static wire on the existing structures. As described earlier, where static wire is not present, an attachment would be built to hold the new OPGW in place below the transmission line conductors near the bridge of the structure. If a suitable attachment were not possible, it was thought that the line could continue underground between the towers where the static wire is missing. However, after evaluating the options it has been determined that trenching in these instances is not preferable and the intent is to attach the OPGW to the existing structures above ground.

The following paragraphs describe the proposed route in more detail, moving from McCullough Substation to Liberty Substation, in segments from one regeneration station to the next. At each regeneration station the site description includes property ownership, access, and power supply. Where there are alternatives within a segment, they are listed in bullet form for easy reference. Maps illustrating the route in detail are located in Appendix B.

If approved, construction may be initiated anywhere along the route. For descriptive purposes, the project would begin at the McCullough Substation site where a regeneration station, the McCullough 
Regeneration Station, would be constructed to connect existing Reclamation fiber optics coming from the Mead Substation to the project. This is also the location where future commercial fiber optics attached to existing structures to the north and west would tie into this project. This regeneration station would occupy a one-acre area and is the largest regeneration station in the project. The additional size is necessary to accommodate the equipment for the operation of a commercial telecommunications junction. There are two alternatives for the location of the regeneration station at McCullough:

- entirely within the fenced yard of the existing substation compound with the OPGW dropping directly into the substation

- immediately outside the existing substation compound on withdrawn land with the OPGW entering and exiting the regeneration station underground and connecting with the nearest transmission line structure (within a few hundred feet)

Both alternative locations for the McCullough Regeneration Station have existing access roads and power available. Power would be supplied by Nevada Power Company.

Near the McCullough Substation, several high-voltage transmission lines converge and cross over the McCullough-Davis line. In this area, there is currently no static wire. The following alternatives have been considered:

- attaching to the structures at alternative positions and continuing overhead

- trenching within the existing right-of-way for 3,500 feet between the regeneration station and structure number $0 / 4$

- trenching approximately 6,000 feet along the existing access road from the regeneration station site to structure $1 / 2$ where the existing line crosses the access road 
After evaluating these options it has been determined that trenching is not preferable and the intent is to attach the OPGW to the existing structures above ground.

The route then continues southwest from the first regeneration site on the McCullough-Davis $230 \mathrm{kV}$ transmission line structures. Approximately seven miles from the McCullough Substation site, the route turns to the southeast, crossing under another transmission line, making it necessary again to attach the OPGW to existing structures at alternative positions parallel to or below the existing conductors.

The route continues south and southeast on the McCullough-Davis 230kV line for approximately 19 miles to the second regeneration station, which would be located directly west of the city of Searchlight near structure 26/1. The Searchlight Regeneration Station would be constructed adjacent to the McCullough-Davis transmission line right-of-way on BLM land. At this location, the OPGW would drop down the transmission line tower and continue underground within the existing right-of-way for approximately 200 feet in order to enter and exit the proposed regeneration station. Construction activities at this site would use existing access roads. The power would be provided at the site by an existing distribution line owned and operated by Nevada Power.

From Searchlight the route continues on the McCullough-Davis $230 \mathrm{kV}$ line southeast for 23 miles, then turns to the east for about 6 miles along the southern boundary of the Lake Mead National Recreation Area, continuing into the Davis Dam Substation. Directly south of the Davis Dam Substation within Western property, the third regeneration station, Davis Dam Regeneration Station, would be located at an abandoned building site owned by Western. Power would be supplied by Western and obtained by tapping into an adjacent Reclamation owned distribution line. Approximately three distribution poles would be necessary to span the 1,000 feet between the existing electrical distribution line and the regeneration site. The three new distribution poles would be set on withdrawn land.

From the Davis Dam area, the route continues on the Davis-Parker No. $2230 \mathrm{kV}$ transmission line southeast for approximately 41 miles. Near the intersection of the Davis-Parker No. 2 line and State Route 95 at structure 41/3, another regeneration station, Topock Regeneration Station, would be constructed on BLM land adjacent to the Davis-Parker No. 2 transmission line right-of-way. Power 
would be obtained by tapping into a distribution line owned by Citizens Utilities Company approximately 250 feet away. Construction of this regeneration station would be accomplished using existing access.

From the Topock site, the route continues on the Davis-Parker No. $2230 \mathrm{kV}$ transmission line southeast through the Crossman Peak Natural Scenic Area to Parker Dam Substation-a total distance of 27 miles. The line would pass through approximately eight miles of the Crossman Peak Natural Scenic Area. For this segment there are the following two alternatives for access during the construction:

- using helicopters to supplement construction crews

- using existing roads and making limited improvements followed by reclamation

At Parker Dam Substation, the Parker Dam Regeneration Station would be constructed on Western property. Power would be supplied by Western from existing structures, along existing access to the site. In this area the OPGW would cross the lake and river on existing structures. Also from the Parker Dam Substation site there would be a 2-mile, 8-fiber OPGW spur connecting the main fiber optic wire to the Lake Havasu Pumping Plant. This lateral connection is the first of three spurs for the entire project and would involve a river crossing on existing structures.

From Parker Dam Substation, the route attaches to the Parker-Liberty No. $1230 \mathrm{kV}$ transmission line structures and continues southeast for approximately 44 miles to the existing Harcuvar Substation, where the sixth regeneration station (Harcuvar Regeneration Station) is proposed. The regeneration station would be built adjacent to the southeast portion of the existing substation on withdrawn land. Power would be obtained in one of the following two ways:

- installing a transformer inside the existing substation

- installing a new distribution line from an existing Arizona Public Service distribution line located near the Alamo Dam Road, for approximately one mile along the south side of the HarcuvarBouse Hills $115 \mathrm{kV}$ transmission line to the regeneration site 
A 25-mile, 8-fiber OPGW spur would connect the Bouse Hills Pumping Plant to the main OPGW. The lateral would replace the overhead existing static wire on the Harcuvar-Bouse Hills $115 \mathrm{kV}$ wooden $\mathrm{H}$ frame structures and use existing access. This lateral connection is the second of three spurs proposed for the entire project.

The route continues from the Harcuvar regeneration site east about 22 miles to Structure No. $66 / 5$ where the Aguila Regeneration Station is proposed. The Aguila Regeneration Station would be built adjacent to the Parker-Liberty No. 1 transmission line right-of-way on property that is currently owned by BLM southeast of Eagle Eye Road. The site is intersected by an existing Arizona Public Service distribution line that would serve as the power source.

The route continues on the existing transmission line structures for approximately 32 miles to the Hassayampa Tap Substation, where the last regeneration station is proposed. The Hassayampa Tap Regeneration Station would be located on the southeast corner outside the substation yard on withdrawn land and would utilize existing access for construction. Power here would be supplied in one of the three following ways:

- locating transformers inside the existing substation

- replacing a static wire with an electrical distribution line along the Hassayampa pumping plant's transmission line; this would require burying approximately 1,000 feet of the wire from the proposed regeneration station to the first structure

- attaching a new electrical distribution line below the conductors along the Hassayampa pumping plant's transmission line as an underbuild; this new line would attach to the existing structures at or near the waist of each tower and would enter the regeneration station in the same way as proposed in the static wire replacement alternative 
A third 6.7-mile, 8-fiber OPGW spur would connect the regeneration station to the Hassayampa Pumping Plant by replacing an existing static wire and attaching to the existing Hassayampa Tap $230 \mathrm{kV}$ transmission line structures.

The route continues southeast and east for about 17 miles from the Hassayampa Tap Regeneration Station on the Parker-Liberty No. $1230 \mathrm{kV}$ line to the Liberty Substation, which is the termination point for the proposed project.

\section{Ancillary Facilities}

\section{Cable Splice Cases}

Cable splice cases are small boxes where the OPGWs are joined together. The cases are approximately 24 inches in length and 8 inches in diameter and mounted on the lattice transmission line structures below the conductors ( 15 feet above the ground). Splice cases are located along the line approximately three miles apart. OPGW cable is pulled from splice to splice.

\section{Regeneration Stations}

A regeneration station is a location where the signal carried by the OPGW is enhanced or amplified. There are eight regeneration stations proposed along the route spaced between 20 and 45 miles apart. There are two sizes of regeneration stations proposed for the project. Seven of the eight regeneration stations require a maximum area of 100 by 100 feet bounded by a six-foot-high chain link security fence with a locking gate. The size of the actual area required for each individual station may be smaller, and would not be determined until final design. The one larger regeneration station functions as a junction for telecommunications and occupies a one-acre site nearly 208 by 208 feet. Within the compound, each site would contain one-half inch to three-quarter inch broken aggregate gravel. A 1,000-square-foot single story, flat roofed structure would occupy each site and house the equipment. Two such buildings 
would be required for the larger site. The buildings are constructed of precast, exposed aggregate concrete. They are constructed on a concrete slab foundation and have precast, tilt-up, concrete walls. Buildings are equipped with electronic equipment, lighting, temperature control systems (heating and air conditioning), and two emergency engine generators with propane tank.

The following are the major construction activities for regeneration station sites:

- conduct surveying and staking

- conduct archaeological and threatened and endangered species field investigations

- prepare site

- pour concrete building pad

- assemble pre-manufactured structure

- install security fence

- install regeneration equipment

Each of the regeneration sites would require $800 \mathrm{amps}$ of electricity, which would be supplied in the following ways. Where it is necessary to build an electrical distribution line, the equipment used to construct the line would include three separate rubber tired vehicles-one with an auger, another referred to as a "bucket truck" with the equipment that places the woodpoles, and a pole truck. The auger would drill the holes for the poles to a depth of six feet. The bucket truck would place the poles in the holes. Augured soil would be backfilled and tamped around the pole. The poles would be approximately 34 feet high and pole spacing would be approximately 300 feet. The area of disturbance would be confined to a few feet immediately around each pole. Once the poles are in place, the conductor would be pulled into place with a rubber tire reel truck and tension truck. Whenever a regeneration station is powered by an existing or proposed distribution line, a pole-mounted transformer would be necessary. An electrical distribution line running more than 1,000 feet may need to be installed at one regeneration station.

At all other regeneration locations, electrical power would be provided via the local existing and adjacent electrical distribution system with less than a few hundred feet between the existing line and the regeneration station. 
Emergency back-up power would be provided by propane-powered electric generators located at each regeneration site. These generators would utilize a 500 -gallon tank of propane gas capable of sustaining electrical power for 11 hours.

In two of the regeneration stations it may be necessary to build transformers within the adjacent substations to accommodate the power needs of the regeneration equipment. In these two cases transformers would convert high-voltage power to a useable voltage.

\section{Project Design and Construction Standards}

\section{Construction Techniques}

Equipment, OPGW, and other construction material would be acquired from various vendors and stockpiled along the route at previously disturbed sites under the jurisdiction of Federal agencies or their contractors. During the construction phase, contractors would obtain material from these sites.

The OPGW would be constructed in spreads consisting of equipment and crews handling various phases of construction for a given line segment. The equipment utilized in the construction would include a tensioner and cable puller. These vehicles are large 10-wheel trucks designed for heavy loads. Tensioners also may be mounted on a trailer.

The process of replacing the static wire with the OPGW would be accomplished by first mounting a traveler or pulley on each structure near the place where existing wire attaches to the structure. Next, the existing static wire would be released from its attachment to the structure, placed into the traveler, and cut at one end. The OPGW would be then tied to the end of the old static line and pulled through the travelers, removing the static line and installing the OPGW in one motion. Workers would then remove the new OPGW from the travelers and attach them to the structures. Wire is typically pulled for about three miles at a time. 


\section{Environmental Field Survey}

As described earlier, along most of the route the project would be constructed overhead avoiding new ground disturbance. However, where new ground disturbance is proposed, a field survey would be performed prior to construction. The field survey would involve identifying sensitive or protected plants, wildlife, and cultural resources for avoidance including wetlands and floodplains.

\section{Flagging and Staking of Right-of-way}

All activities associated with the construction, operation, and maintenance of the right-of-way would be conducted within the authorized limits of the temporary and permanent disturbance. The maximum disturbance area for seven of the eight regeneration sites is expected to be 100 by 100 feet and 150 by 150 feet for temporary and permanent respectively. The eighth site, located at the McCullough Substation, would require an area of 250 by 250 feet and 208 by 208 feet as temporary and permanent disturbance. For the undergrounding areas, trenching would displace soil to a depth of 48 inches and a width of 18 inches for the length of the trench. The length of the trench depends on the alternative selected; however, for the entire length of nearly 250 miles of the main trunk line and 32 miles of spurs, less than 3 miles was under consideration for trenching on any alternative.

Sensitive areas as identified by the specialist (e.g., biologist, archaeologist) where construction equipment and vehicles are planned to disturb would be clearly marked for avoidance before any construction or surface disturbing activities begin.

\section{Temporary Construction Areas}

Two to four temporary staging areas for equipment and materials storage, each approximately 50 by 100 feet in size, would be required. These marshaling yards would be located on previously disturbed sites 
under the jurisdiction of Federal agencies or their contractors, avoiding wetlands and other environmentally sensitive areas.

\section{Clearing and Grading of the Right-of-way}

In some areas, the existing access road to the transmission line structures may require improvement in order to accommodate cable trucks or construction vehicles. Improvements would be limited to blading the existing alignment to remove erosion ruts. Road improvements are known to be necessary to access the Aguila Regeneration site.

No construction or routine maintenance activities would be performed during periods when the soil is too wet to adequately support construction equipment. If equipment creates ruts in excess of six inches deep, the soil is deemed too wet to adequately support construction equipment.

The width of the disturbance zone along the route would be minimized to the extent practicable. Construction vehicles would be excluded from traveling or turning around in undisturbed areas outside the right-of-way, except for reasons of safety.

\section{Access}

New road construction is not anticipated. Construction-related traffic would be restricted to existing routes approved by the authorized specialist assigned by Western to monitor biological or cultural resources during construction. 
Fences and Range Improvements and Existing Land Uses

All existing improvements would be protected. If damage occurs it would be repaired immediately to the satisfaction of the owner or land manager.

Western would protect all public survey monuments found within or adjacent to the right-of-way. Survey monuments include but are not limited to General Land Office and BLM Cadastral Survey Corners; reference corners; witness points; U.S. Coastal and Geodetic benchmarks and triangulation stations; military control monuments; and recognizable civil (both public and private) survey monuments. If any of the above are obliterated or disturbed, Western would report the incident, in writing, to the BLM Field Office Manager and the respective installing authority, if known. Where BLM or General Land Office right-of-way monuments or references are obliterated during operations, Western would secure the service of a registered land surveyor or a staff cadastral surveyor to restore the disturbed monument according to procedures found in the latest edition of the manual of surveying instructions for the survey of the public lands of the United States. Western would record such survey in the appropriate county and send a copy to the authorized specialist.

\section{Work Force}

Each construction spread would require 15 to 20 workers including foremen, equipment operators, general laborers, and environmental monitors and construction inspectors. Each spread would require three to five pieces of equipment and support vehicles. There may be as many as three spreads under construction at any one time over the entire route, accounting for approximately 45 to 60 workers and 10 to 15 pieces of equipment.

Construction workers would not be permitted to camp on public lands while participating in construction activities. Construction camps would not be necessary. 


\section{Vegetation}

Disturbance of vegetated areas would be avoided where possible. In those areas where the development of the regeneration station would disturb previously undisturbed areas, significant or protected species would be avoided.

\section{Safety}

The following measures would be undertaken to ensure the health and safety of agency personnel, contractors, and the general public:

- de-energize the existing power line

- adhere to applicable DOE construction and safety standards

- control boat traffic at crossings of navigable waters as approved by Army Corps of Engineers

- control traffic at road crossings, as approved by state highway departments

\section{Hazardous/Toxic Materials}

No hazardous material would be generated by the actions required for the operation and maintenance of the project. To minimize the impact of hazardous materials used during construction activities (fuels and lubricating oils), all equipment would be regularly inspected for leaks. Any significant leaks detected would be promptly corrected. Fueling operation would be conducted at commercial filling stations, truck to truck in areas greater than $\mathbf{5 0 0}$ feet from existing drainage channels or waterways. In addition, filling trucks would be limited to a capacity of two 660 gallon tanks, for a total volume of 1,320 gallons. Fuel farms would not be developed for the project. 


\section{Maintenance and Operation}

Supervisors and field personnel would monitor and control the system by driving throughout the project area inspecting facilities and checking equipment. Periodic reconnaissance of the OPGW right-of-way would be conducted twice a year by driving the entire route on the existing roads or an aerial patrol. Improvements and repairs would be conducted as necessary. Right-of-way maintenance procedures would remain unchanged with the addition of the OPGW.

Regeneration stations would not be manned, but would be visited every month for inspection and maintenance. Back-up generators at regeneration stations would provide extended service in the case of a power outage.

Once the proposed facilities are in place and functioning, they would remain in continuous operation.

\section{Indian Trust Assets}

The proposed project would not affect any Indian trust lands. By enhancing the reliability of the Central Arizona Project aqueduct system, the proposed project would benefit those tribes with allocations of water delivered by the system.

\section{ALTERNATIVES}

The action alternatives considered for the project are minor variations to the proposed action and include locations of regeneration sites, sources of power, and placing wires overhead versus burying them. In addition, the no-action alternative was considered. 


\section{No Action}

The no-action alternative would not meet the purpose and need of the project.

\section{Alternatives Considered but Eliminated from Further Study}

Two additional regeneration sites were evaluated in the vicinity of the intersection of the Davis-Parker No. 2 line, Interstate Highway 40, and State Highway 95 near Topock, Arizona. These sites would be located immediately adjacent to State Highway 95 . They were rejected because of safety concerns, proximity to floodplains, proximity to several high-pressure gas pipelines, and the need for power.

An additional regeneration site was evaluated near Aguila, Arizona immediately adjacent to Eagle Eye Road. The site was rejected because of the need for power on site, visual resources, safety, and security concerns.

An alternative line location was considered near Lake Havasu that would avoid the Crossman Peak Natural Scenic Area and pass through the city. The route was considered initially in the event that land management restrictions would prevent the OPGW on the Davis-Parker No. 2 line; however, this alternative involved changing from the Davis-Parker No. 2 line to the Davis-Parker No. 1 line near the Topock Regeneration Station and then changing back to the Davis-Parker No. 2 line near the Black Mesa Substation. The Davis-Parker No. 1 line is owned and operated by Western, and the route was eliminated because the ownership of the segment complicated the contractual arrangement among Reclamation, Western, and the commercial partner. In addition, BLM issued a letter authorizing the development of the OPGW on existing structures as a maintenance action on Reclamation's existing easement. 



\section{CHAPTER 3 - AFFECTED ENVIRONMENT AND ENVIRONMENTAL CONSEQUENCES}

\section{GENERAL SETTING}

The proposed project would be within or adjacent to existing utility rights-of-way. The project study area includes areas within the Mohave and Sonoran desert ecosystems between Boulder City, Nevada and Phoenix, Arizona. The proposed route trends from the north to the southeast on the east side of the Black Mountains in the Lower Colorado River Basin, passing through the Mohave Valley on the east side of the Colorado River and past the Mohave Mountains to the southeast on its path to Parker Dam. As the route continues to the east it passes through Butler Valley, the Harcuvar Mountains, and on to the Hassayampa River before entering the more populated areas approaching Phoenix, Arizona.

\section{NEGATIVE DECLARATION}

The following critical elements have been reviewed in conjunction with the project and would not be affected:

- air quality

- fugitive dust

- hazardous or solid wastes

- health and safety

- Indian trust assets

- Native American religious concerns
- prime or unique farm lands

- socioeconomic resources

- water quality

- wetlands/riparian zones

- wild and scenic rivers

- wilderness areas 


\section{LAND USE}

\section{Affected Environment}

The right-of-way and OPGW lines proposed to be used for the project's development were acquired for the construction and operation of the Granite Reef Aqueduct (now named the Hayden Rhodes Aqueduct), a feature of the Central Arizona Project. Western continues to manage the right-of-way and the electrical transmission lines pursuant to agreements made with BLM and Reclamation.

Additional right-of-way would be required for three regeneration stations proposed on BLM property and located near Searchlight, Nevada and Topock and Aguila, Arizona. These proposed areas are located adjacent to existing sources of power and access along the proposed route. Temporary disturbance to improve all regeneration sites would total approximately five acres, most of which has been previously disturbed. Permanent disturbances or total area occupied by the eight new regeneration stations would be 2.61 acres.

As shown on the map titled Harcuvar Regeneration Site in Appendix A, about 1,500 feet of the distribution line proposed for the regeneration station of Harcuvar would cross a patented mining claim, which is privately owned.

\section{Environmental Consequences}

Impacts to the land uses along the route would be low. The proposed action would be consistent with the management plans developed for the maintenance and operation of the transmission lines. The inclusion of the regeneration station property as part of the existing right-of-way is consistent with BLM's governing management plans for the relevant areas. Existing land uses adjacent to the proposed action would be unaffected by the change including but not limited to mining, grazing, residential, recreation, and transportation. 
As for the distribution line proposed for the regeneration station at Harcuvar, BLM's management plan directs utilities to construct within designated utility corridors. This is accomplished by paralleling the existing Bouse Hills Pumping Plant power line within the designated BLM utility corridor that contains the Parker-Liberty transmission lines. An easement would have to be obtained from the owner of the patented mining claim, but it is not anticipated that the regeneration station would impact potential mining activities.

Regulated materials would be handled in conjunction with Federal, state, and local laws. There would be no regulated material left on site.

\section{Mitigation}

None.

\section{AREAS OF CRITICAL ENVIRONMENTAL CONCERN}

\section{Affected Environment}

\section{Crossman Peak Natural Scenic Area}

The study area includes the portion of the Davis-Parker No. 2 line that passes through eight miles of the Crossman Peak Natural Scenic Area as designated in the Yuma District Resource Management Plan (1987). The Crossman Peak Natural Scenic Area was designated as an area of critical environmental concern in order to manage scenery as well as plant and wildlife habitat. Rugged conditions are predominant in this area of the Mohave Mountains. Direct and continued access below the existing line is not available. Off-road vehicles are permitted only on existing access roads and additional utility easements are restricted. 


\section{Eldorado Desert Wildlife Management Area}

In June 1994, the U.S. Fish and Wildlife Service (FWS 1994b) published a Desert Tortoise (Mojave population) Recovery Plan. The objective of the Recovery Plan is to recover the species to the point where it can be removed from the list of threatened species. Part of the recovery strategy is to establish Desert Wildlife Management Areas (DWMAs). Special protective measures are enforced within DWMAs to ensure the survival of the species. The establishment and management of DWMAs is to be accomplished by agencies, such as the BLM, responsible for the management of lands supporting desert tortoises. Management of DWMAs includes securing habitat, developing management plans to eliminate factors that have caused declines, implementing management decisions, and monitoring recovery (FWS 1994b). The proposed project would traverse the Paiute-Eldorado DWMA which encompasses southern Clark County, Nevada. Tortoise population densities in this DWMA, and thus the project area, range from 40 to 90 adults per square mile (FWS 1994b).

\section{Environmental Consequences}

\section{Crossman Peak Natural Scenic Area}

On-site investigations revealed that the replacement of the existing static wire with the new OPGW could be performed using existing access roads. No trenching would occur within the Crossman Peak Natural Scenic Area. Each access road was evaluated for its ability to accommodate the necessary equipment and although continuous access below the line is not possible each structure is accessible on existing access roads (POWER Engineers 1987). Minor road improvements may be required within existing access where erosion has created an abrupt change in the path's surface. Improvements would include pushing slough on existing alignments but would not include substantial grading or road realignment.

The installation of the new OPGW would not require additional land for a utility right-of-way or access roads. Existing land uses would continue unaffected. Impacts on the Crossman Peak Natural Scenic Area would be low, and could be further minimized by using the helicopter construction alternative. 
Although helicopter construction would not eliminate the need for tensioning and pulling equipment, it would reduce the need for vehicles required to access each structure and the time necessary to travel between structures. Workers could be moved quickly from structure to structure without ground disturbance.

The second alternative through this area is a more traditional approach and involves workers accessing structures in standard $4 \times 4$ field vehicles. Both alternatives would require limited road improvements along existing access roads to accommodate the tensioning and pulling equipment; however, the volume of traffic in the second alternative is greater.

\section{Eldorado Desert Wildlife Management Area}

Because the Eldorado DWMA is created and managed for the desert tortoise, effects are discussed in detail in the biology section under the heading of desert tortoise. A Biological Assessment was prepared in conjunction with the proposed action and is on file with Western.

\section{Mitigation}

\section{Crossman Peak Natural Scenic Area}

Standard mitigation would include the reclamation of roads where improvements are necessary and return to pre-existing conditions as desired by the authorized officer of the BLM. Consultation with the BLM regarding suitable access routes would occur prior to construction in this area. Impacts created by the second alternative, although low, would be mitigated by using small lightweight all-terrain vehicles for the workers. These lightweight vehicles would be less likely to dislodge soil or require road improvements along the existing access roads. 


\section{Eldorado Desert Wildlife Management Area}

Proposed mitigation that would reduce impacts on habitat and the desert tortoise is discussed in the biological resource section.

\section{VISUAL RESOURCES}

\section{Affected Environment}

The visual studies for the project include the regeneration stations and the proposed electrical distribution lines because they represent a new feature on the landscape. Cable splice boxes were considered insignificant modifications because they are small and widely dispersed. The OPGW is a cable slightly narrower than the existing conductors of the transmission line. It is a steel cable that will weather to a dull grey shade in a one- to two-year period.

Three of the regeneration sites would be located on BLM property and are identified for a grant of rightof-way. Visual resources are managed by the BLM under the Visual Resource Management (VRM) Program. The VRM program has several components that are used to evaluate visual environments and manage visual resources. Two components of the VRM discussed in this review are the Scenic Classes and the Visual Resource Management Classes. The scenic classes define scenic quality as A, B, or C. " $A$ " class scenery has the most outstanding characteristics of the three.

The VRM classes are assigned to areas by the BLM in order to manage visual resources. There are four management classes actively used by the BLM ranging from Class I to Class VI. Class I is the most restrictive to changes in the visual landscape.

Neither Western nor the Reclamation use a system for evaluating visual impacts; however, the BLM uses the Contrast Rating System as its primary tool for analyzing impacts (BLM 1980). In the consequences section a statement of the potential for the project to contrast with the existing setting is provided for 
evaluating impacts on visual resources. For purposes of evaluation, where higher contrasts are proposed greater impacts would be expected. Contrast evaluation would consider existing conditions compared to the proposed action. Comparisons would contrast size, form, color, and texture. In circumstances where sensitivity of the landscape is not high or where few viewers interact with the setting, contrast levels of low or moderate would produce low impacts.

\section{Environmental Consequences}

At the McCullough Substation, where the new regeneration station is proposed, the contrasts would be low. The substation is located on the west side of a broad valley of desertscrub where large power lines converge on the substation apparatus and control buildings. The regeneration station would be minimal in scale compared to the existing industrial surroundings, resulting in low contrast whether it was developed inside or outside the substation yard.

The regeneration site at Searchlight would be located west of town adjacent to two parallel transmission lines and an intersecting distribution line. BLM has classified the area as VRM Class III, directing modification to be subordinate to the existing landscape (BLM 1980). Visual contrast would be low at this site because of the existing transmission line and vegetation height and density. There is limited visibility provided to observers at this location by virtue of the rolling topography. In addition, the existing electrical transmission and distribution lines create a rural industrial character consistent with the character of the proposed regeneration facility.

Davis Dam Substation is also an area where many power lines converge and substation apparatus create an industrial setting. Views of this site would be limited and contrast would be low.

The Topock Regeneration Station would be visible from State Highway 95 on the west side of the road near the location where the Davis-Parker No. 2 line crosses the road. Two large transmission lines and an electrical distribution line converge at this location. The BLM has not assigned VRM Classes for this 
area; however, the recent EA conducted for the Kingman-Havasu Transmission Project 1997 described the area as Class B scenery. Contrast of the proposed regeneration facility would be low to moderate.

Parker Dam Substation is surrounded by rugged mountains identified as Class A scenery in early studies conducted for the Kingman-Havasu Transmission Project. The substation itself can be characterized as an industrial setting with converging power lines and substation apparatus. Views to the regeneration station site would be limited because of the low profile structure proposed for the regeneration control building and the rock outcropping feature that forms a wall around sections of the substation. Contrast for the regeneration station would be low.

Harcuvar Regeneration Station would be located on the southern slope of the Harcuvar Mountains on the east side of the existing substation. Because of the converging power lines and existing substation, contrast would be low.

In addition to the Harcuvar Regeneration Station, a one-mile distribution line would be considered as an alternative to installing additional transformers within the substation. Views to the proposed distribution line would be limited except where the line crosses the Alamo Dam Road. Contrast for the distribution line would be low to moderate, because of its proximity to the existing transmission line.

In the wide plain southeast of Eagle Eye Mountain a distribution line intersects the transmission line proposed to carry the new OPGW. The broad valley is characterized as open desertscrub, with distant views to mountains. The BLM has designated this area as VRM Class IV. Views to the regeneration site would be limited to individuals traveling along the right-of-way. The flat topography and the low profile building, combined with the height of the surrounding vegetation, would limit views to the site. Contrast in this area would be low.

Transmission lines converge at the Hassayampa Tap Substation. Topography in this area undulates allowing some distant views and other limited short views. Contrast for the regeneration station would be low, compared to the existing substation transmission lines. 
Three alternatives are discussed for power supply at the Hassayampa Regeneration Station. The first would involve building a transformer or transformers on site and would have minimal effect on the existing setting. This is the environmentally preferred alternative. The other two alternatives would involve the construction of an electrical distribution line from the Hassayampa Tap Regeneration Station along the Hassayampa Pumping Plant $230 \mathrm{kV}$ line to a power source located at the Hassayampa Pumping Plant, a distance of nearly seven miles. The new distribution line would replace an existing static line on the transmission line or be added as a new conductor below the existing conductors, attaching to the waist at each tower. Views to this area are limited to individuals on the existing power line access road or recreating in the Hassayampa riverbed. The area has elements of Class B scenery. The area surrounding the Hassayampa Substation and pumping plant is predominantly undeveloped private land. Contrast for the new line would be low.

In summary, overall impacts on visual resources would be low for the proposed action and its alternatives.

\section{CULTURAL RESOURCES}

\section{$\underline{\text { Affected Environment }}$}

The cultural environment includes those aspects of the physical environment that relate to human culture and society, along with the social institutions that form and maintain communities and link them to their surroundings. The following two issues related to the cultural environment were considered as components of this environmental assessment (EA):

- historic preservation concerns, related primarily to prehistoric and historic archaeological sites

- traditional cultural concerns, related primarily to places and resources having significance for traditional American Indian communities 
The Council on Environmental Quality regulations (40 CFR Part 1502.25) encourage agencies to coordinate preparation of EAs with other environmental review and consultation requirements, such as those of Section 106 of the National Historic Preservation Act. Accordingly, a Class I cultural resources survey has been prepared (Appendix C), and initial consultations with State Historic Preservation Officers have been made. A Class III survey also has been initiated to provide documentation to support continuing consultations.

A series of cultural resource surveys was conducted between 1973 and 1980 in conjunction with the planning of the Granite Reef Aqueduct (now Hayden-Rhodes Aqueduct) transmission system that would be used by the proposed fiber optic wire (Table 1). These surveys identified 27 archaeological sites and 8 other small field loci not formally designated as sites. Between 1976 and 1980, 4 other studies were conducted to recover archaeological data from 18 of these sites and 4 field loci as mitigation for the impacts of constructing the transmission system. The results of these studies were incorporated into a synthesis of many other survey and data recovery studies undertaken for the Granite Reef Aqueduct system (Brown and Stone 1982).

In sum, these studies indicate that archaeological sites are the most common type of cultural resource identified within the study area. Some of the recorded scatters of chipped stone artifacts are quite extensive, but usually the density of artifacts are confined to the surface of the ground and are not very dense or complex.

Traditional cultural places and resources have been inventoried far less thoroughly than archaeological sites or historic buildings and structures. Ethnographic studies indicate that the study area crosses the traditional territories of several American Indian communities. Prior consultation by the BLM had documented that Crossman Peak (Akoke-humi) is an important landscape feature named in traditional ceremonial stories of the Mojave, and also is important in Mojave funerary beliefs and practices (BLM 1979, 1994; Kroeber 1972). The mountain also is identified as a distinctive place in the lore of other tribes, including the Hualapais, Yavapais, Chemehuevis, and Hopis. Spirit Mountain (Avikame), a peak in the Newberry Mountains within the Lake Mead National Recreation Area, is considered to be a sacred peak to Yuman groups of the lower Colorado River Valley (Bee 1983; Stewart 1983). 


\begin{tabular}{|c|c|c|c|c|}
\hline \multicolumn{5}{|c|}{$\begin{array}{c}\text { TABLE } 1 \\
\text { SUMMARY OF PRIOR CULTURAL RESOURCE STUDIES } \\
\text { FOR THE GRANITE REEF AQUEDUCT TRANSMISSION SYSTEM }\end{array}$} \\
\hline Segment & Surveys & $\begin{array}{l}\text { Number of } \\
\text { Archaeological } \\
\text { Sites Recorded }\end{array}$ & $\begin{array}{l}\text { Data Recovery } \\
\text { Studies }\end{array}$ & $\begin{array}{c}\text { Number of Sites } \\
\text { Studied }\end{array}$ \\
\hline McCullough-Davis & $\begin{array}{l}\text { Bondley and Brooks } \\
\text { 1973; Dobbins 1979b }\end{array}$ & $\begin{array}{l}4 \text { prehistoric sites and } \\
4 \text { historic sites }\end{array}$ & Dobbins $1980 \mathrm{c}$ & 2 sites \\
\hline Davis-Parker & $\begin{array}{l}\text { Bondley and Brooks } \\
1973\end{array}$ & $\begin{array}{l}14 \text { prehistoric and } \\
2 \text { historic sites }\end{array}$ & Larson and others 1976 & 14 prehistoric sites \\
\hline Parker-Liberty & $\begin{array}{l}\text { Bair } 1974 \\
\text { Dobbins 1978a, 1978b }\end{array}$ & $\begin{array}{l}3 \text { prehistoric sites } \\
\text { and } 8 \text { field loci }\end{array}$ & $\begin{array}{l}\text { Brown } 1978 \\
\text { Dobbins } 1980 \mathrm{a} \\
\text { also see Brown and } \\
\text { Stone } 1982\end{array}$ & $\begin{array}{l}2 \text { prehistoric sites and } \\
4 \text { field loci }\end{array}$ \\
\hline Parker-Havasu & $\begin{array}{l}\text { Bair 1974; Dobbins } \\
\text { 1978a }\end{array}$ & none & & \\
\hline Harcuvar-Bouse & $\begin{array}{l}\text { Bair 1974; Dobbins } \\
\text { 1979a }\end{array}$ & none & & \\
\hline Hassayampa Tap & Brown 1980 & none & & \\
\hline \multicolumn{2}{|l|}{ Total } & $\begin{array}{l}27 \text { sites and } \\
8 \text { field loci }\end{array}$ & & $\begin{array}{l}18 \text { sites and } \\
4 \text { field loci }\end{array}$ \\
\hline
\end{tabular}

Tribal groups commonly are concerned about disturbances of aboriginal burials, but no human remains have been documented at any of the archaeological sites recorded along the study area. Contacts with nine American Indian groups have been made to determine whether they may have concerns about potential impacts on traditional cultural places and resources (refer to Chapter 5 for a listing). The only response received was from the Hopi Tribe, which recommended that impacts to all archaeological sites be avoided, that construction be monitored, and that an ethnographic study be undertaken to document aboriginal use of the study area. Given the minimal ground disturbance of the proposed project, an ethnographic study was determined not to be warranted, but installation of the OPGW will be monitored and efforts will be made to avoid impacts on all significant archaeological sites. 


\section{Environmental Consequences}

Significant impacts on cultural resources are defined as unavoidable project effects that cannot be satisfactorily mitigated. Criteria for defining significant levels of impact are based on procedures for making determinations of effect as defined in regulations for Protection of Historic Properties (36 CFR Part 800), which implement Section 106 of the National Historic Preservation Act. These regulations stipulate that Federal agencies consult with State Historic Preservation Officers, the Advisory Council on Historic Preservation, and other interested parties to make one of four possible determinations of effect:

- no historic properties within the area of potential effect

- no effect

- no adverse effect

- adverse effect

Regulations for Protection of Historic Properties, which implement the National Historic Preservation Act, state that an undertaking will affect a historic property when it "may alter characteristics of the property that may qualify the property for inclusion in the National Register," which could involve "alteration to features of the property's location, setting, or use" (36 CFR Part 800[a]). Although the compilation of available inventory data indicates that cultural resources are not dense in the study area, some historic properties may be present within the area of potential effect.

An effect is defined as adverse when it may "diminish the integrity of the property's location, design, setting, materials, workmanship, feeling, or association. Adverse effects on historic properties include, but are not limited to:

(1) physical destruction, damage, or alteration of all or part of the property

(2) isolation of the property from or alteration of the character of the property's setting when that character contributes to the property's qualification for the National Register 
(3) introduction of visual, audible, or atmospheric elements that are out of character with the property or alter its setting

(4) neglect of a property resulting in its deterioration or destruction

(5) transfer, lease, or sale of the property" (36 CFR Part 800.9[b])

It is recognized that construction of the proposed project potentially could result in the types of adverse impacts identified as 1 and 3.

For purposes of consultation with the appropriate State Historic Preservation Offices (SHPOs) and the Advisory Council on Historic Preservation (ACHP), the project was divided into two phases. Phase 1 involves stringing the OPGW on existing structures in place of the existing static line. Because existing disturbed areas would be utilized for the majority of the work conducted during this phase, no impacts on cultural resources are expected. Phase 2 involves consultation for ground disturbing activities which would include the construction of the regeneration sites, trenching, and the building of the electrical distribution lines. On these sites a detailed inventory would be conducted. Currently it is anticipated there may be minor impacts on a few historic properties that may be eligible for listing; however, a detailed inventory has yet to be completed. The impact assessment conducted at this phase of analysis is only a projection of the probable outcome of the formal Section 106 consultations with the State Historic Preservation Offices and the ACHP. These consultations can be undertaken only after an inventory and evaluation of cultural resources within the impact zones of an approved plan are completed.

\section{Mitigation}

During construction of Phase 1, an archaeological monitoring of construction operations will be conducted to ensure that these activities, including stringing and tensioning the fiber optic cable and any needed upgrading of existing access roads, do not affect any cultural resources throughout the study area. With this mitigation commitment, SHPOs of all three states have concurred with no effect. 
For Phase 2, a Class III (intensive) survey will be completed for all areas to be disturbed by the new regeneration sites. A Class III report will be submitted to the SHPOs and consultation will be completed prior to initiation of construction activities. This will involve Class III survey of the limited areas of new ground disturbance at the proposed regeneration sites, the limited areas where the fiber optic cable may have to be buried, and areas where new power lines may have to be developed to serve regeneration facilities. A total of approximately 90 acres of survey is anticipated to encompass these areas, alternative facility locations, and buffer zones around each location. (The area of actual ground disturbance will be substantially less.) This survey also will evaluate indirect impacts on existing substation facilities. Measures will be developed and implemented to avoid or mitigate impacts identified at any sites discovered within zones of new ground disturbance. These measures could entail minor project modifications, preconstruction archaeological data recovery studies, or monitoring of nearby cultural resources to prevent inadvertent damage during construction.

The available inventory data indicate that the vast majority of cultural resources previously recorded within the study area are archaeological sites. The significance of these sites typically stems from their potential to yield important information about the prehistory or history of the region (Criterion D for listing on the National Register). The regulations for Protection of Historic Properties specifically state that when such informational values can be substantially preserved through the conduct of appropriate research, and such research is conducted in accordance with applicable professional standards and guidelines, impacts on such sites can be considered to be not adverse (36 CFR Part 800.9[c][1]).

Archaeological sites may be valued for characteristics other than their information potential, especially by traditional American Indian groups who identify traditional cultural associations with sites. Special concerns often focus on sites that contain human remains and petroglyphs (rock writing) and physical destruction, damage, or alteration of such sites is likely to be considered an adverse effect. Although such sites are present in the region, they are relatively rare and not expected within the area of potential effect. Nor are any impacts anticipated on Crossman Peak, which is approximately 3.5 miles from the existing transmission line. No new ground disturbance is anticipated in the vicinity of the mountain because access is confined to existing roads under the guidance of an on-site cultural specialist and the replacement of one existing static wire with an OPGW would not introduce any new visual intrusions into 
the setting of Crossman Peak. Spirit Mountain, a traditional cultural property in the region, is even more distant, located six or more miles to the east and north of the existing transmission line.

A few cultural resources that appear to be significant for qualities other than their information potential have been identified in the immediate vicinity of the study area (such as Parker Dam and Davis Dam and associated facilities, which are more than or almost 50 years old). It is anticipated that the proposed project would not directly disturb these resources.

If human remains were to be encountered at any time during cultural resource survey or construction, activities would be stopped in the immediate area and measures taken to protect the resources in place. The responsible agency would be immediately notified so consultations could be conducted in compliance with the Native American Graves Protection and Repatriation Act or relevant state laws.

\section{BIOLOGICAL RESOURCES}

\section{Affected Environment}

The McCullough to Liberty OPGW traverses predominantly desertscrub vegetative and associated wildlife communities. The following provides a description of the major vegetation types, wildlife, and special status species identified as occurring in the project vicinity.

\section{Vegetation}

The northern portion of the study area, from the McCullough Substation south to Interstate 40 in Arizona, is within the Mohave desertscrub biome. Mohave desertscrub vegetation is shrub-dominated. The principal, dominant shrub species include creosotebush (Larrea tridentata), all-scale (Atriplex polycarpa), brittlebush (Encelia farinosa), desert holly (Atriplex hymenelytra), white burrobush (Hymenoclea salsola), and blackbrush (Coleogyne ramosissima) (Turner and Brown 1982). Joshua tree (Yucca 
brevifolia) "woodlands" (not a true woodland due to the wide spacing of plants) are a diverse vegetation type. Joshua trees form a scattered, open overstory surrounded by a wide variety of shrub and succulent (cacti) species. Creosotebush typically dominates on bajadas and well-drained sandy flats, usually at elevations below about 4,000 feet. Creosotebush often occurs in association with white bursage (Ambrosia dumosa) in two-layered stands of uniform sized plants over extensive areas. Such stands often give the appearance of being monotypically dominated by creosotebush owing to the lesser stature of white bursage.

The southern portion of the study area, from Interstate 40 south to Liberty, is within the Sonoran desertscrub biome. Two subdivisions of this biome occur in the study area-Lower Colorado River Valley and Arizona Upland. The Lower Colorado River Valley Subdivision is characteristic of the broad, flat, alluvial valleys and plains such as the Butler and McMullen valleys (Brown and Lowe 1980). Similar to Mohave desertscrub, vegetation is typically dominated by creosotebush or an association of creosotebush and white bursage. Vegetation characteristic of the Arizona Upland Subdivision covers slopes; broken ground; and multi-dissected, sloping plains (Turner and Brown 1982) including most of the Buckskin, Harquahala, and Harcuvar mountains (Brown and Lowe 1980). This subdivision appears as an arborescent woodland of leguminous trees with intervening spaces occupied by a variety of large and small shrubs and cacti. Areas dominated by foothill paloverde (Cercidium microphyllum) with local, secondary participation by ironwood (Olneya tesota) and saguaro cactus (Cereus giganteus) are extensive and characteristic of the subdivision. Patches of chaparral habitat are found in portions of the upper reaches of the Harcuvar and Harquahala mountains (Brown and Lowe 1980). Chaparral is a shrubdominated vegetation type that is composed of evergreen species with dense, compact crowns and small, sclerophyllous leaves. The most characteristic, dominant plant species in chaparral is shrub live oak (Quercus turbinella) (Pase and Brown 1982).

Ephemeral, normally dry drainageways can have sufficient water to support taller trees such as mesquite (Prosopis ssp.), catclaw (Acacia greggii), blue paloverde (Cercidium floridum), and ironwood (Olneya tesota) often referred to as microphyll woodlands. In general, these woodlands are better developed within the Arizona, Sonoran Desert portion of the study area. Riparian areas along the Colorado River 
support primarily salt cedar (Tamarix ramosissima) along with interspersed mesquite, scattered cottonwood (Populus fremontii), and Goodding willow (Salix gooddingii).

\section{Wildlife}

Large mammals occurring in the study area include desert bighorn sheep (Ovis canadensis nelsoni and O. c. mexicana), mule deer (Odocoileus hemionus), collared peccary (Tayassu tajacu), coyotes (Canis latrans), and mountain lion (Felis concolor). Desert bighorn sheep occur primarily in mountainous terrain, although rams may occasionally be found on desert flats some distance from mountainous habitat. Remnant or reintroduced populations of this species are present in the Eldorado, Newberry, Mohave, Buckskin, Harcuvar, Harquahala, and Little Harquahala mountains and cliffs adjacent to the Colorado River (BLM). The proposed OPGW would traverse 3.9 miles of designated bighorn sheep lambing habitat located in the foothills of the Mohave Mountains. This area is subject to seasonal closure from January 1 to June 1 .

Mule deer range throughout the area. Collared peccary is most likely to be found in Arizona Upland (Hoffmeister 1986). Mountain lions may occur in virtually any mountainous terrain. However, they are less common in the isolated, desert mountain ranges than elsewhere in their range (Hoffmeister 1986).

Many species of mammals, by virtue of their high mobility (e.g., coyotes) and migratory habits (e.g., bats), are likely to occur in several of the habitat types. Habitat specialists include the beaver (Castor canadensis) which is likely to be restricted to riparian habitats along the Bill Williams River, and the kit fox (Vulpes macrotis), which is restricted to flat desertscrub habitats such as found in the Eldorado, Butler, and McMullen valleys.

Sparsely vegetated, lower elevation, desertscrub habitats are poor in bird species composition. Due to a greater diversity of plants in terms of both composition and structure, Arizona Upland habitats support a greater variety of bird life. Important game birds in the region include doves, ducks, geese, and Gambel's quail (Callipepla gambelii). 
The region supports a diverse array of reptiles, particularly lizards and snakes. Soil types in desertscrub frequently determine distribution of reptiles and small mammals.

From the standpoint of wildlife diversity, microphyll woodlands and riparian associated with the Colorado River support the greatest diversity of species in the region by providing abundant food, cover, and relatively more water for wildlife. These habitats support more nesting bird species than the surrounding desertscrub and represent a significant resource for migrating birds.

\section{Special Status Species}

Special status species are those that, because of their scarcity or documented declining population numbers in the state or nation, have been placed on lists of endangered, threatened, proposed, candidate, or otherwise sensitive species. FWS and state agencies maintain such lists. Species protected under the Endangered Species Act (ESA) which may be affected by the project are addressed in detail in a separate Biological Assessment (BA) prepared for the project (Appendix D). These and other special status species of wildlife identified as occurring in the vicinity of the project are identified in Table 2 along with their preferred habitats. None of these species or their habitats would be adversely effected by this project in any significant way. Further, no similar species (e.g., other species of mammals, birds, reptiles or amphibians) would be adversely affected in any significant way (see environmental consequences). Examples of other species occurring in desertscrub habitats in the region include Mexican free-tailed bats (Tadarida brasiliensis), zone-tailed hawks (Buteo albonotatus), Gila monsters (Heloderma suspectum), and chuckwallas (Sauromalus obesus).

As indicated in Table 2, desert tortoises (Gopherus agassizii) are found in both Mohave and Sonoran desertscrub habitats. The Mohave population of the desert tortoise occurs in the Nevada portion of the study area and, as a threatened species, is protected by the ESA. However, within the city limits of Boulder City, and in the unincorporated area of Searchlight, a Section 10(a) permit for the incidental take of desert tortoises is already in place. However, no existing incidental take permits are in place for 


\begin{tabular}{|c|c|c|c|}
\hline \multicolumn{4}{|c|}{$\begin{array}{l}\text { TABLE } 2 \\
\text { SPECIAL STATUS WILDLIFE LIKELY TO OCCUR IN THE VICINITY OF THE } \\
\text { MCCULLOUGH TO LIBERTY FIBER OPTICS PROJECT }\end{array}$} \\
\hline California Leaf-nosed Bat & Macrotis californicus & WC & $\begin{array}{l}\text { Caves, mine tunnels of W. and S. Arizona deserts, S. Nevada and } \\
\text { NE California. Likely in project area. }\end{array}$ \\
\hline Bald Eagle & Haliaeetus leucocephalus & E,WC & Riparian habitats, winter visitors, nests on Bill Williams River. \\
\hline Clark's Grebe & Aechmophorus clarkii & WC & Known from lakes on the Colorado River. \\
\hline Peregrine Falcon & Falco peregrinus & E, WC & Open areas involving nestings cliffs; Colorado River. \\
\hline Southwestern Willow Flycatcher & Epidonax traillii extimus & E, WC & $\begin{array}{l}\text { Buttonbush swamps of the Sonoran Zone, dense willow, salt cedar } \\
\text { along Colorado River. }\end{array}$ \\
\hline Western Least Bittern & Ixobrychus exilis hesperis & WC & Fresh water brackish marshes; tall vegetation. \\
\hline Yellow-billed Cuckoo & Coccyzus americanus & WC & Stream-side willow and mesquite bosques. \\
\hline $\begin{array}{l}\text { Desert Tortoise (Sonoran } \\
\text { populatation) }\end{array}$ & Gopherus agassizii & WC & $\begin{array}{l}\text { Arizona portion; primarily in Arizona Upland Subdivision of } \\
\text { Sonoran desertscrub in broken terrain. }\end{array}$ \\
\hline Mohave Fringe-toed Lizard & Uma scoparia & WC & Found in Mohave desertscrub. \\
\hline Lowland Leopard Frog & Rana yavapaiensis & WC & Requires aquatic habitats. \\
\hline Bonytail & Gila elegans & E,WC & $\begin{array}{l}\text { Aquatic, Colorado River (designated critical habitat) Lake } \\
\text { Mohave. }\end{array}$ \\
\hline Razorback Sucker & Xyrauchen texanus & $\mathrm{E}, \mathrm{WC}$ & $\begin{array}{l}\text { Aquatic, Colorado River (designated critical habitat) Lake } \\
\text { Mohave. }\end{array}$ \\
\hline \multicolumn{4}{|c|}{$\begin{array}{l}\text { 'Status } \\
\mathrm{E}=\text { A species which is in danger of extinction throughout all or a significant portion of its range. } \\
\mathrm{T}=\text { Any species which is likely to become an endangered species within the foreseeable future throughout all or a significant portion of its range. } \\
\text { WC = Wildlife of Concern }\end{array}$} \\
\hline
\end{tabular}


activity in tortoise habitat for the remaining portions of the route in Nevada. These portions of the route are within critical habitat. The Mohave population is treated in detail in the BA prepared for the project.

Sonoran population of the desert tortoise is not protected by the ESA, but is afforded special protection by the BLM via the protective measures set forth in the Desert Tortoise Habitat Management on the Public Lands: A Rangewide Plan (BLM 1988), which outlined how the BLM will manage for the desert tortoise. The BLM categorizes tortoise habitat according to four criteria: (1) importance of habitat to maintaining viable populations, (2) resolvability of conflicts, (3) tortoise density, and (4) population trend (increasing, stable, or decreasing) (BLM 1988). Pursuant to these policies, special protective measures would be afforded Sonoran desert tortoises in the implementation of this project (see mitigation measures on page 44).

Based on available information, no plants which are currently listed, proposed, or candidates for protection under ESA occur in the study area. Former candidates for Federal listing include the subspecies of the genus Penstemon. Various taxa of plants are protected by the Arizona Native Plant Law in Arizona, and the Cactus and Yucca Law in Nevada.

\section{Environmental Consequences}

\section{Vegetation}

A minimal area of desertscrub vegetation would be lost as a result of construction of the regeneration stations. Of the 2.61 acres of land to be permanently occupied by the regeneration stations, more than 60 percent was previously disturbed and is no longer vegetated. Likewise, a minimal area of desertscrub vegetation would be temporarily disturbed during the installation of the OPGW. Trenching alternatives for the line and site preparation activities at the regeneration stations may temporarily disturb as much as nine acres for the entire route. In addition, the construction of the new one-mile distribution line to the Harcuvar Regeneration Station would use existing access for construction but may temporarily disturb as much as one acre. 


\section{Wildlife}

A minimal loss, or modification, of wildlife habitat would result from project implementation. Due to the short duration of construction, there would be minimal potential for disruption of wildlife (e.g., desert bighorn sheep). Construction activity in the designated 3.9 miles of lambing habitat would be completed in less than one day. This, along with proposed mitigation, would greatly reduce any potential for disturbance. Some wildlife, particularly small mammals and reptiles, could or may be killed or injured as a result of vehicular traffic associated with the project.

The potential for bird collisions with the OPGW would not increase over existing conditions. Replacement of an existing static wire with the OPGW does not alter the configuration of the cables and wires. Further, installation of the OPGW within the existing cables would not likely increase the potential of bird collisions in that birds are likely to avoid flying together into a grouping of cable.

The following two alternatives would increase the potential for bird collisions because they would represent new conductors in the area:

- installing a new distribution line from an existing Arizona Public Service distribution line located near the Alamo Dam Road, for approximately one mile along the south side of the Harcuvar-Bouse Hills $115 \mathrm{kV}$ transmission line to the regeneration site

- attaching a new electrical distribution line below the conductors along the Hassayampa pumping plant's transmission line as an underbuild; this new line would attach to the existing structures at or near the waist of each tower and would enter the regeneration station in the same way as proposed in the static wire replacement alternative

However, impacts on wildlife would be minimal. 


\section{Special Status Species}

Implementation of this project would result in no adverse effects on the Yuma clapper rail (Rallus longirostris yumanensis), bald eagle (Haliaeetus leucocephalus), peregrine falcon (Falco peregrinus anatum), southwestern willow flycatcher (Empidonax traillii extimus), razorback sucker (Xyrauchen texanus), or bonytail (Gila elegans). This conclusion is based on the lack of any significant loss or alteration of the habitats on which these species depend. Further, it is not likely that one of these protected species would be killed or injured from project related activities.

Small areas of desert tortoise habitat (both populations) would be permanently committed to the project as a result of the construction of the regeneration sites. Small areas of habitat would be temporarily disturbed at splicing and pulling sites. At these sites, two vehicles would leave the access road and crush vegetation within the existing right-of-way. Trenching would be required for underground portions of the line causing an insignificant amount of temporary habitat disturbance. With strict adherence to mitigation measures, this disturbance would be kept to a minimum. Given the short time frame of construction activities there is a very low potential tortoise mortality from vehicle collision with tortoises. A Biological Assessment was submitted to USFWS and Section 7 consultation was initiated. USFWS has issued the Biological Opinion, which is included in Appendix E. The Biological Opinion concluded that the proposed project is not likely to result in jeopardy to the desert tortoise or destruction or adverse modification of Critical Habitat. USFWS anticipates the following take could occur as a result of the proposed action:

1. Two (2) desert tortoises may be accidentally injured or killed during construction of the OPGW and the regeneration stations. In addition, two (2) tortoises may be accidentally injured or killed per year during use of access roads for maintenance.

2. Five (5) desert tortoises may be taken by capturing and moving out of harm's way during construction. In addition, two (2) desert tortoises may be taken per year by capturing and moving out of harm's way during use of access roads for maintenance. 
USFWS further concluded that a total of 2.05 acres of desert tortoise habitat, including 0.83 acres of Critical Habitat may be disturbed.

According to USFWS the effect of the take would not reduce appreciably the likelihood of survival and recovery of the Mojave population of the desert tortoise in the wild or diminish the value of Critical Habitat for survival and recovery of the desert tortoise.

The following reasonable and prudent measures were identified by USFWS as necessary and appropriate to minimize take of desert tortoise:

1. Measures shall be taken to minimize take of desert tortoises associated with the installation of the optic ground wire and construction of the Searchlight regeneration station.

2. Measures shall be taken to minimize predation on tortoises by ravens drawn to the proposed project area.

3. Measures shall be taken to minimize destruction of desert tortoise habitat, such as soil compaction, erosion, or crushed vegetation, due to surface-disturbing activities.

4. Measures shall be taken to ensure compliance with the reasonable and prudent measures, terms and conditions, reporting requirements, and reinitiation requirements contained in this biological opinion.

In addition, USFWS recommended a conservation measure of rehabilitating a disturbed area or closed road within the proposed Paiute-Eldorado DWMA.

All salvageable plants protected by the Arizona Native Plant Law and Nevada Cactus and Yucca Law would be transplanted to a nearby site (i.e., within 100 yards). Less than 10 such plants are likely to be affected. 


\section{$\underline{\text { Mitigation }}$}

The following mitigation measures are designed to reduce the impacts of the proposed project on biological resources:

1. All protective measures set forth in the Biological Assessment and incorporated into Biological Opinion would be implemented. These are as follows:

- A tortoise biologist would be present during all construction activities where one or more pieces of heavy construction equipment are being used.

- All construction-vehicle movement outside of the right-of-way would be restricted to predesignated access, or public roads.

- The area limits of construction activities would be predetermined, with activity restricted to and confined within those limits. No paint or permanent discoloring agents would be applied to rocks or vegetation to indicate survey or construction activity limits.

- Hazardous materials would not be drained onto the ground or into streams or drainage areas. Totally enclosed containment would be provided for all trash. All construction waste including trash and litter, garbage, other solid waste, petroleum products, and other potentially hazardous materials would be removed to a disposal facility authorized to accept such materials.

- The two regeneration sites and construction activity sites (e.g., pulling and splicing areas) would be clearly marked or flagged at the outer limits prior to the onset of any surfacedisturbing activity. All personnel would be informed that their activities must be confined to within the marked or flagged areas. All construction and activity sites would be surveyed by qualified tortoise biologists no more than 15 days prior to the initiation of construction. 
Surveys would provide 100-percent coverage of the entire construction area. Any desert tortoise burrows located would be conspicuously flagged or marked, and avoided.

- Procedures for handling, holding, or relocating tortoises from the right-of-way would follow the most current procedures established by the Service and Bureau.

- To prevent mortality, injury, and harassment of desert tortoises and damage to their burrows and coversites, no pets would be permitted in any project construction area unless confined or leashed.

- Totally enclosed, raven-proof containment would be provided for all trash.

- No widening or upgrading of existing access roads would be undertaken in the area of construction, except for repairs necessary to make roads passable. There would be no blading of new access roads.

- A biologist would be assigned to the pre-construction survey team(s). The biologist would be responsible for ensuring that all work areas (e.g., splicing, pulling sites, trenched areas) would also be surveyed by a biologist as construction proceeds. Potential work areas would be flagged several days prior to construction for review by a biologist. All tortoise burrows (or other shelter sites) would be avoided.

- Overnight parking and storage of equipment and material would be in previously disturbed areas (i.e., lacking vegetation). These areas would also be designated by the preconstruction survey team.

- No blading of splicing and tensioning sites would occur. Construction workers would strictly limit their activities and vehicles to construction areas and routes of travel which have been flagged to eliminate adverse impacts to desert tortoises and their habitat. Aside from these 
areas, workers may not drive cross-country even within the right-of-way. All workers would be instructed that their activities are restricted to flagged and cleared areas.

- Western would designate a field contact representative (FCR). The FCR would be responsible for overseeing compliance with protective stipulations for the desert tortoise and for coordination on compliance with Western. The FCR would have the authority to halt activities of construction equipment which may be in violation of the stipulations.

- All construction personnel would participate in a tortoise-education program. The program would be developed by Western prior to the beginning of construction. The program would be submitted to the Service for review and approval prior to implementation. The program would include, at a minimum, the following topics: (a) the occurrence of desert tortoises; (b) sensitivity of the species to human activities; (c) legal protection for desert tortoises; (d) penalties for violations of Federal and state laws; (e) general tortoise activity patterns; (f) reporting requirements; (g) measures to protect tortoises; and (h) personal measures employees can take to promote the conservation of desert tortoises.

- The Service would be notified of any tortoise death or injury caused by project activities. Notification would include the date, time, circumstances, and location of any injury or death. Dead animals may be marked and left onsite. Injured animals would be transported to a qualified veterinarian. The Service would furnish direction on the final disposition of tortoises taken to a veterinarian.

- No later than 90 days after completion of construction within tortoise habitat, the FCR and onsite biologist would prepare a report for Western and the Service. The report would document the effectiveness of the tortoise mitigation measures. The report would include an assessment of any habitat disturbance. 
In addition, the terms and conditions of the Reasonable and Prudent Measures (see page 16 of the Biological Opinion, Appendix E) would be implemented, including the payment of fees for surface disturbing activities within desert tortoise habitat and desert tortoise critical habitat.

2. All salvageable plants protected by the Arizona Native Plant Law and Nevada Cactus and Yucca Law would be transplanted to a nearby site (i.e., within 100 yards).

3. A biologist would accompany all construction and survey crews throughout the project area to ensure implementation of Measures \#1 and \#2. Further, the biologist would ensure that the same protective measures established for desert tortoises in Nevada would be implemented in the Arizona and California portions of the project area as well.

4. Scarification and seeding would occur on all areas disturbed by construction activities that are not needed for permanent facilities. The seed mix would be one that has been approved by the BLM and/or has the concurrence of the appropriate state resource agency.

5. In designated bighorn sheep habitat subject to seasonal closure, the biologist assigned to the project will be experienced in locating bighorn sheep and will coordinate with BLM to determine how construction should proceed.

\section{GEOLOGY AND SOILS}

\section{Affected Environment}

The majority of the study area is in the Basin and Range Physiographic Province. This portion of the Basin and Range Province is typified generally by rugged northwest and north-trending mountain ranges that are separated by broad, sediment-filled desert valleys. The basin elevations range from about 500 to 3,000 feet above mean sea level and the mountain ranges typically rise to 5,000 feet, although the Hualapai Mountains rise to an elevation of 8,266 feet. 
A variety of rock types are exposed in the vicinity of the study area and are grouped into categories including Precambrian granitic and metamorphic rocks, Paleozoic sedimentary rocks, Mesozoic sedimentary rocks, Cretaceous volcanic rocks, Laramide granitic and siliceous intrusive rocks, Tertiary and quaternary volcanic rocks, and Tertiary sediments.

Soils within the alternative study corridors are included in the following categories:

- alluvial fans (silty sands, gravelly sands with gravel deposits, desert pavement)

- stream alluvium in active channels (sand, gravel, cobbles, silt), floodplains (silts, clays, fine sands) and other stream terraces

- colluvium (loose sands and silty sands)

- wind-blown sand deposits (sand dunes, drifts, sheets)

- lake deposits (range from sand and gravel near shore to silts and clays at center)

Low rainfall and coarse surface sediments restrict the amount of erosion in the study area compared to other areas, but the potential to accelerate erosion is possible in areas where steep slopes, sparse vegetation, and nonresilient soils beneath some of the protective surface gravels prevail. Water is usually the most significant erosive agent, although wind is also a capable erosive agent, especially in arid regions.

The following study area soils have the highest potential to experience accelerated erosion due to proposed project activities:

- floodplains

- active stream channels

- existing sand dune or drift areas 
- lake deposits

- fine sediments on very steep slopes

- noncohesive colluvium on steep slopes

- desert pavement areas with fine sediments beneath the pavement gravels

\section{Environmental Consequences}

Impacts on geology and soils are expected to be low on all action alternatives and limited to those areas where ground disturbing activities would expose soils susceptible to erosion. Alternatives reducing the amount of ground disturbance are preferred. Regeneration sites require the disturbance of soils during construction; however, the preparation of the site with a one-half to three-quarter inch broken gravel base effectively eliminates erosion potential at these locations.

In areas where trenching is proposed, temporary ground disturbance occurs over a short period of time and within an 18-inch trench. Side casting would temporarily bury as much as 36 inches of area adjacent to the trench for a few days. The scale of the disturbance is expected to produce low impacts at trenching locations.

\section{Mitigation}

None. 


\section{FLOODPLAINS/WETLANDS}

\section{Affected Environment}

The hydrological regime in the vicinity of the transmission lines is such that surface water flows only on an intermittent basis in conjunction with significant precipitation events. Numerous dry washes and channels also occur throughout the study area.

Information on potential floodplain and wetlands within the project area was obtained from maps provided by the Federal Emergency Management Agency's National Flood Insurance Program. In addition, an on-the-ground reconnaissance survey of the eight regeneration sites was conducted in order to identify floodplain and wetlands. No wetlands were identified.

The Federal Emergency Management Agency (FEMA) floodplain maps show that the floodplains in the project area can be separated into four main divisions-Colorado River influence zone, central upland portion in Arizona, Eldorado-Paiute Valley of Nevada, and Hassayampa River influence zone. For this proposed project, the floodplain areas are categorized as Zones A, B (same as Zone X), and C which are defined as follows:

- Zone A-areas of 100-year flood

- Zone B or X-areas between limits of 100-year flood and 500-year flood or certain areas subject to 100-year flood with average depths of less than 1 foot

- Zone $\mathrm{C}$-areas of minimal flooding

Proposed regeneration sites that are located in the major river influences are Hassayampa Tap Substation (Zone C), Davis Dam Substation (Zone C), and Parker Dam Substation (Zone C). Two proposed regeneration station sites located in the Eldorado-Paiute Valley include McCullough Substation (Zone $\mathrm{X}$ ) and Searchlight (Zone X). Three other regeneration sites in the central upland portion include Topock 
(Zone C), Harcuvar Substation (Zone C), and Aguila (undetermined as shown on Firm Panel Map 04013C0575D).

In general, the large aerial extent of floodplains are due to the relative flatness of the terrain and the low infiltration rates of most of the desert soils. During the relatively infrequent periods of heavy precipitation, the rivers and washes fill their channels and overflow their banks with runoff. Thus, these 100-year and 500-year flood events can be characterized as shallow, of short duration, and without significant current.

\section{Environmental Consequences}

The proposed project would cross several 100-year and 500-year floodplains identified by FEMA. These floodplains include ephemeral dry washes that can potentially fill with water following heavy precipitation. Some regeneration sites would be located in designated floodplains; however, these floodplains are basically flat overflow areas associated with dry washes, the Colorado River, and the Hassayampa River. Flooding associated with these areas, should it occur, would be characterized by shallow water without strong currents.

The project would not increase any scouring action or aerial extent of floodplains.

\section{Mitigation}

At regeneration sites located in shallow flooding areas (Zones B and X), sites would be elevated with earth fill to prohibit flooding control buildings. 


\section{ENVIRONMENTAL JUSTICE}

Executive Order 12898 requires Federal agencies to ensure environmental conditions and human health in minority and low-income communities are considered in Federal decision making, ensure that these communities are not discriminated against by Federal undertakings, and give these communities more information about and greater opportunities to participate in formulating Federal actions which may impact them.

This project would not directly affect minority and low-income communities; however, the Central Arizona Project that services these communities would be improved.

\section{CUMULATIVE EFFECTS}

The OPGW would be constructed on existing structures for the majority of the route and within an existing right-of-way for the entire distance. The OPGW would be patrolled by Western linemen as part of the existing maintenance and operation program currently applied to the existing line two times each year. Because the OPGW replaces an existing wire and no additional maintenance and operation efforts are applied to the lines or the rights-of-way, cumulative effects are negligible.

The regeneration stations would add facilities to the existing environment; however, the scale of these changes would be a minor modification to the environment, particularly considering the setting of each site. Maintenance and operation activities would increase visits to each site by approximately 12 visits per year. Right-of-way acquisition would be required for three regeneration sites located on BLM lands for a total of 0.69 acre. A 10 -foot right-of-way also may be required from the BLM for a one-mile electrical distribution line.

The distribution line would be a new feature to the landscape, but is subordinate to the existing transmission lines in the area of the Harcuvar Regeneration Station. 


\section{WESTERN AREA POWER ADMINISTRATION}

John Bridges

Environmental Specialist

John Holt

Environmental Manager

Mary Barger

Archaeologist

HPO

Bill Snowden

Project Manager
MS, Zoology

BS, Zoology

22 years of experience

BS, Community Health Education

20 years of experience

BS, Anthropology

20 years of experience

BS, Engineering

14 years of experience

\section{BUREAU OF RECLAMATION}

Pat Hicks

Archaeologist

Tom Lincoln

Archaeologist

Carol Telles

Archaeologist

Brad Augustine

Geologist

Diane Laush

Biologist

Sandy Eto

Environmental Protection

Specialist
MS, Anthropology

BS, Anthropology

23 years of experience

BS, MS, Anthropology

18 years of experience

BA, Anthropology

13 years of experience

BS, Geology

23 years of experience

BS, Biology

14 years of experience

BA, Sociology

18 years of experience 
DAMES \& MOORE

Garlyn Bergdale

Principal-in-Charge

Mike Warner

Project Manager

Mark Cochran

Senior Biologist

Gene Rogge

Cultural Resources

Kristin Darr

Editor

\section{RECOM Technologies}

Karim Dada

Environmental Specialist

Greg Wold

Environmental Specialist
MLA, Landscape Architecture, BS, Geography

22 years of experience

MLA, Landscape Architecture, BS, Plants and Soils 10 years of experience

BA, Biology, graduate studies in Zoology and Wildlife Management

16 years of experience

PhD, Anthropology

23 years of experience

BA, Political Science and Journalism

6 years of experience in technical communication
BS, Animal Science

1 year of experience

BS, Biology

6 years of experience 
The preparation of this EA required communication and coordination with various Federal and state agencies as well as American Indian tribes. The following list summarizes the agencies contacted. These agencies were contacted primarily to identify any issues or concerns that may be related to development of this project.

\section{FEDERAL AGENCIES}

\section{Bureau of Land Management}

Nevada State Office

Mr. Rob Nauert

Arizona State Office

Ms. Denise Meredith, State Director

Ms. Carol Kershaw

Ms. Cindy Alvarez

Mr. Ted Bingham

Phoenix Field Office

Mr. Mike Taylor, Field Manager

Mr. Hector Abrego

Mr. Milton Rupp

Ms. Cheryl Blanchard

Mr. David Redmond

Mr. Ken Drew

Mr. John Jamrog

Lake Havasu Field Office

Mr. Jaime Provencio, Field Manager

Mr. Cory Bodman

Kingman Field Office

Mr. John Christensen, Field Manager

Mr. Bill Wadsworth

Las Vegas Field Office

Mr. Jerry Wickstrom

Mr. Jeff Steinmetz

Mr. Jim Abbot 
Ms. Jacqueline Gratton

Mr. Jimmy Williams

Mr. Dennis Samuelson

Ms. Jenny Cole

\section{National Park Service}

Mr. Alan O'Neill, Superintendent, Lake Mead National Recreation Area

\section{U.S. Fish and Wildlife Service}

Mr. Donald Steffeck, Ventura Field Office (California)

Mr. David Harlow (Nevada)

Mr. Michael L. Burroughs, Fish and Wildlife Biologist (Nevada)

Ms. Selena J. Werdon, Fish and Wildlife Biologist (Nevada)

Mr. Sam F. Spiller, Field Supervisor (Arizona)

Ms. Debbie MacAller (California)

\section{U.S. Army Corps of Engineers, Los Angeles District}

Ms. Marjorie E. Blaine, Senior Project Manager, Arizona-Nevada Area Office

\section{STATE AGENCIES}

\section{Arizona}

Mr. Duane Shroufe, Arizona Game \& Fish Department

Ms. Nancy Olson, Project Evaluation Specialist, Arizona Game \& Fish Department

Mr. John Kelly, Executive Assistant, Office of the Governor

Mr. James Garrison, State Historic Preservation Office

\section{Nevada}

Mr. Mike Del Grosso, Senior Planner, State Lands of Nevada

Mr. William Molini, Administrator, Nevada Division of Wildlife

Ms. Becky Jones, Word Processor, Nevada Division of Wildlife

Ms. Julie Butler, Nevada State Clearinghouse Department of Administration

Ms. Alice Baldrica, State Historic Preservation Office

Ms. Terri Rodefer, Environmental Advocate, Nevada State Clearinghouse

Mr. Thomas H. Henderson, Senior Analyst, Public Service Commission of Nevada 


\section{California}

Mr. Vic Holland, Deputy Director, Office of Permit Assistance

Mr. Hans Keinoehl, State Historic Preservation Office

\section{TRIBAL CONTACTS}

\section{Fort Mojave Indian Tribe}

Ms. Patricia Madueno, Chairperson

Ms. Elda Butler, Aha Makav Culture Society

\section{Colorado River Indian Tribes}

Mr. Daniel Eddy, Jr., Chairman

Ms. Betty Cornelius, Museum Director

Mr. Weldon Johnson, Museum Staff

Ms. Viola Stone, Acting Chairperson, Mohave Elders Committee

\section{Las Vegas Paiute Tribe}

Ms. Alfreda Mitre, Chairperson, Las Paiute Tribe

\section{Southern Paiutes of Pahrump}

Mr. Richard Arnold

\section{Fort Yuma-Quechen Tribe}

Mr. Mike Jackson, President

Ms. Paulina Owls, Cultural Committee

\section{Hualapai Tribe}

Mr. Delbert Havatone, Chairman, Hualapai Tribal Council

Ms. Loretta Jackson, Office of Cultural Resources

\section{Chemehuevi Indian Tribe}

Mr. Mathew Leivas, Senior, Chairman

Ms. Amy Johnson

\section{Hopi Tribe}

Mr. Veron Masayesva, Chairman 



\section{CHAPTER 6 - REFERENCES}

Arizona Game \& Fish Department (AGFD). 1993. Bats of Arizona. Special Heritage Edition of Arizona Wildlife Views. Arizona Game and Fish Department, Phoenix, Arizona. 37 pp.

1988. Threatened Native Wildlife in Arizona. Arizona Game \& Fish Department Publication. Phoenix, Arizona. 32 pp.

Bair, Gerald. 1974. An Archaeological Reconnaissance Survey of the Proposed Liberty-Parker 230kV Transmission Line. Department of Anthropology, Arizona State University, Tempe.

Bee, Robert L. 1983. Quechan. In Handbook of North American Indians, Volume 10: Southwest, edited by Alfonso Ortiz, pp. 86-98, Smithsonian Institution, Washington, D.C.

Bondley, George A. and Richard H. Brooks. 1973. An Archaeological Survey of the Mead-Davis-Parker $230 k V$ Transmission Line No. 2. Nevada Archaeological Survey, University of Nevada, Las Vegas.

Brown, D.E. and C.H. Lowe. 1980. Biotic Communities of the Southwest. USDA Forest Service General Technical Report RM-78. 1 p. map. Rocky Mountain Forest and Range Experiment Station. Fort Collins, Colorado.

Brown, Patricia Eyring. 1980. Letter Report Regarding Cultural Resource Survey of the Liberty-Parker$115 k$ V Hassayampa Transmission Line. Department of Anthropology, Arizona State University, Tempe.

1978. Letter Report Regarding Archaeological Investigations Along Reach 7, Granite Reef Aqueduct, Supplemental Survey Along the Liberty-Parker Transmission Line, and Survey at the Havasu Pumping Plant Borrow Area. Department of Anthropology, Arizona State University, Tempe.

Brown, Patricia Eyring and Connie Lynn Stone (eds). 1982. Granite Reef: A Study in Desert Archaeology. Arizona State University Anthropological Research Papers No. 28. Tempe.

Bureau of Land Management (BLM). 1996. Kingman-Havasu Transmission Project Environmental Assessment and Proposed Plan Amendment. Havasu Field Office, Lake Havasu City, Arizona.

1994. Proposed Yuma District (Havasu) Resource Management Plan Amendment and Final Environmental Assessment. Yuma District Office, Yuma, Arizona.

1993. Kingman Resource Area Proposed Management Plan and Final Environmental Impact

Statement. Kingman District. Kingman, Arizona.

1993. Environmental Assessment, Proposal to Construct a Fiber Optic Line from Phoenix to Las Vegas. Phoenix District, Phoenix, Arizona. 
Bureau of Land Management. 1992. Yuma District Resource Management Plan Amendment Yuma District, Yuma, Arizona.

1988. Desert Tortoise Habitat Management on the Public Lands: a Rangewide Plan. Bureau of Land Management. 23 pp.

. 1988. Arizona Mohave Draft Wilderness Environmental Impact Statement. Phoenix District. Phoenix, Arizona.

- 1988. Proposed Phoenix Resource Management Plan and Final Environmental Impact Statement. Phoenix District. Phoenix, Arizona.

. 1985. Final Yuma District Resource Management Plan and Environmental Impact Statement. Yuma District Office, Yuma, Arizona.

. 1985. Final Resource Management Plan and Environmental Impact Statement. Yuma District, Yuma, Arizona.

1982. Draft Environmental Impact Statement Proposed Grazing Management Program of the Lower Gila North EIS Area Yuma, Mohave, Yavapai, and Maricopa Counties, Phoenix District, Phoenix, Arizona.

. 1979. Crossman Peak Proposed Radar Facility Environmental Impact Statement. Yuma District Office, Yuma, Arizona.

nd. Visual Resource Management Program. Washington D.C.

nd. Final Environmental Impact Statement Proposed Wilderness Program for the Upper Sonoran Wilderness EIS Area. LaPaz, Maricopa, Mohave, and Yavapai Counties. Phoenix District, Phoenix, Arizona.

Bureau of Reclamation. 1974. Final Environmental Statement Granite Reef Aqueduct Transmission System. A Feature of the Central Arizona Project. Lower Colorado Region, Phoenix, Arizona.

Dobbins, Ed. 1980a. Archaeological Investigations Along the Liberty-Parker 230kV Transmission Line, Central Arizona Project. Department of Anthropology, Arizona State University, Tempe.

1980b. Archaeological Investigations Along the Bouse Hills-Harcuvar-Little Harquahala Transmission Lines, Features of the Granite Reef Aqueduct, Central Arizona Project. Department of Anthropology, Arizona State University, Tempe.

- 1980c. Archaeological Investigations Along the McCullough-Davis Transmission Line, A Feature of the Granite Reef Aqueduct, Central Arizona Project. Department of Anthropology, Arizona State University, Tempe. 
Dobbins, Ed. 1979a. Granite Reef Aqueduct and Transmission System Project: A Cultural Resource Survey of the Bouse Hills-Harcuvar-Little Harquahala 115kV Transmission Line, Central Arizona Project. Department of Anthropology, Arizona State University, Tempe.

1979b. A Cultural Resource Survey of the McCullough-Davis 230kV Transmission Line, Clark County, Nevada, A Feature of the Granite Reef Transmission System, Central Arizona Project. Department of Anthropology, Arizona State University, Tempe.

1978a. A Cultural Resource Survey of Realigned Portions of the Liberty-Parker and ParkerHavasu Transmission Lines and Harcuvar Substation, Interim Report. Department of Anthropology, Arizona State University, Tempe.

1978b. Granite Reef Aqueduct and Transmission System Project: A Cultural Resource "ReSurvey" of the Liberty-Parker 230kV Transmission Line Right-of-Way, Central Arizona Project Addendum I. Department of Anthropology, Arizona State University, Tempe.

Federal Emergency Management Agency. nd. Flood Insurance Rate Maps for Clark County, Nevada, and Mohave, La Paz, and Maricopa Counties, Arizona.

Hoffmeister, D.F. 1986. Mammals of Arizona. The University of Arizona Press and The Arizona Game and Fish Department, Tucson, Arizona. 601p.

Kroeber, Alfred L. 1972. More Mohave Myths. Anthropological Records, Vol. 27. University of California, Berkeley.

Larson, Daniel O., K. Olson, J. Moore, J. King, K. Bergin, E. Bussard, R. Wilson, H. Turner, R. Leavitt and R.H. Brooks. 1976. An Archaeological Investigation of Sites Located Along the Mead-DavisParker Transmission System (Granite Reef). Nevada Archaeological Survey, University of Nevada, Las Vegas.

Maricopa County. nd. White Tanks Agua Fria Policy and Development Guide. Phoenix, Arizona.

Minckley, W.L. 1973. Fishes of Arizona. A publication of the Arizona Game \& Fish Department. Sims Printing Company, Phoenix, Arizona. 293 pp.

Monson, G. and A.R. Phillips. 1981. Annotated Checklist of Birds of Arizona. Tucson: University of Arizona Press. 240 pp.

Pase, C.P. and D.E. Brown. 1982. Interior Chaparral. Pp. 95-99 in D.E. Brown (ed). Biotic Communities of the American Southwest-United States and Mexico. Desert Plants 4(1-4).

Stebbins, R.C. 1985. A Field Guide To Western Reptiles and Amphibians. Sponsored by the National Audubon Society. Houghton Mifflin Company, Boston. 279 pp. 
Stewart, Kenneth M. 1983. Mohave Alfonso Ortiz (ed.) pp. 55-70. In Handbook of North American Indians, Volume 10: Southwest. Smithsonian Institution, Washington, D.C.

Turner, R.M. 1982. Mohave Desertscrub. pp. 157-168 D.E. Brown (ed). In Biotic Communities of the American Southwest-United States and Mexico. Desert Plants 4(1-4).

Turner, R.M. and D.E. Brown. 1982. Sonoran Desertscrub. pp. 181-221 D.E. Brown (ed). In Biotic Communities of the American Southwest-United States and Mexico. Desert Plants 4(1-4).

U.S. Department of Energy-Western Area Power Administration. 1996. Draft Environmental Impact Statement. Navajo Transmission Project.

Project.

1986. Environmental Assessment, Liberty-Parker No. 2, 230kV Transmission Line Project in La Paz and Maricopa Counties, Arizona.

1983. Mead-Phoenix $\pm 500 k V$ DC Transmission Project Draft Environmental Impact Statement.

U.S. Fish and Wildlife Service (USFWS). 1991. Endangered and Threatened Species of Arizona. U.S. Fish and Wildlife Service, Phoenix, Arizona. $102 \mathrm{pp}$. 




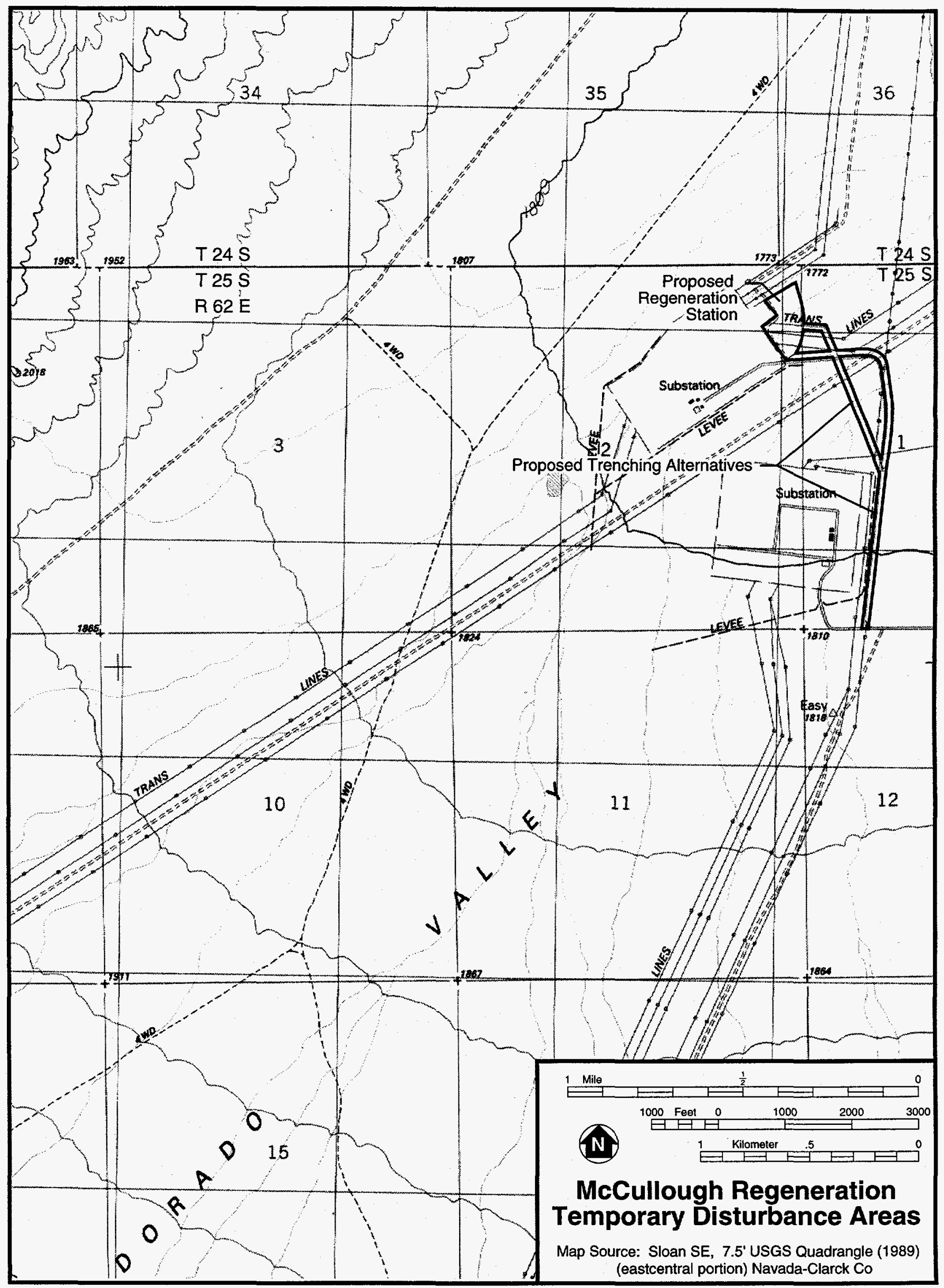





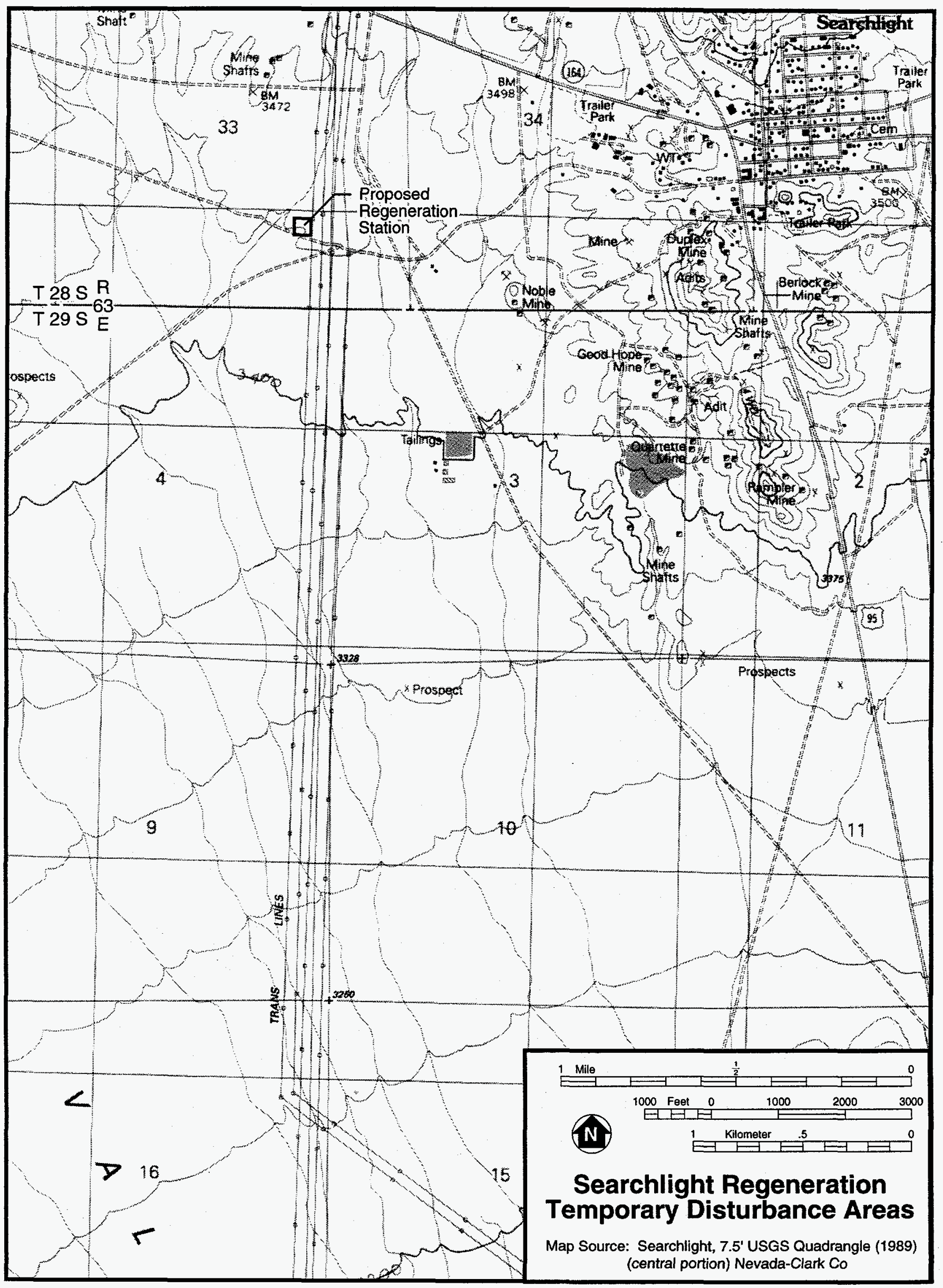





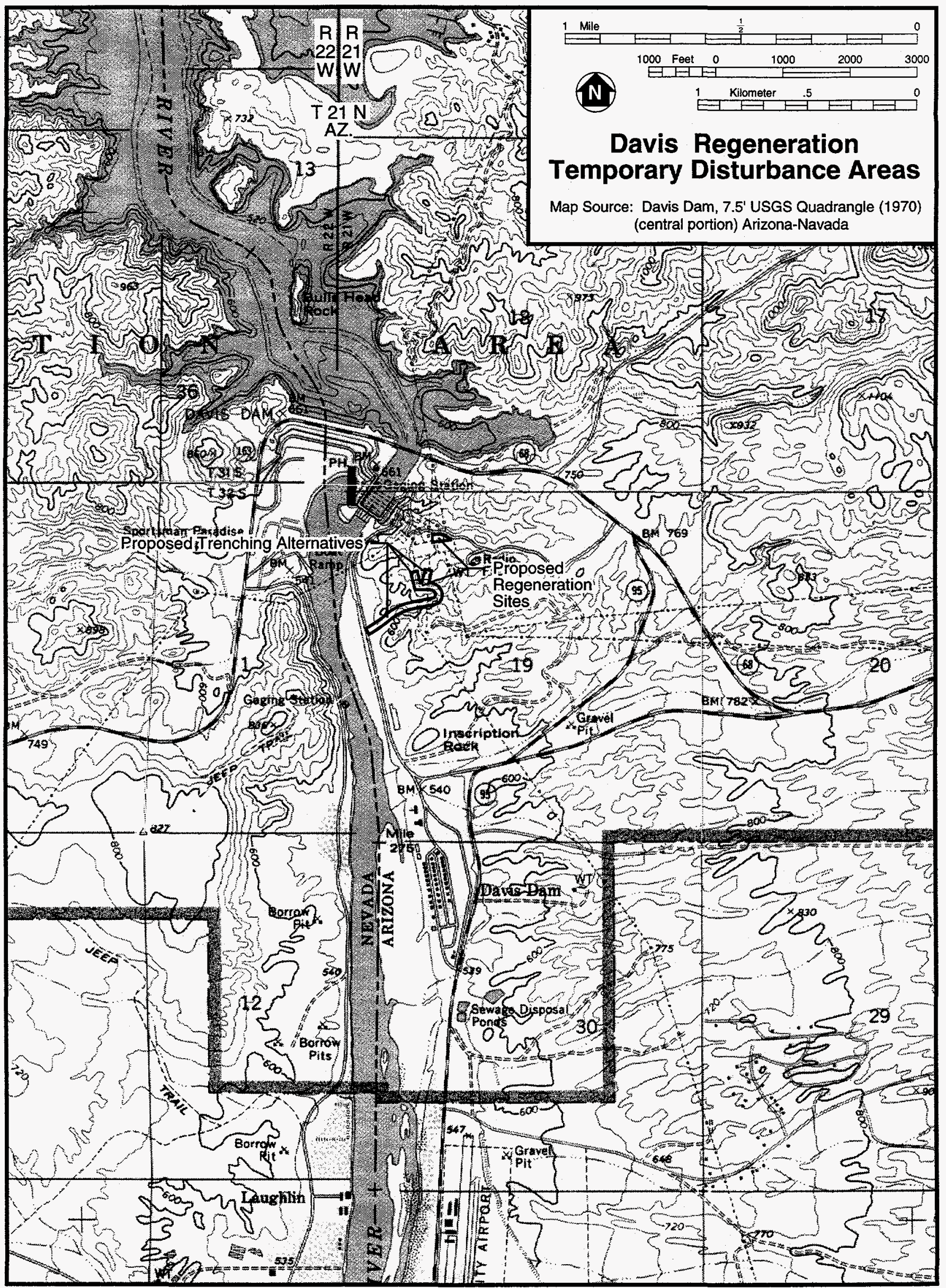





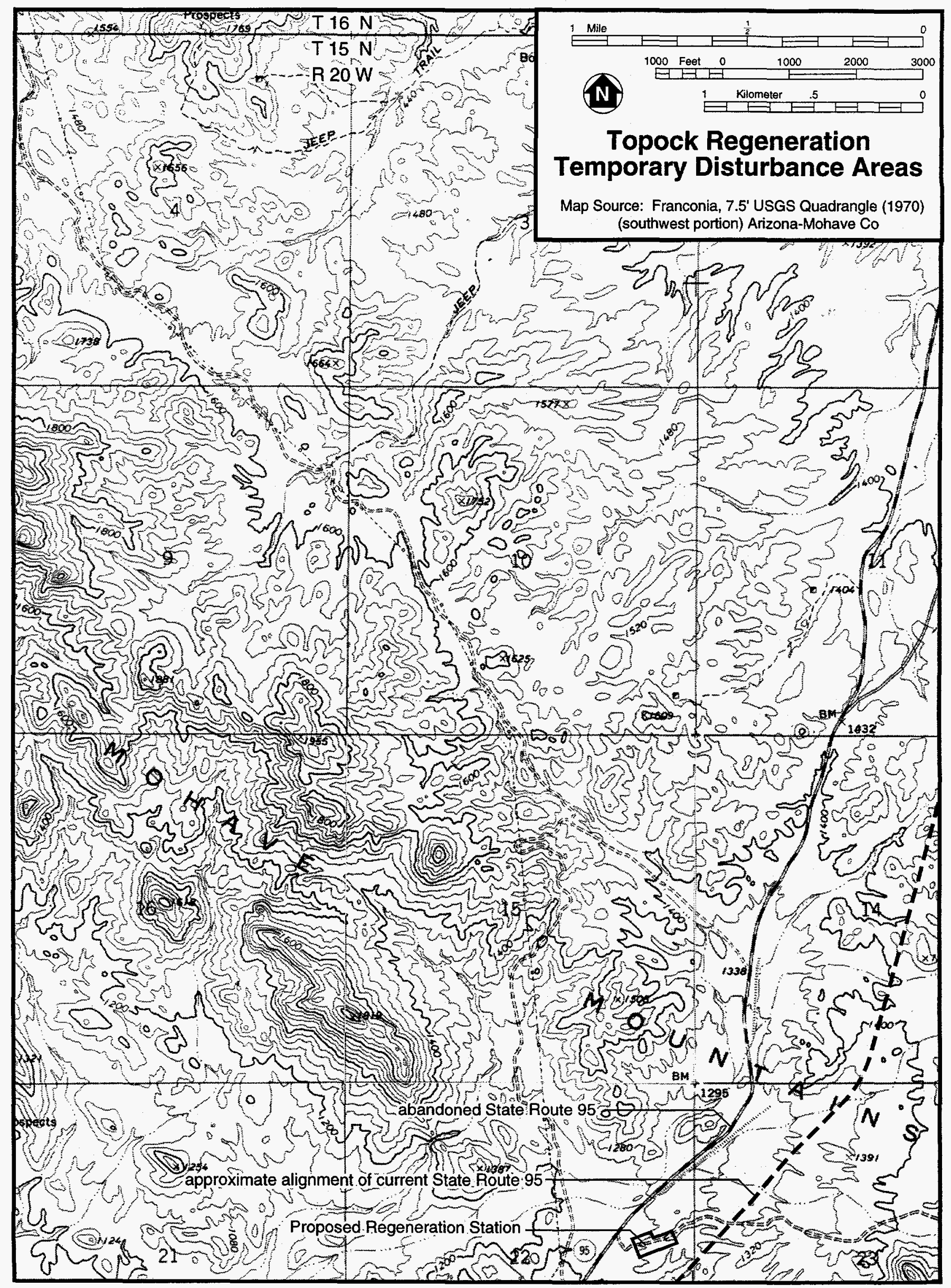





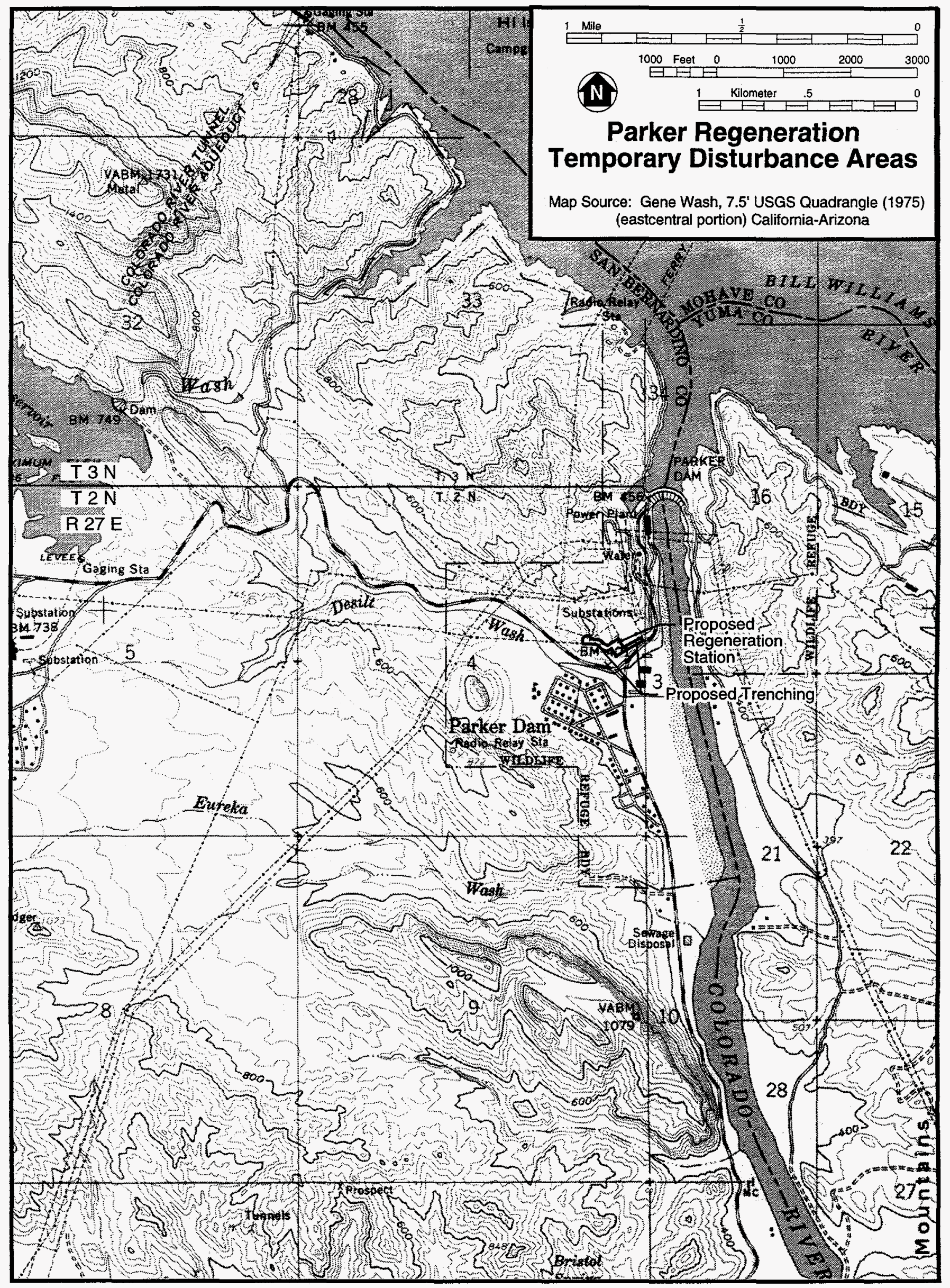





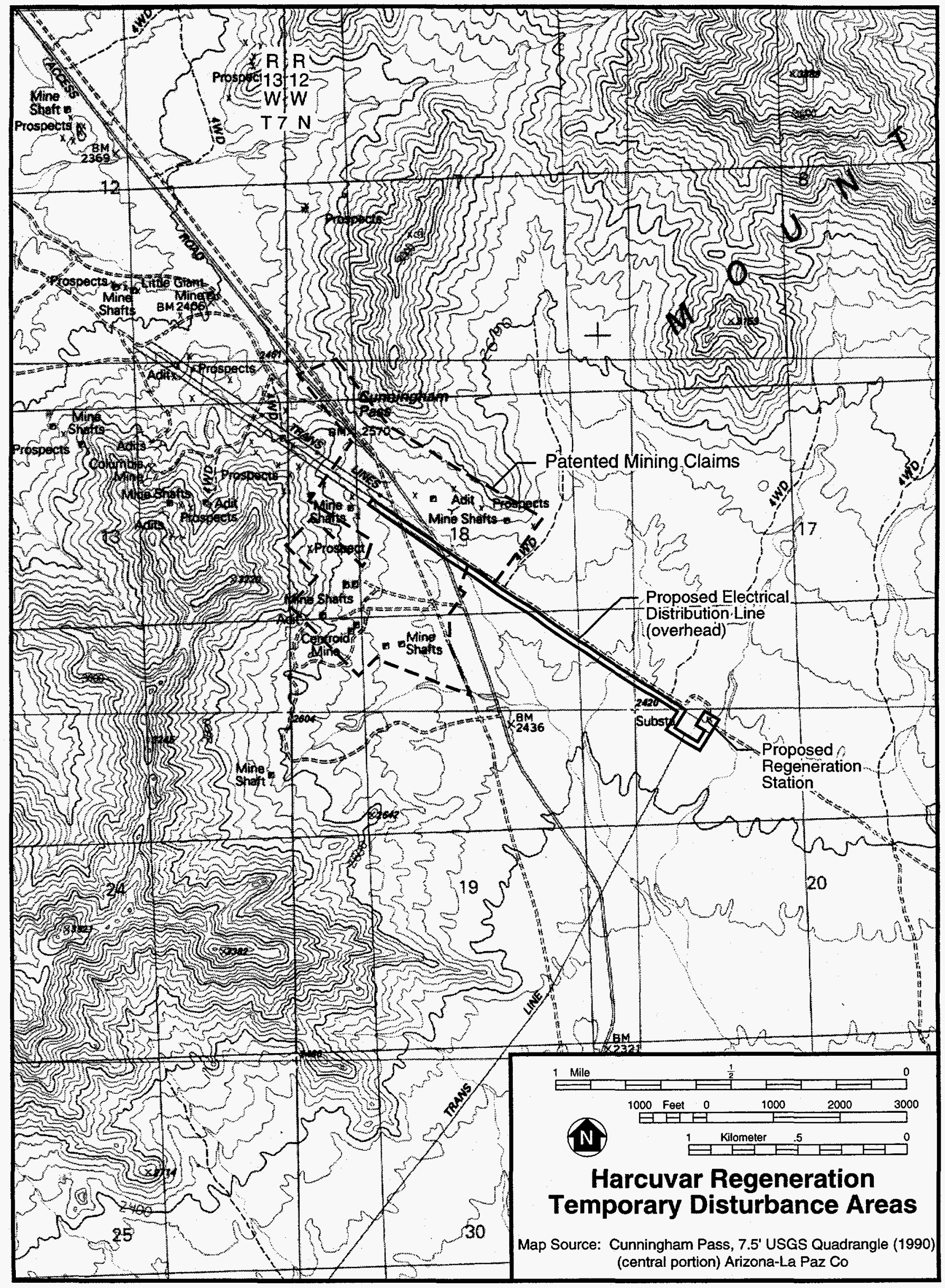





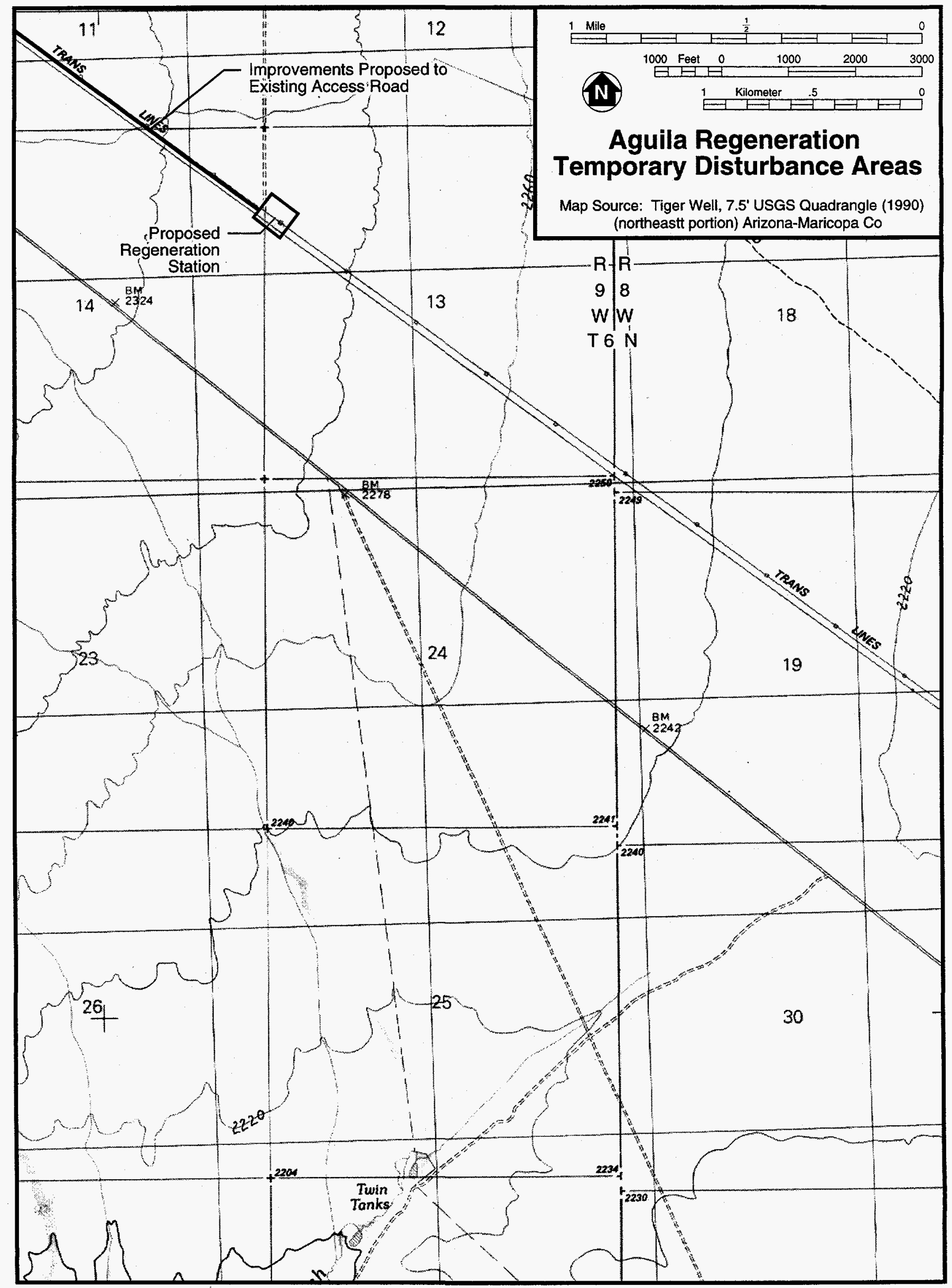





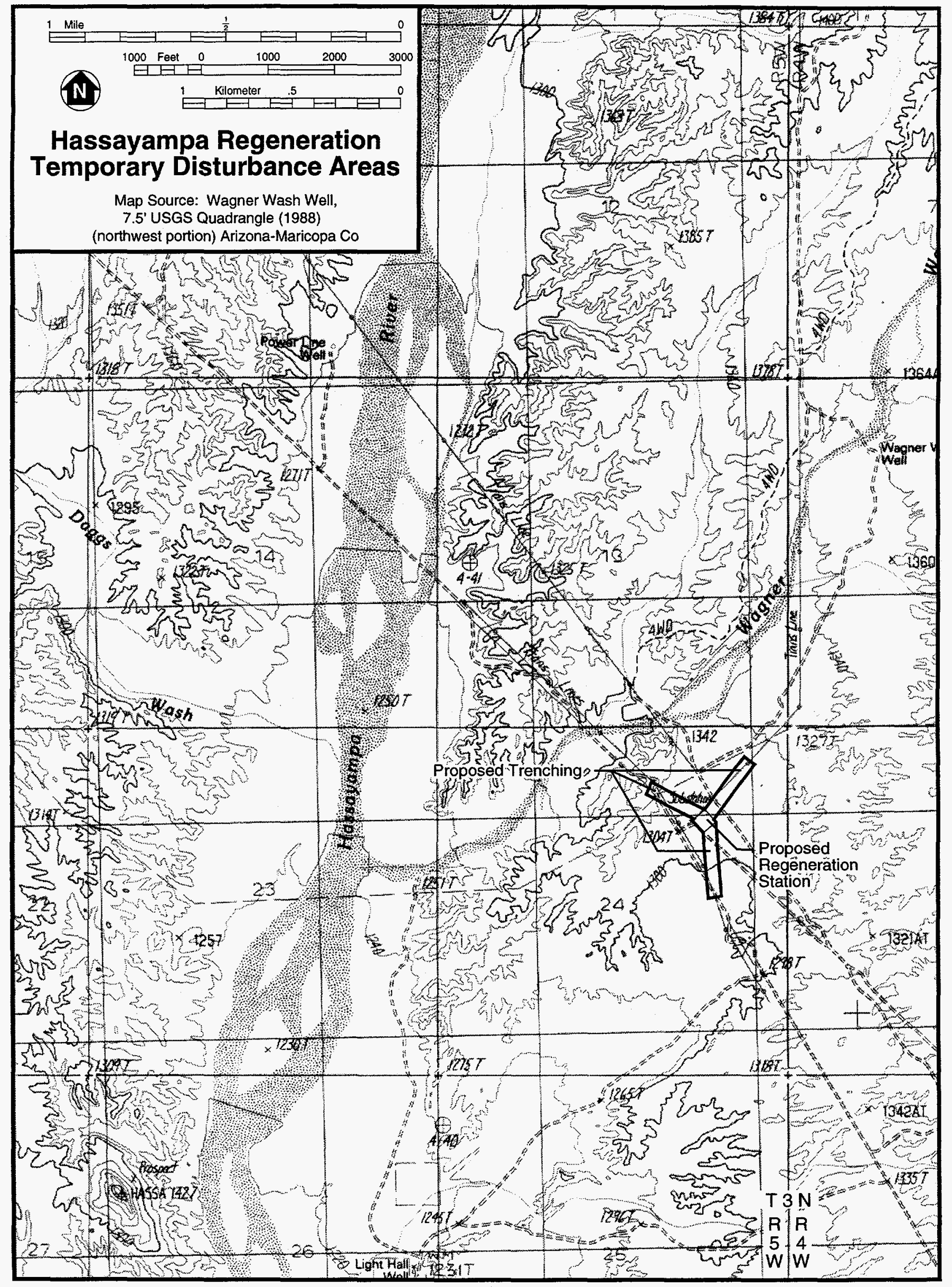




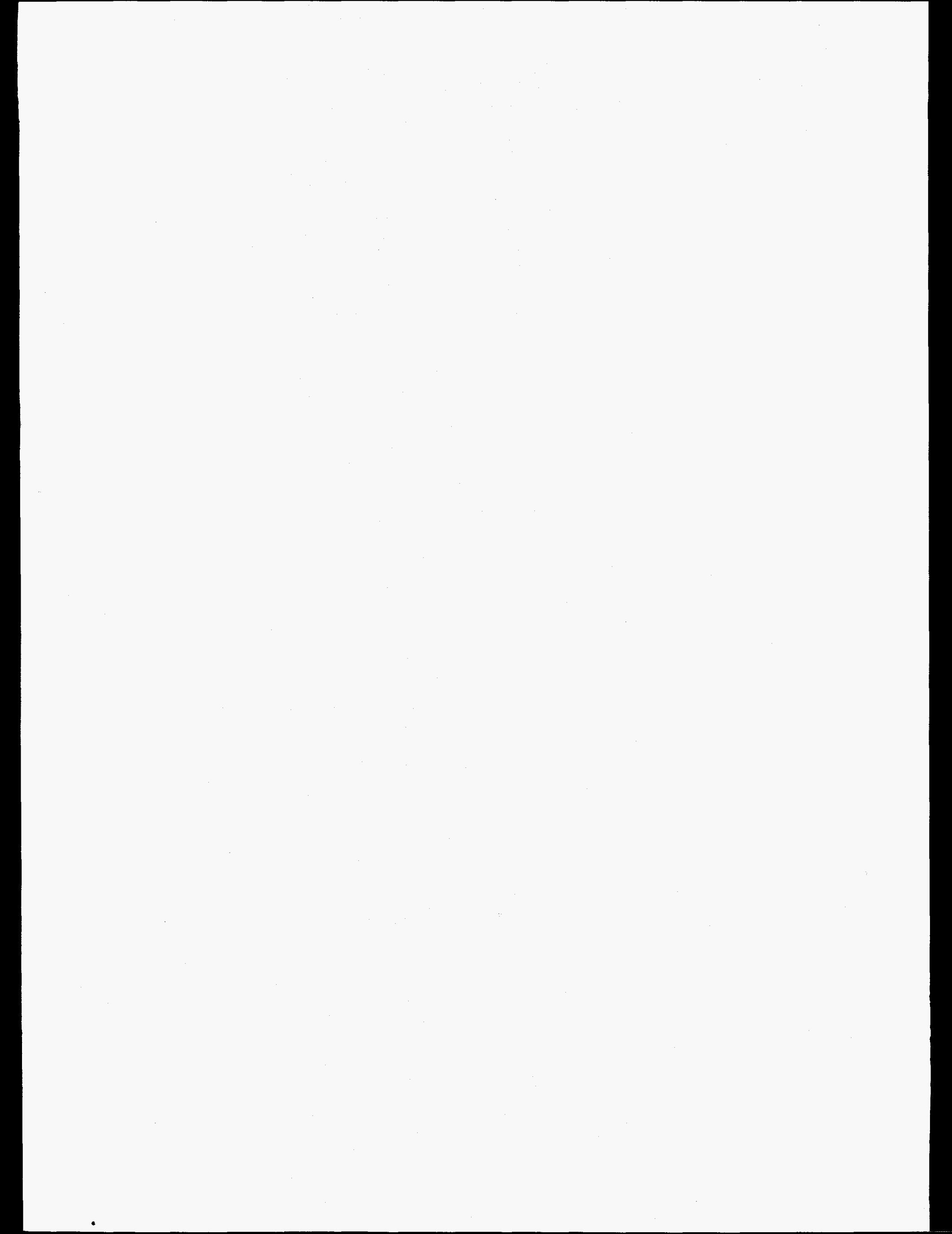





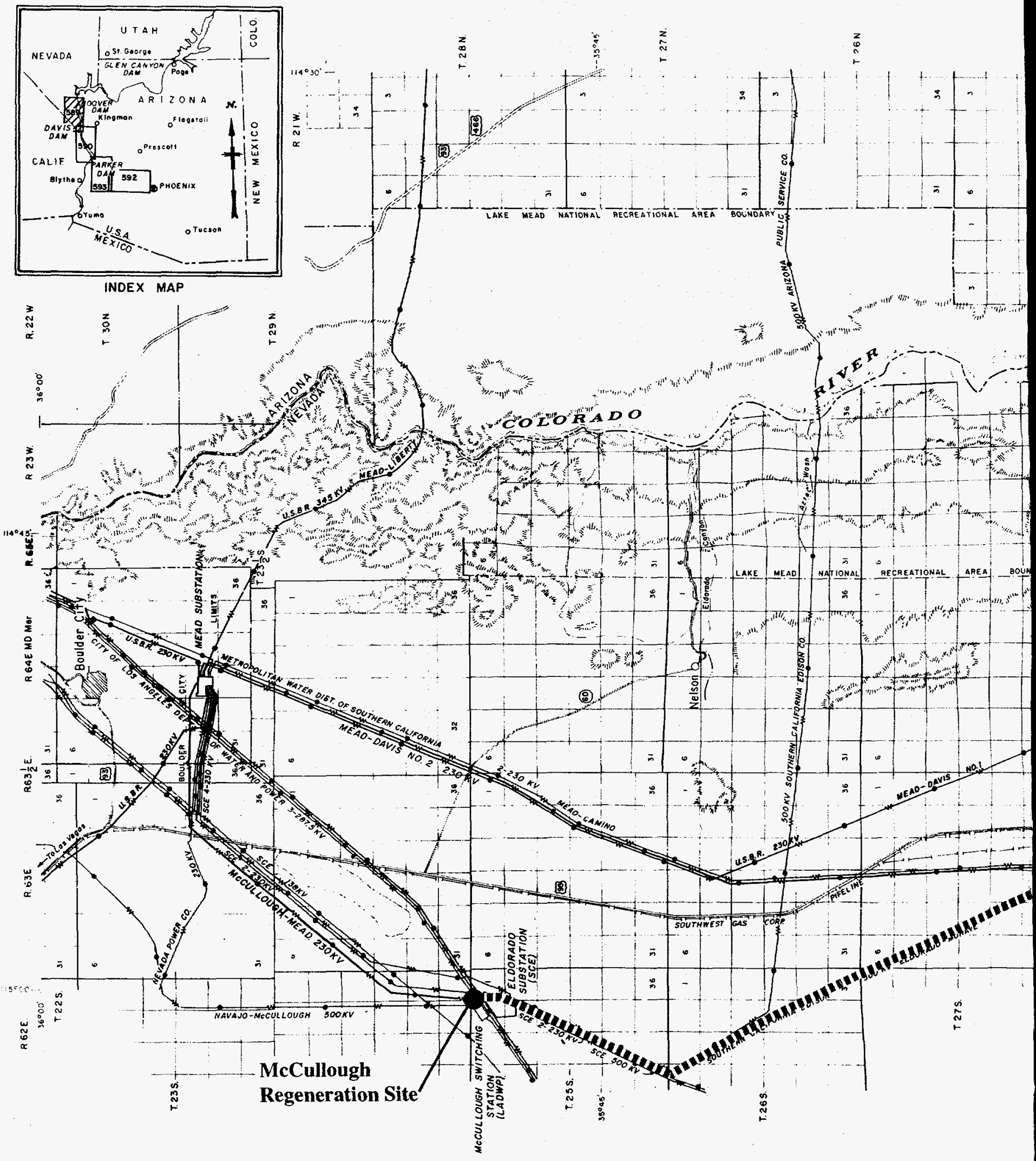

Source: FEIS Granite Reef Aqueduct Transmission System Department of the Interior. USBR. 1975 


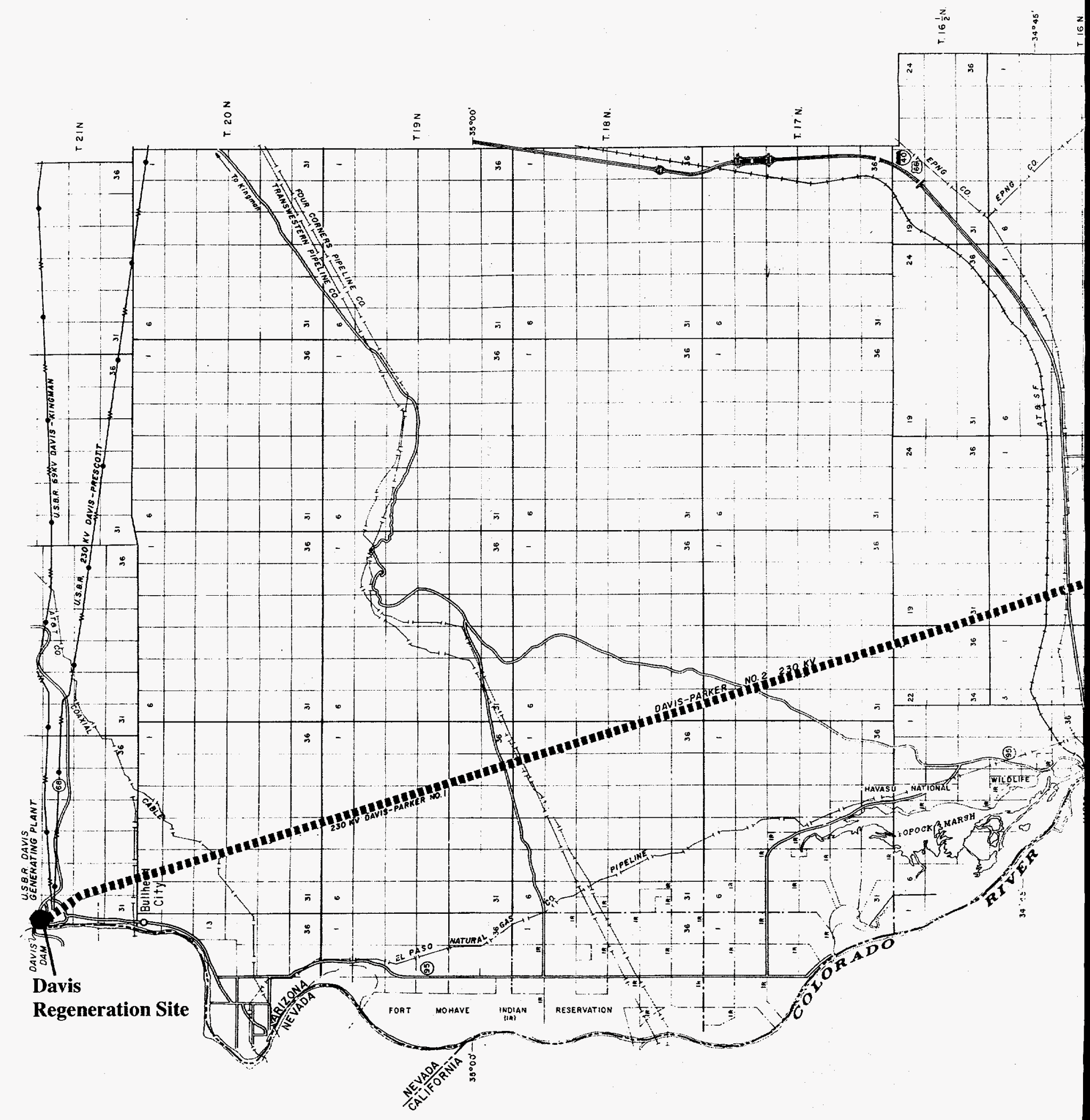




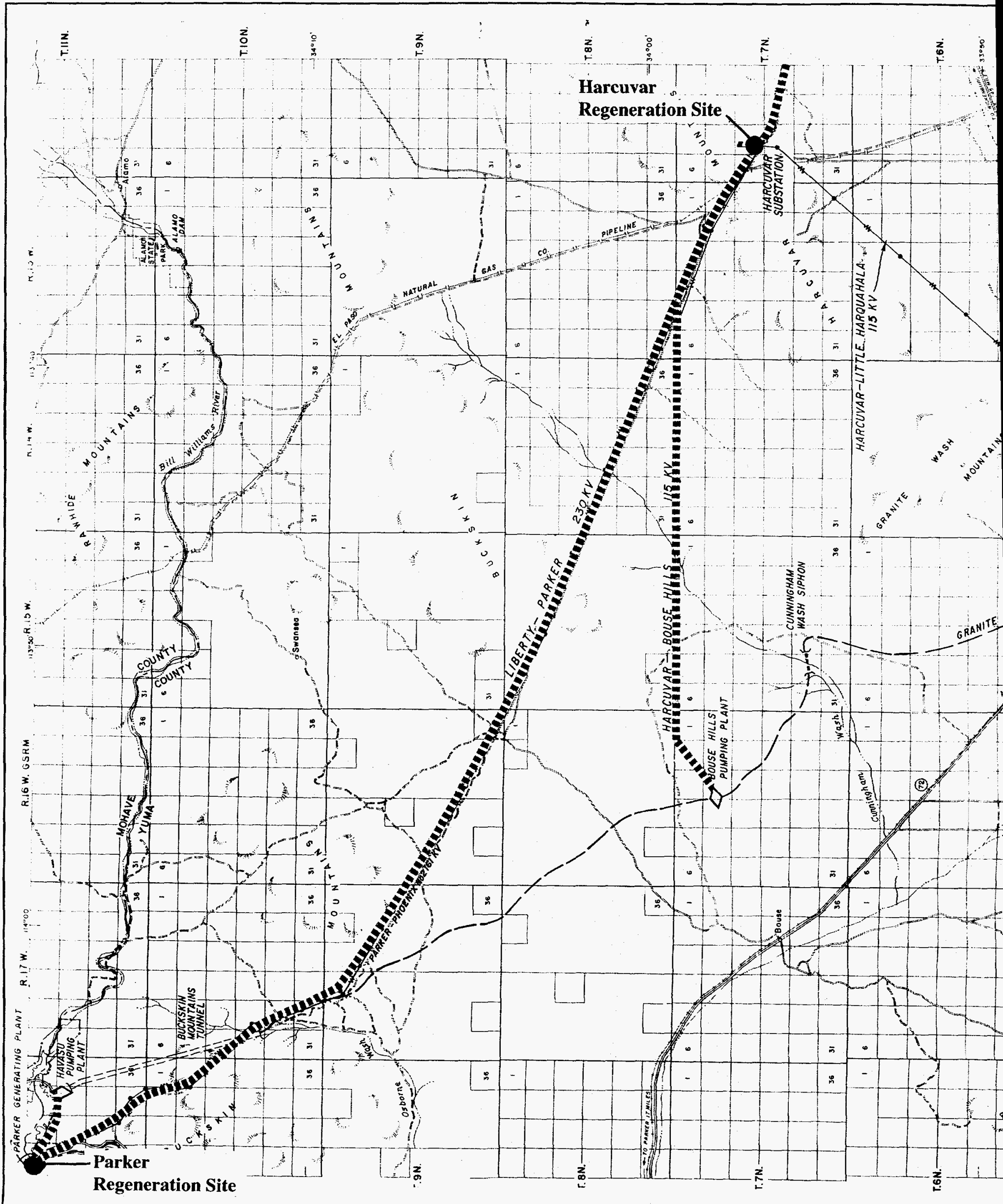

Source: FEIS Granite Reef Aqueduct Transmission System Department of the Interior, USBR, 1975 


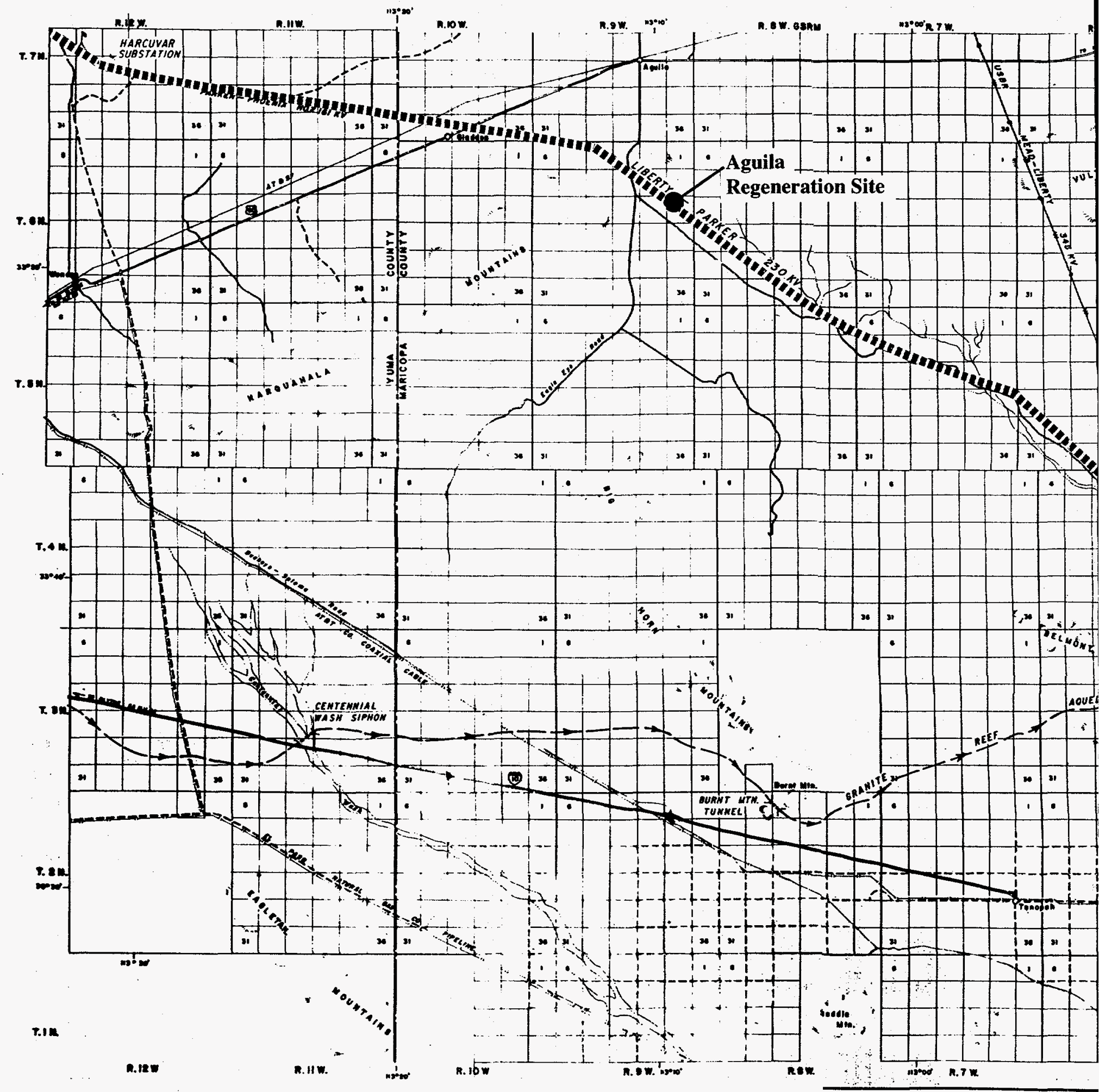

Source: FEIS Granite Reef Aqueduct Transmission System Department of the Interior, USBR, 1975 

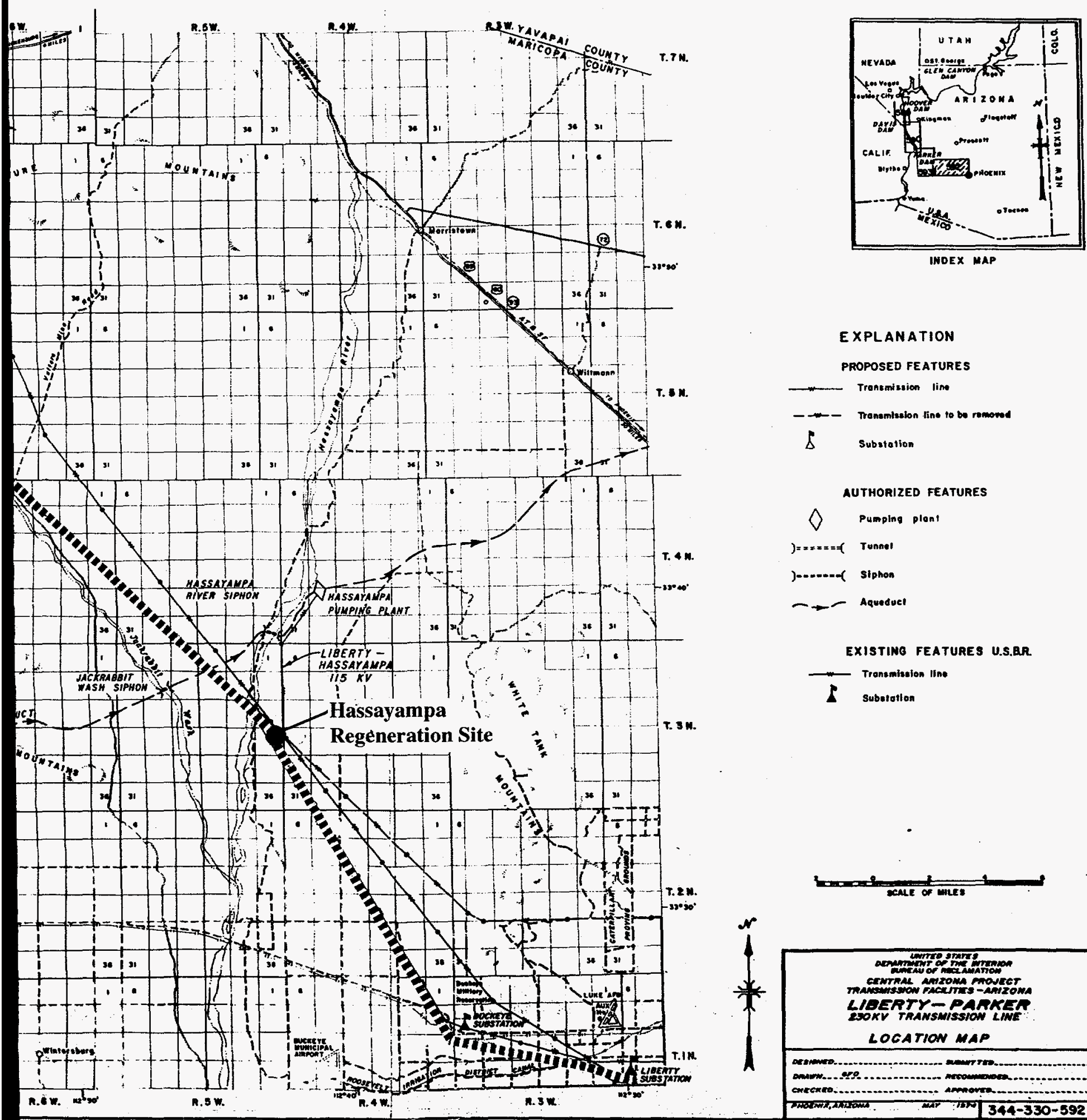

EXPLANATION

PROPOSED FEATURES

$\longrightarrow$ Transmission line

- $\rightarrow$ Trensmizesion line to be romonod

8 Substation

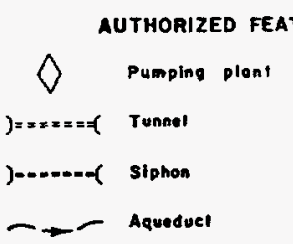

EXISTINO FEATURES U.S.BR.

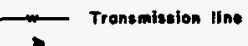

I Subatation
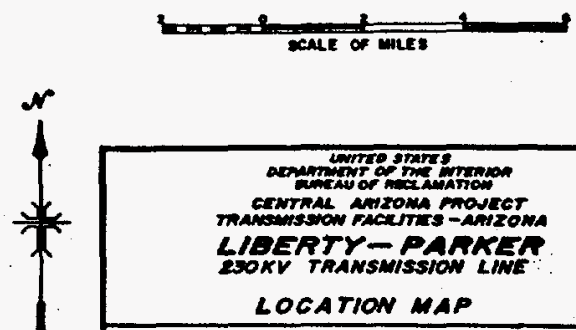

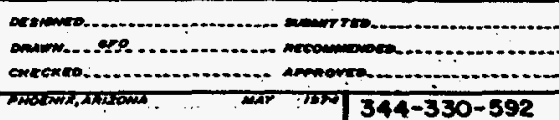

Figure 7 

Class I Cultural Resources Analysis of

IXC Optical Ground Wire Upgrade Project

Bureau of Reclamation

Phoenix Area Office

Carol Telles

January 1997 



\section{Class I Cultural Resources Analysis of IXC Optical Ground WireUpgrade Project}

\section{Previous Research}

A Class I cultural resources survey (literature search) is conducted during and after the planning stages of the project to identify all known cultural resources located within the boundaries of the specified study area through published and unpublished documents and through recorded archaeological and historical sites. This information is an important tool in identifying known cultural resources and discussing the possible location of other archaeological or historical sites that might affect the overall engineering design of the project.

The transmission line runs through a varied and diverse area used by several occupations of prehistoric and historic peoples (Keller 1986). The potential for finding archaeological remains for the following time periods is probable. The following information was obtained from Keller (1986) and Larson (1976).

Paleo-Indian Period The earliest known occupation is attributed to the Paleo-Indian Period ranging from circa 6000 to 9500 B.C. The people of this time and the next period, the Archaic, were nomadic and their basic subsistence was hunting and gathering. They followed the animals to hunt and gathered seasonal plants. Artifacts consisted of stone tools, easy to create carrying equipment, and transportable tools. Due to their highly mobile existence and lack of artifacts, sites of this nature are difficult to identify, the same can be said for the Archaic Period. No site with intact cultural deposits is currently attributed to this period, but sites of this period may be present (Keller 1986).

Archaic Period The Archaic Period in this region is separated into two traditions (Keller 1986). The San Dieguito Tradition (9000 to 7000 B.C.) is a chipped stone industry and typified by crude choppers, biface planes, and scrapers. Sites have been identified primarily on the terraces of the Colorado River valley. San Dieguito sites are difficult to identify due to their similar uses of materials as later peoples.

The other tradition occurring in the Archaic Period is the Desert Culture Tradition which consists of the Pinto-Gypsum and Amargosa cultures. The Pinto-Gypsum culture forms a tradition from early Archaic Period to the Amargosa cultural tradition, ranging from 1000 B.C. to A.D. 600 . This cultural tradition is characterized by knife blades, drills, scrapers, grinding implements and a series of distinctive projectile points, tools used in pursuing a wide variety of plants food and modern game. Sites of this cultural tradition are most commonly located on bajada edges and lower mountain slopes, or along secondary riverine zones (Swarthout 1981).

The Amargosa cultural tradition is divided into two phases (Rogers 1966). Amargosa I is characterized by Gypsum and Elko-eared projectile points and milling stones. Amargosa II is characterized by manos and metates, the bow and arrow (by implication), and Elko Corner-notched projectile points (Keller 1986).

Prehistoric Period The next distinctive occupation is the Prehistoric or Ceramic Period which ranges from A.D. 300 to A.D. 1700. During this time the people began becoming more sedentary and began making ceramic pottery, prior to this period the people created more easy to make baskets and other 
transportable artifacts. This period covers several groups of people occupying various areas along the transmission line route. The first noted occupation is the habitation of the Cerbat peoples. The Cerbat occupied areas near Kingman to the Music Mountains and Cross Mountain, Big Sandy drainage, Union Pass, Aquarius Mountains, Hualapai Mountains, and Trout Creek (Dobyns 1956).

Tizon Brownware ceramics are the distinctive pottery of the Cerbat. This ceramic is crudely made and tempered with mica and sand, and undecorated. Shelters usually consisted of circular brush structures, but they also show a preference for rockshelters. Pai projectile points are small, triangular with concave or flat bases. Agriculture was practiced whenever feasible. Cerbat sites have been identified in Matawidita and Spencer Canyons along the Big Sandy drainage (Euler 1958).

Another group of people are the Prescott inhabitants. The Prescott peoples used pottery similar to Tizon brownwares. The Prescott ware is more gray to brown, tempered with coarse mica, and with poorly executed designs. Structures are stone masonry construction in the form of small pueblos and forts, with pithouses also present. Agriculture was practiced more with the Prescott as compared to the Cerbat. Recorded sites are located in the Copper Basin Archaeological District, the Kirkland Junction Archaeological site, the Kings' ruins, several important sites in the Prescott area, and at a number of sites on the plateaus northeast of Bagdad. The Prescott occupation appears to have ended around A.D. 1200 (Linford 1979:39).

The Lowland Patayan are another group of inhabitants along the transmission line route. The Lowland Patayan are characterized by their unslipped buffware, red slipped and white slipped ceramics, intrusive Hohokam artifacts, and stuccoed vessels. Agriculture was practiced about 50 percent of the time. Recorded sites have been identified only in the Lower Colorado River valley and date from A.D. 800 to A.D. 1700 (McGuire and Schiffer 1982).

As the transmission line comes into the Phoenix area then the Hohokam culture is encountered. The Hohokam are characterized by their buff and red-on-buff pottery, pithouse villages, large coursed adobe structures, elaborate canal systems, ballcourts, mounds, and technological and decorative attributes of Mesoamerican origins. Agriculture was the primary subsistence base and practiced 100 percent of the time. The Hohokam cover all the Phoenix area and most areas of the tributaries of the Gila and Salt rivers. The sites date from A.D. 300 to A.D. 1450 (Linford 1979:35; Jennings 1974; McGuire and Schiffer 1982).

Protohistoric Period The next period of occupation along the transmission line route is the Protohistoric Period. This Period varies in its beginning date for the project area depending on where you are. But the dates generally for the southwest range from approximately A.D. 1600 to as late as the early 1800 's. This period is distinguished as the time when the Native Americans were first encountered by European explorers, thus creating the beginning date encounter problem. It was at this encounter when the people were first recorded in the historical accounts.

There are several occupations that may be encountered along the transmission line route. The Pai culture, appear to be the descendants of the earlier Cerbat peoples, although no direct lineage has been archaeologically proven. The Pai were living in the same geographical area as the prehistoric Cerbat, were creating similar artifacts, and basically living in the same manner as the archaeological record indicates for the Cerbat. In the late 1800's and early 1900's the Pai peoples were forced and scattered onto 
reservations created by the government. Many of the people suffered from disease, unfamiliar climates, and drastically changed lifeways. Many escaped and returned to their aboriginal territories. Today the Yavapai, Hualapai, and Havasupai represent this culture and many remain in reservations (Khera and Mariella 1983; Dobyns and Euler 1970; Gifford 1936; Matson 1971).

Another significant Protohistoric group are the Paiute. Archaeological evidence is poor for these people in the project area, but evidence from nearby areas indicate that they occasionally practiced agriculture representing only a small percent of their subsistence base. They are located in the Mojave Desert along the lower reaches of the Virgin River and across to the Arizona Strip (Kelly 1936; Swarthout 1981; Woods 1983).

The Mojave people are also located in the transmission line route. The Mojave appear to be descendants of the prehistoric Patayan people who lived in this area. The Mojave were first encountered in 1605 , which marked the beginning of not-so friendly meetings thereafter. They were a sedentary group who practiced floodplain agriculture, and gathered wild plants in times of drought or less rain. The Mojave are located along the Colorado River south of Black Canyon (Swarthout 1981; Wright 1954).

The Pima and Maricopa of the Gila River also occupied some areas near Phoenix but only minimally in the project area (Brown and Stone 1982; McGuire and Schiffer 1982).

Historic Period The Historic Period, like the Protohistoric, varies on a beginning date. Overall the Historic Period is the time of mountain men, military explorations and actions, mining, Mormon settlements, and more importantly expansion and growth. Archaeological evidence of these activities and others are noted throughout the project area.

Records indicate that traders led by Pattie in 1826, moved along the Salt River valley and then up the Colorado River and west across Hualapai country. While in 1826 and 1827, parties led by Jed Smith traveled down the Virgin River and into Arizona along the Colorado River, then headed west from the river at Needles. In 1829, Young led his group up the Verde River and across the Hualapai and Yavapai territories (Morgan 1953; Walker and Bufkin 1979).

The military played major roles during this time. One thing the military was assigned to do was to remove the Native American groups from their aboriginal territories and force them unto reservations. The military also used this time to explore routes to bring forces from the Rio Grande valley to California. These explorations went through many areas in the west. They established camps and forts in various areas they felt needed to be defended (Walker and Bufkin 1979).

The thrill of riches was the rush for many miners at that time. Early prospectors came in during the $1850 \mathrm{~s}$, and they soon found rich deposits of gold, silver, copper, gemstones, and turquoise. The large scale mining operations were soon sprouting out in canyons and river areas all over the west. Mining towns soon brought cattle ranching and other necessities of the miners. Many towns were established as a result of the mining towns such as Katherine's Landing, Hardyville, and Mohave City along the Colorado River were set up as commercial and shipping centers (Belshaw 1979; Belshaw and Peplow 1978). While mining towns in the project area consists of Oatman, Mineral Park, Chloride, and Cerbat in the northern part of the project area. The southern portion has mining districts having been established 
throughout the Bagdad and Prescott areas, with the Congress, Vulture, Crown King, Jerome, and Lynx Creek mines being the most productive (Granger 1960; Hinton 1968; Sherman and Sherman 1969).

Mormon settlement in the area took place primarily in the lower Virgin River and the Las Vegas regions. The Mormon settlements in the project area are located at ferry crossing on the Colorado River and include Pierce Ferry, Bonelli's Ferry, and Rioville and Stone's Ferry. Most are now under Lake Mead (Belshaw and Peplow 1978; Keller 1983; Scrattish 1982).

Perhaps the most conspicuous development of the area took the form of commercial settlement and expansion. Railroads created much of the expansion and movement beginning in the 1880's. The Atlantic and Pacific Railroad (later the Atchison-Topeka-Santa Fe) reached Kingman in 1883 which made cattle shipping into the area much easier. By 1900 , Prescott had been linked to the Santa Fe Railroad to the north and the Southern Pacific Railroad in the south, spurring off development in that area (Walker and Bufkin 1979).

In the southern portion of the project area came the development of Phoenix, among other smaller establishments associated with farming and ranching. Phoenix first settled in 1865 as a hay station for Camp McDowell and was called Smith's Station. In 1867, Jack Swilling visited the station and saw the need for irrigation in the area and established the Swilling Irrigation Canal Company. This growth and now supply of water brought an increase of population and businesses attempting to cash in on the growth of what was now being called Phoenix. Phoenix was incorporated in 1881 and by 1899 was established as the state capitol, taking the seat from Prescott (Granger 1960).

Another important city during the late 1800's was the establishment of Wickenberg and the Vulture Mine in 1864. The gold mine discovered by Heinrich Heintzel, an Austrian refugee supplied gold to the Union during the Civil War. The mine also brought in miners and businessmen into the newly established town of Wickenberg. This increase of Anglos also created conflicts with the Yavapai culture who resented this intrusion onto their land. The most notable conflict was the Wickenberg Massacre (a.k.a. as the Loring Massacre), where numerous people of the Wheeler surveying expedition of 1871 were killed (Keller 1986).

Big plans were being established for the townsite of Aguila. In 1909, the town consisted of only a small railroad siding. Plans for creating a commercial settlement soon fell through the cracks, but a post office was established in 1910, and stagecoach and the railroad lines passed through (Comeaux 1981).

\section{Analysis of Existing Cultural Resources}

The cultural resources analysis is based on the beneficial and adverse issues that would be involved with the project. These issues were identified by conducting initial onsite investigations on December 10 and 11, 1996 and January 7, 1997, as well as by reviewing existing literature and by personnel contacts with experts.

Several Class III cultural resources surveys (inventory) have been conducted in the project area. These surveys include those by Dobbins (1978a, 1978b, May 1979, August 1979, 1980a, 1980b, and 1980c), Killiam (1986), and Keller (1986). The sites identified along the transmission line route were recorded 
with a description and location. The sites were given preliminary evaluations to determine possible eligibility for each site for their inclusion in the National Register of Historic Places as required under 36 CFR 800 . The Bair 1974 survey report was not located at this time.

\section{Survey}

In 1973, Reclamation contracted the University of Nevada to conduct an intensive survey of the MeadDavis-Parker portion of the transmission line system route (Reclamation 1975). Other portions consisting of the Liberty-Parker, Harcuvar-Little Harquahala, and Harcuvar-Bouse Hills routes of the transmission line were conducted by Arizona State University (Reclamation 1975). These surveys resulted in the identification of 27 prehistoric and 6 historic sites (Table 1).

\section{Table 1. 1973 Survey Results}

\begin{tabular}{|c|c|c|c|}
\hline State & Time Period & Sitename & Remarks \\
\hline Nevada & Prehistoric & Boulder City 1 & $\begin{array}{l}\text { Thin lithic scatter, metate } \\
\text { fragments, trail related }\end{array}$ \\
\hline Nevada & Prehistoric & Boulder City 2 & Thin lithic scatter, trail related \\
\hline Nevada & Prehistoric & Boulder City 3 & $\begin{array}{l}\text { Related to quarry site El } \\
\text { Dorado Mtn. No. } 1\end{array}$ \\
\hline Nevada & Prehistoric & El Dorado Mtns 1 & Quarry \\
\hline Nevada & Prehistoric & $\begin{array}{l}\text { Metropolitan Water } \\
\text { District (MWD) } 1\end{array}$ & Widespread lithic scatter \\
\hline Nevada & Prehistoric & MWD 2 & Widespread lithic scatter \\
\hline Nevada & Prehistoric & MWD 3 & $\begin{array}{l}\text { Widespread lithic scatter, } \\
\text { quarry }\end{array}$ \\
\hline Nevada & Prehistoric & MWD 4 & Widespread lithic scatter \\
\hline Nevada & Prehistoric & Searchlight 1 & One stone circle, basalt metate \\
\hline Nevada & Prehistoric & Newberry Mtns 2 & $\begin{array}{l}\text { Three large rock-lined circular } \\
\text { depressions }\end{array}$ \\
\hline Nevada & Prehistoric & $\begin{array}{l}\text { Davis Dam and } \\
\text { Mohave Plant } 1\end{array}$ & One disturbed rock feature \\
\hline Arizona & Prehistoric & Bullhead City 1 & Chipping station \\
\hline Arizona & Prehistoric & Bullhead City 2 & Chipping station \\
\hline Arizona & Prehistoric & Oatman 1 & Widespread lithic scatter \\
\hline
\end{tabular}


Table 1. 1973 Survey Results

\begin{tabular}{|c|c|c|c|}
\hline State & Time Period & Sitename & Remarks \\
\hline Arizona & Prehistoric & Oatman 2 & Widespread lithic scatter \\
\hline Arizona & Prehistoric & Oatman 3 & Three circular depressions \\
\hline Arizona & Prehistoric & Oatman 4 & $\begin{array}{l}\text { Rock alignment, widespread } \\
\text { lithic scatter }\end{array}$ \\
\hline Arizona & Prehistoric & Oatman 5 & Widespread lithic scatter \\
\hline Arizona & Prehistoric & Oatman 6 & Thin restricted lithic scatter \\
\hline Arizona & Prehistoric & Oatman 7 & $\begin{array}{l}\text { Rock alignment, widespread } \\
\text { lithic scatter }\end{array}$ \\
\hline Arizona & Prehistoric & Oatman 8 & $\begin{array}{l}\text { Rock alignment, widespread } \\
\text { lithic scatter }\end{array}$ \\
\hline Arizona & Prehistoric & Oatman 9 & Widespread lithic scatter \\
\hline Arizona & Prehistoric & Basalt Basin 1 & $\begin{array}{l}\text { Rock alignment, widespread } \\
\text { lithic scatter }\end{array}$ \\
\hline Arizona & Prehistoric & Topock 1 & $\begin{array}{l}\text { Aboriginal trail, widespread } \\
\text { lithic scatter }\end{array}$ \\
\hline Arizona & Prehistoric & Sacramento Wash 1 & Chipping station \\
\hline Arizona & Prehistoric & AZ T:10:18(ASU) & Sherd scatter (potbreak) \\
\hline Arizona & Prehistoric & AZ S:2:1(ASU) & Low density sherd scatter \\
\hline Nevada & Historic & $\begin{array}{l}\text { Searchlight Mining } \\
\text { District (SMD) } 1\end{array}$ & $\begin{array}{l}\text { Historic mining claims and } \\
\text { related activity }\end{array}$ \\
\hline Nevada & Historic & SMD 2 & $\begin{array}{l}\text { Ruins of ore processing mill, } \\
\text { associated camps, dumps, and } \\
\text { mining claims }\end{array}$ \\
\hline Nevada & Historic & SMD 3 & $\begin{array}{l}\text { Historic foundation and dump } \\
\text { of edge of historical railroad } \\
\text { bed (Crescent Railroad) }\end{array}$ \\
\hline Nevada & Historic & Newberry Mtns 1 & Historic cache \\
\hline Arizona & Historic & Buck Mtns 1 & $\begin{array}{l}\text { Walled arroyo for placer } \\
\text { mining }\end{array}$ \\
\hline
\end{tabular}


Table 1. 1973 Survey Results

\begin{tabular}{llcc}
\hline State & Time Period & Sitename & Remarks \\
\hline Arizona & Historic & Buck Mtns 2 & $\begin{array}{c}\text { Historic foundations, dump, } \\
\text { and shafts }\end{array}$ \\
\hline
\end{tabular}

Totals: 27 Prehistoric and 6 Historic Sites and 51 isolated artifacts were also found during the surveys

Recommendations in 1973 for these 33 sites prior to construction of the transmission line portions included photographing all prehistoric sites. Surface collections and archaeological test pit excavations were recommended for the four Metropolitan Water District sites, and all but the first of the Oatman sites, as well as the Basalt Basin 1 site. No recommendations were advised for the Boulder City and Bullhead City sites, as well as the Historic sites.

In 1976, archaeological investigations (data recovery) were conducted for thirteen sites located on along the proposed Mead-Davis-Parker 23kV Transmission Line \#2 (Table 2) (Larson 1976).

\section{Table 2. 1976 Data Recovery}

\begin{tabular}{|c|c|c|}
\hline Sitename & 1973 Recommendations & 1976 Mitigation \\
\hline Bullhead City 1 & No Recommendations & Photographed \\
\hline Bullhead City 2 & No Recommendations & Collected and Photographed \\
\hline Oatman 1 & $\begin{array}{c}\text { Photography, Collection, and } \\
\text { Test Pitting }\end{array}$ & Collected and Photographed \\
\hline Oatman 2 & $\begin{array}{c}\text { Photography, Collection, and } \\
\text { Test Pitting }\end{array}$ & Collected and Photographed \\
\hline Oatman 3 & $\begin{array}{c}\text { Photography, Collection, and } \\
\text { Test Pitting }\end{array}$ & Photographed \\
\hline Oatman 4 & $\begin{array}{c}\text { Photography, Collection, and } \\
\text { Test Pitting }\end{array}$ & Collected and Photographed \\
\hline Oatman 5 & $\begin{array}{c}\text { Photography, Collection, and } \\
\text { Test Pitting }\end{array}$ & Collected and Photographed \\
\hline Oatman 6 & $\begin{array}{c}\text { Photography, Collection, and } \\
\text { Test Pitting }\end{array}$ & Collected and Photographed \\
\hline Oatman 7 & $\begin{array}{c}\text { Photography, Collection, and } \\
\text { Test Pitting }\end{array}$ & Collected and Photographed \\
\hline Oatman 8 & $\begin{array}{c}\text { Photography, Collection, and } \\
\text { Test Pitting }\end{array}$ & $\begin{array}{c}\text { Random Collection and Random } \\
\text { Photography }\end{array}$ \\
\hline
\end{tabular}




\begin{tabular}{ccc}
\hline Sitename & 1973 Recommendations & 1976 Mitigation \\
\hline Oatman 9 & $\begin{array}{c}\text { Photography, Collection, and } \\
\text { Test Pitting }\end{array}$ & Collected and Photographed \\
Basalt Basin 1 & $\begin{array}{c}\text { Photography, Collection, and } \\
\text { Test Pitting } \\
\text { Topock 1 }\end{array}$ & Collected and Photographed \\
& $\begin{array}{c}\text { Photography, Collection, and } \\
\text { Test Pitting }\end{array}$ & Collected \\
Sacramento Wash 1 & Photography & No Collection \\
\hline Thirteen sites were examined for eligibility for inclusion in the National Register.
\end{tabular}

Based on the field and laboratory analysis of the thirteen sites, twelve were determined ineligible for inclusion in the National Register of Historic Places. Site Oatman 8, consisted of many lithic scatters and chipping stations and although the total size of the site is not determined, it did extend over 0.5 miles to the south and over 1.0 miles to the east. Construction of the present transmission line, old US Highway 66 , and a dirt road destroyed a corridor through the site. The extent of the site suggests that a great deal of aboriginal activity occurred there, although chronology was difficult to determine due to lack of diagnostic artifacts. The research potential and information that may be derived from this site may make it eligible for inclusion in the National Register as required under 36 CFR 800 . If the proposed recommendations to avoid the site were met in 1976, the site would not have been impacted.

\section{Survey}

Arizona State University conducted a survey for the realigned portions of the Liberty-Parker and ParkerHavasu Transmission Lines and Harcuvar substation. These impact areas surveyed were: 1) 14.1 miles of right-of-way (ROW) near the eastern end of the Liberty-Parker route in T1N, R4W; T2N, R4W; and T3N, R4W, an area totaling 354.5 acres, 2) the Harcuvar substation in the NW1/4. SW1/4, Section 17, T7N, R12W and totaling 15.0 acres, 3) 1.3 miles of ROW near the western end of the Liberty-Parker line in T11N, R18W, Sections 14, 15, 16, 22, and 23, and 4) a contiguous 2.1 mile stretch of the Parker-Havasu corridor in T11N, R18W, Section 22 totaling 460 acres. The corridor was 80 to 100 meters wide with crew members spaced parallel to each other at 15 to 20 meters apart.

Previous archaeological research for this area identified eleven sites. Two small sherd scatters were identified during Bair's 1974 survey with one located in the White Tanks Mountains and the second in Cunningham Pass in the Harcuvar Mountains (Bair 1974). The other 8 sites were found during the 1972 Arizona State Museum survey, these sites represent lithic scatters, trails, and rock rings (Kemrer, Schultz, and Dodge 1972). A small lithic scatter was identified on the Bill Williams River near the Havasu Pumping Plant (Stone 1978). The present survey results for all impact areas included the identification of four field loci and 2 isolated artifacts (Table 3) (Dobbins 1978). 
Table 3. 1978 Survey Results

\begin{tabular}{llcc}
\hline State & Time Period & Sitename & Remarks \\
\hline Arizona & Prehistoric & Field Loci 1 & $\begin{array}{c}10-20 \text { sherd scatter - Lower } \\
\text { Colorado Buffware and } 7 \\
\text { reddish plainware }\end{array}$ \\
Arizona & Prehistoric & Field Loci 2 & $\begin{array}{c}20-25 \text { sherd scatter - all appear } \\
\text { to be from a single Sacaton red- } \\
\text { on-buff vessel }\end{array}$ \\
Arizona & Prehistoric & Field Loci 3 & $\begin{array}{c}\text { 25-30 sherd scatter - polished } \\
\text { Lower Colorado Buffware and } \\
\text { appears to have been from a } \\
\text { single vessel }\end{array}$ \\
Arizona & Prehistoric & Field Loci 4 & $\begin{array}{c}10-15 \text { flake scatter - flakes of } \\
\text { rhyolite, chert, and chalcedony }\end{array}$ \\
\hline Isolated artifacts consisted of one chert core and one unifacially flaked quartzite river cobble. \\
Although not recorded as locus, several historic hearths and trash areas were noted.
\end{tabular}

Recommendations for the survey determined that the sites are not considered eligible for inclusion in the National Register. If future specifications indicate these sites will be affected, the recommendations then involve the relocation and collection of Field Locus 2 and 3, and the systematic mapping and collection of Field Locus 4. It is also proposed that the transmission line be resurveyed when the route crossed undisturbed desert areas. Resurvey of tower locations along the western portion of the Liberty-Parker and Parker-Havasu lines in the Buckskin Mountains, once the route has been specifically identified (Dobbins 1978).

In 1980, further archaeological investigations (data recovery) were conducted for the Liberty-Parker portion of the transmission line. Data recovery was determined on recommendations from the 1978 survey results. Mitigation was completed for the four field loci identified during the survey which included mapping, photographing, and surface collection of the sites. During the mitigation phase two other sites and two field loci were also studied (Table 4).

Table 4. 1980 Data Recovery

\begin{tabular}{ccc}
\hline Sitename & 1978 Recommendations & 1980 Mitigation \\
\hline Field Loci 1 & No Recommendations & Mapped, $\begin{array}{c}\text { Photographed, and } \\
\text { Collected }\end{array}$ \\
Field Loci 2 & Collection & Mapped, \\
& & $\begin{array}{c}\text { Photographed, and } \\
\text { Collected }\end{array}$
\end{tabular}




\begin{tabular}{ccc}
\hline Sitename & 1978 Recommendations & 1980 Mitigation \\
\hline Field Loci 3 & Collection & $\begin{array}{c}\text { Mapped, Photographed, and } \\
\text { Collected }\end{array}$ \\
Field Loci 4 & $\begin{array}{c}\text { Systematic Mapping and } \\
\text { Collection }\end{array}$ & $\begin{array}{c}\text { Mapped, Photographed, and } \\
\text { Collected }\end{array}$ \\
AZ M:13:1(ASU) & Additional Site Studied & Mapped and Excavated \\
AZ T:5:5(ASU) & Additional Site Studied & $\begin{array}{c}\text { Random Sample Collection, with a } \\
\text { total of 836 artifacts collected }\end{array}$ \\
Field Loci 14 & Additional Site Studied & Mapped and Collected \\
Field Loci 15 & Additional Site Studied & Mapped and Collected \\
\hline Eight sites were examined for eligibility for inclusion in the National Register.
\end{tabular}

None of the sites were determined eligible for the National Register and no further archaeological investigations are necessary along this portion of the Liberty-Parker line. This report did not include any data recovery plans or results from any possible work on the Parker-Havasu line or the Harcuvar substation (Dobbins 1980a).

\section{9 (May) Survey}

Arizona State University conducted a survey for the Bouse Hills, Harcuvar, and Little Harquahala 115kV transmission lines. The two transmission lines surveyed for this project originates at the proposed Harcuvar substation along the Liberty-Parker line on the south slopes of the Harcuvar Mountains east of Cunningham Pass. The Harcuvar-Bouse Hills line proceeds northwest from this point paralleling the Liberty-Parker line for approximately 6.0 miles then turns west through Butler Valley to the Bouse Hills pumping plant, an approximate total distance of 23.3 miles. From the substation, the Harcuvar-Little Harquahala line travels southwest through McMullen Valley along the southeastern bajada of the Harcuvar Mountains then south through portions of the Granite Wash and Little Harquahala Mountains resulting in a total distance for the line is 25.9 miles. Total acreage for the lines is approximately 1,194 acres (Dobbins, May 1979).

Previous archaeological research identified three sites: AZ S:6:5(ASU), a historic army bunker area, AZ S:6:4(ASU), a trail, two sherd scatters and one rock ring, and site AZ S:6:3(ASU) a large area of isolated and clustered lithics (Dobbins 1978a). Mitigation was completed at some of these sites and some of the isolated features (Dobbins 1978d; Stone 1978). The present survey results include the identification of one site, three field loci, and eight isolated artifacts (Table 5).

Bair's 1974 survey identified one small sherd scatter within the Liberty-Parker ROW in Cunningham Pass, while the 1978 ASU resurvey found two sites, numerous isolated artifacts, and other small field 
loci. Two of the field loci were sherd scatters located southeast of the Harcuvar substation. All these sites, scatters, and isolates were subsequently collected (Dobbins 1978e). Site AZ S:6:1(ASM), a series of three rockshelters was identified east of the Harcuvar-Little Harquahala transmission line during a 1966 survey. To summarize the previous research, the nature of these cultural resources consist primarily of surficial cobble features, trails, and small artifact scatters. With the exception of the rockshelters, none of the above features contained any indications of subsurface components (Dobbins May 1979).

\section{Table 5. 1979 (May) Survey Results}

\begin{tabular}{llcc}
\hline State & Time Period & Sitename & Remarks \\
\hline Arizona & Prehistoric & $\begin{array}{c}\text { AZ S:6:7(ASU) - Made } \\
\text { up Field Locus } \\
2,3,4,5,6\end{array}$ & $\begin{array}{c}\text { Eleven cobble features and } \\
\text { artifacts, rock piles, and } \\
\text { sleeping rock circles }\end{array}$ \\
Arizona & Prehistoric & Field Loci 1 & $\begin{array}{c}10-15 \text { sherd scatter, appears to } \\
\text { be from a single vessel }\end{array}$ \\
Arizona & Prehistoric & Field Loci 7 & $\begin{array}{c}25-40 \text { rhyolite flakes, appears } \\
\text { to be a chipping station }\end{array}$ \\
\hline $\begin{array}{l}\text { Isolated artifacts consisted of three rhyolite flakes, a metate, a sherd, obsidian flake and } \\
\text { quartzite flaked cobble, and a chalcedony biface. Historic isolates include shrapnel, wiring, } \\
\text { tank tracks, and an unexploded artillery shell, these artifacts and features are believed to be } \\
\text { from the Desert Training Center military maneuvers conducted throughout western Arizona } \\
\text { during World War II. }\end{array}$ &
\end{tabular}

Recommendations for the survey indicated that further investigations be made at site AZ S:6:7(ASU). These would consist of mapping and partial excavation of three of the five features. Testing of some of the sleeping circles may provide additional information on limited habitation of these sites.

In 1980, further archaeological investigations (data recovery) were conducted for the Bouse HillsHarcuvar-Little Harquahala lines. Data recovery was determined on recommendations from the 1979 survey results. Mitigation was completed for site AZ S:6:7(ASU), field loci 1, and an additional field loci 9 discovered during mitigation. Field loci 7 was not mitigated (Table 6).

None of the sites were determined eligible for the National Register and no further archaeological investigations are necessary along this portion of the Bouse Hills-Harcuvar-Little Harquahala line. The excavations at site AZ S:6:7(ASU) did not result in any subsurface features (Dobbins 1980b). 


\begin{tabular}{ccc}
\hline Sitename & 1979 Recommendations & 1980 Mitigation \\
\hline Field Loci 1 & No Recommendations & Mapped and Collected \\
Field Loci 9 & Additional Site Studied & Mapped, Photographed, and \\
& Collected \\
AZ S:6:7(ASU) & Mapping and Partial & Mapped, Photographed, Collected, \\
& Excavation & and Excavation \\
\hline
\end{tabular}

Three sites were examined for eligibility for inclusion in the National Register.

\section{9 (August) Survey}

Arizona State University conducted a survey for the McCullough-Davis $230 \mathrm{kV}$ transmission line. The line originates at the McCullough substation in the northern portion of the El Dorado Valley and travels south along the eastern edge of the McCullough Mountains to 3.0 miles beyond Searchlight, Nevada where it turns southeast across the El Dorado and Paiute valleys. Near State Highway 77 and U.S. 95 the line turns east along the southern margin of the Lake Mead Recreation Area through the Newberry Mountains to Davis Dam. The total distance is approximately 61.0 miles (Dobbins August 1979).

Previous archaeological research identified along the original McCullough-Davis $230 \mathrm{kV}$ line, three historic sites associated with mining activities in the Searchlight area and two prehistoric loci at the eastern base of the Newberry Mountains. The area between El Dorado substation and Searchlight revealed one prehistoric lithic scatter. In 1949, Carl Tuthill surveyed the lower Davis Dam Reservoir between Cottonwood Island and Davis Dam, resulting in the discovery of 21 sites consisting primarily of artifact scatters, but some contained rock rings, trail shrines, shelter sites, and hearths (Brooks and Brooks 1978; McClellan, Phillips, and Belshaw 1978). To summarize, over 40 sites have been recorded within an approximate 6.0 miles of the survey corridor. The sites range from small artifact scatters, lithic scatters, various rock features, petroglyphs, trails, and a few rock shelters. It is difficult to determine age for the sites, since the area was used by both the prehistoric people and the later Paiute and Mojave (Ruppert 1976). Historic military remains were also found from the Desert Training Center during WWII (Brooks and others 1977). Present survey results identified three field loci and ten isolated artifacts (Table 7) (Dobbins August 1979). 
Table 7. 1979 (August) Survey Results

\begin{tabular}{llcc}
\hline State & Time Period & Sitename & Remarks \\
\hline Nevada & Prehistoric & $\begin{array}{c}\text { AZ F:5:1(ASU), consist } \\
\text { of 2 field loci }\end{array}$ & $\begin{array}{c}\text { High density artifact scatter } \\
\text { divided into 2 components, } \\
\text { consisting of chipped stone } \\
\text { debitage and 2 flake knives, } \\
\text { other features include rock } \\
\text { alignments, fire cracked rock, } \\
\text { and trails }\end{array}$ \\
Nevada & Prehistoric & AZ F:5:2(ASU) & $\begin{array}{c}\text { Possible quarry with debitage } \\
\text { of flakes and cores }\end{array}$ \\
\hline $\begin{array}{l}\text { Isolated artifacts consisted four flakes and two flake core tools of quartz, jasper, rhyolite, and } \\
\text { chert. Also found was a rhyolite biface fragment, two Lower Colorado Buffware sherds, and a } \\
\text { shallow basin metate. }\end{array}$
\end{tabular}

Recommendations for site AZ F:5:1(ASU) is to complete a sample surface collection in the impact zone. If surface collections determine the possibility for subsurface features then excavation is recommended if to be impacted. Recommendations for site AZ F:5:2(ASU) is a random sample surface collection of artifacts. No further investigations are recommended for the historic features (Bondley and Brooks 1973) identified outside the line's centerline.

In 1980, further archaeological investigations (data recovery) were conducted for the McCullough-Davis line. Data recovery was determined on recommendations from the 1979 survey results. Mitigation was completed for sites AZ F:5:1(ASU), and AZ F:5:2(ASU) (Table 8).

Table 8. 1980 Data Recovery

\begin{tabular}{ccc}
\hline Sitename & 1979 Recommendations & 1980 Mitigation \\
\hline AZ F:5:1(ASU) & Sample Surface Collection & Mapped and Collected \\
AZ F:5:2(ASU) & Random Sample Surface & Mapped, Collected, with the \\
& Collection & Excavation of Three Test Pits \\
\hline
\end{tabular}

Two sites were examined for eligibility for inclusion in the National Register.

Neither of the sites were determined eligible for the National Register and no further archaeological investigations would be necessary along this portion of the McCullough-Davis line. The excavations at site AZ F:5:2(ASU) did not result in any subsurface features (Dobbins 1980c). 


\section{Recommendations for Fiber Optic Upgrade}

Previous archaeological surveys and mitigation for the whole transmission line from the McCullough to Liberty indicate there has been much work done on the project. Recommendations for the project are to survey any new areas, such as the regeneration stations, all trenching locations, tensioning truck locations, and any new created roads (trails) not presently used for operation and maintenance of the line. A cultural resources survey will need to be conducted for all areas of impacts.

If any previously unidentified cultural remains are located, activity in that area will cease until proper authorities are notified. An archaeologist will determine significance and prepare a data recovery plan in conjunction with State Historic Preservation Office (SHPO) and the Advisory Council on Historic Preservation (ACHP). During all work the National Preservation Historic Act (NPHA) will be upheld. 


\section{$\underline{\text { References }}$}

Bair, Gerald

1974 An Archaeological Reconnaissance Survey of the Proposed Liberty-Parker 230kV

Transmission Line. For the Arizona Archaeological Center of the National Park

Service. Ms, Department of Anthropology, Arizona State University. Tempe, Arizona.

Belshaw, Mike

1979 Mines and Mining Districts in the Lake Mead National Recreation Area: Supplement to Lake Mead National Recreation Area, Nevada. Historical Resources Study. Ms. Lake Mead National Recreation Area. Boulder City, Nevada.

Belshaw, Mike and Ed Peplow, Jr.

1978 Historic Resources Study, Lake Mead National Recreation Area, Nevada. Ms. Lake Mead National Recreation Area. Boulder City, Nevada.

Bondley, George A. and Richard H. Brooks

1973 An Archaeological Survey of the Mead-Davis-Parker 230kV Transmission Line \# 2. Report Prepared by Nevada Archaeological Survey, University of Nevada. Las Vegas, Nevada.

Brooks, Richard H. and Sheilagh T. Brooks

1978 A Review of the Archaeological Research in the Lake Mead Recreational Area. National Park Service, Western Archaeological Center. Tucson, Arizona.

Brooks, Richard H. and others

1977 The Fort Mojave Cultural Resource Inventory: An Archaeological Historical Field Investigation in Southern Clark County, Nevada, Second Phase. Report prepared by the Archaeological Research Center, University of Nevada, Las Vegas Museum of Natural History. Las Vegas, Nevada.

Brown, Patricia E. and Connie L. Stone, editors

1982 Granite Reef: A Study in Desert Archaeology. Arizona State University Anthropological Research Papers No. 28. Tempe, Arizona.

Bureau of Reclamation

1975 Final Environmental Statement. Granite Reef Aqueduct Transmission System. Central Arizona Project, Arizona-New Mexico. Prepared by Department of Interior, Bureau of Reclamation, Lower Colorado Region. Boulder City, Nevada.

Comeaux, Malcolm L.

1981 Arizona: A Geography. Boulder: Westview Press. 
1978a A Cultural Resource Survey of Realigned Portions of the Liberty-Parker and ParkerHavasu Transmission Lines and Harcuvar Substation, Interim Report. For Bureau of Reclamation, Phoenix, Arizona. Ms, Department of Anthropology, Arizona State University. Tempe, Arizona.

1978b Granite Reef Aqueduct and Transmission System Project. A Cultural Resource Resurvey of the Liberty-Parker 230kV Transmission Line Right-of-Way, Central Arizona Project - Addendum I. For Bureau of Reclamation, Phoenix, Arizona. Ms, Department of Anthropology, Arizona State University. Tempe, Arizona.

1978d Archaeological Investigations Along Reach 3 of the Granite Reef Aqueduct, Central Arizona Project. Report prepared by the Office of Cultural Resource Management, Department of Anthropology, Arizona State University. Tempe, Arizona.

1979 May. Granite Reef Aqueduct and Transmission System Project. A Cultural Resource Survey of the Bouse Hills - Harcuvar - Little Harquahala 115kV Transmission Line, Central Arizona Project. For Bureau of Reclamation, Phoenix, Arizona. Ms, Department of Anthropology, Arizona State University. Tempe, Arizona.

1979 August. Granite Reef Aqueduct and Transmission System Project. A Cultural Resource Survey of the McCullough-Davis 230kV Transmission Line, Clark County, Nevada, A Feature of the Granite Reef Transmission System, Central Arizona Project. For Bureau of Reclamation, Phoenix, Arizona. Ms, Department of Anthropology, Arizona State University. Tempe, Arizona.

1980a Archaeological Investigations Along the Liberty-Parker 230kV Transmission Line, Central Arizona Project. For Bureau of Reclamation, Phoenix, Arizona. Ms, Department of Anthropology, Arizona State University. Tempe, Arizona.

$1980 \mathrm{~b}$ Archaeological Investigations Along the Bouse Hills-Harcuvar-Little Harquahala Transmission Lines, Features of the Granite Reef Aqueduct, Central Arizona Project. For Bureau of Reclamation, Phoenix, Arizona. Ms, Department of Anthropology, Arizona State University. Tempe, Arizona.

1980c Archaeological Investigations Along the McCullough-Davis Transmission Line, A Feature of the Granite Reef Aqueduct, Central Arizona Project. For Bureau of Reclamation, Phoenix, Arizona. Ms, Department of Anthropology, Arizona State University. Tempe, Arizona.

Dobyns, Henry F.

1956 Prehistoric Indian Occupation within the Eastern Area of the Yuman Complex: A Study in Applied Archaeology. Two Volumes. Unpublished Master's Thesis. University of Arizona. Tucson, Arizona. 
Dobyns, Henry F. and Robert C. Euler

1970 Wauba Yuma's People: The Comparative Socio-Political Structure of the Pai Indians of Arizona. Prescott College Press. Prescott, Arizona.

Euler, Robert C.

1958 Walapai Culture-History. Ph.D. Dissertation. University of New Mexico. Albuquerque, New Mexico.

Gifford, Edward W.

1936 Northeastern and Western Yavapai. University of California Publications in American Archaeology and Ethnology 34(4), pp 247-354, Berkeley.

Granger, Bryd H.

1960 Will C. Barnes' Arizona Place Names. University of Arizona Press. Tucson, Arizona.

Hinton, R.J.

1968 One Thousand Old Arizona Mines. Frontier Book Company. Fort Davis, Texas.

Jennings, Jesse D.

1974 Prehistory of North America, 2nd Edition. McGraw-Hill. New York.

Keller, Donald R.

1986 Archaeological Survey of the Mead to Phoenix $\pm 500 \mathrm{kV}$ Direct Current Transmission Line - Preferred Alternative. Volume I and II, Final Report A-81-90. Prepared for Salt River Project. Phoenix, Arizona.

1983 Mead-Phoenix 500kV DC Transmission Project. Chapter 8: Archaeological and Historical Cultural Resources. WIRTH Environmental Services. Phoenix, Arizona.

Kelly, I.T.

1964 Southern Paiute Ethnography. University of Utah Anthropological Papers, No. 69.

Kemrer, Sandra, Sandra Schultz, and William Dodge

1972 An Archaeological Survey of the Granite Reef Aqueduct. Arizona State Museum Archaeological Series, No. 12. University of Arizona. Tucson, Arizona.

Khera, Sigrid and Patricia S. Mariella

1983 Yavapai. In Handbook of North American Indians - Southwest, edited by William C.

Sturtevant (General Editor) and Alfonso Ortiz (Volume Editor) pp 38-54. Volume 10.

U.S. Government Printing Office, Washington, D.C.

Killiam, W.R.

1986 Cultural Resources Survey of 2.3 Miles of the Liberty-Parker No. 2 Transmission Line in Maricopa County, Arizona. For Western Area Power Administration, Boulder City, Nevada. Ms, State Historic Preservation Office. Phoenix, Arizona. 
Larson, Daniel O.

1976 An Archaeological Investigation of Sites Located Along the Mead-Davis-Parker Transmission System (Granite Reef). Prepared for the Bureau of Reclamation, Arizona Projects Office. Phoenix, Arizona.

Linford, Laurence D.

1979 Archaeological Investigations in West-Central Arizona: the Cyprus-Bagdad Project. Arizona State Museum Archaeological Series No. 136.

Matson, R.G.

1971 Adaptation and Environment in the Cerbat Mountains, Arizona. Ph.D. dissertation, University of California, Davis. Ann Arbor: University Microfilms.

McClellan, Carole, David A. Phillips, Jr., and Mike Belshaw

1978 The Archaeology of the Lake Mead National Recreation Area: An Assessment.

Publications in Anthropology No. 9, National Park Service, Western Archaeological

Center. Tucson, Arizona.

Morgan, Dale L.

1953 Jedediah Smith and the Opening of the West. Lincoln: University of Nebraska Press.

McGuire, Randall H. and Michael B. Schiffer, editors

1982 Hohokam and Patayan: Prehistory of Southwestern Arizona. Academic Press. New York.

Rogers, Malcolm J.

1966 Ancient Hunters of the Far West. San Diego: Union-Tribune Publishing Company. San Diego, California.

Ruppert, David E.

1976 Lake Mead National Recreation Area: An Ethnographic Overview. National Park Service, Western Archaeological Center. Tucson, Arizona.

Scrattish, Nick

1982 Historic Sites within Lake Mead National Recreation Area Deemed Ineligible for National Register Nomination. Ms, National Park Service. San Francisco, California.

Sherman, James E. and Barbara H. Sherman

1969 Ghost Towns of Arizona. Norman: University of Oklahoma Press.

Stone, Connie L.

1978 Granite Reef Aqueduct Archaeological Project. Cultural Resources Survey Results from the Proposed Havasu Pumping Plant Borrow Area. Central Arizona Project. Report prepared by the Office of Cultural Resource Management, Department of Anthropology, Arizona State University. Tempe, Arizona. 
Swarthout, Jeanne

1981 An Archaeological Overview for the Lower Colorado River Valley, Arizona, Nevada, and California. Reach 2, Grand Wash Cliffs to Davis Dam. Manuscripts at Department of Archaeology, Museum of Northern Arizona. Flagstaff, Arizona.

Walker, Henry P. and Don Bufkin

1979 Historical Atlas of Arizona. Norman: University of Oklahoma Press.

Woods, Clyde M.

1983 Mead-Phoenix 500kV DC Transmission Project. Chapter 9, Appendix A: Cultural Environment. Native American Cultural Resources. Detailed Cultural Resources Inventory (confidential). WIRTH Environmental Services, Phoenix, Arizona.

Wright, Barton A.

1954 Excavation of Catclaw Cave, Lower Colorado River. M.A. Thesis, Department of Anthropology, University of Arizona. Tucson, Arizona. 




\section{B I OLOG I CAL ASSESSMENT}

\section{MCCULLOUGH TO}

LIBERTY

FIBER OPTICS

PROJECT

PREPARED FOR

WESTERN AREA

POWER ADMINISTRATION

PREPARED BY

DAMES \& MOORE

JANUARY 1997 



\section{BIOLOGICAL ASSESSMENT}

FOR THE

MCCULLOUGH TO LIBERTY FIBER OPTICS PROJECT

Prepared for:

Western Area Power Administration

Prepared by:

Dames \& Moore

1790 East River Road, Suite E-300

Tucson, Arizona 85718-5876

January 28, 1997 

1.0 Proposed Action and Introduction $\ldots \ldots \ldots \ldots \ldots \ldots \ldots \ldots \ldots \ldots \ldots \ldots \ldots$

2.0 Purpose and Need $\ldots \ldots \ldots \ldots \ldots \ldots \ldots \ldots \ldots \ldots \ldots \ldots \ldots \ldots \ldots \ldots \ldots$

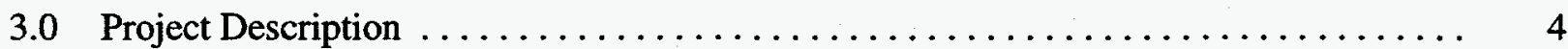

4.0 Environmental Setting $\ldots \ldots \ldots \ldots \ldots \ldots \ldots \ldots \ldots \ldots \ldots \ldots \ldots \ldots \ldots \ldots \ldots \ldots$

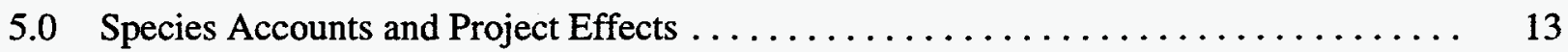

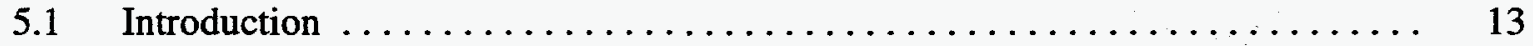

5.2 Desert Tortoise (Mohave Population) $\ldots \ldots \ldots \ldots \ldots \ldots \ldots \ldots \ldots \ldots \ldots$

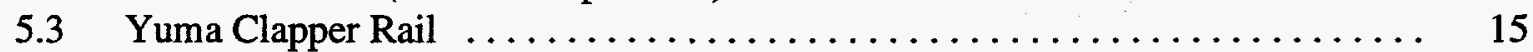

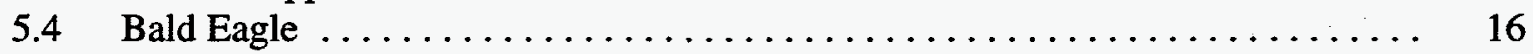

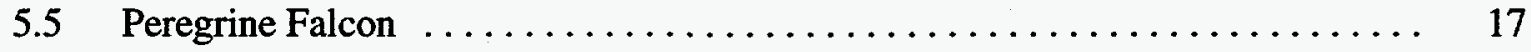

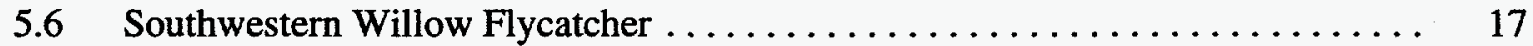

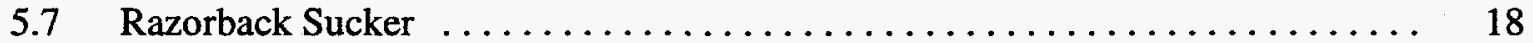

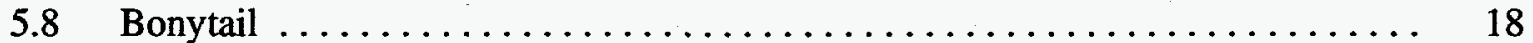

6.0 Cumulative Effects $\ldots \ldots \ldots \ldots \ldots \ldots \ldots \ldots \ldots \ldots \ldots \ldots \ldots \ldots \ldots \ldots$

7.0 Mitigation Measures for the Desert Tortoise $\ldots \ldots \ldots \ldots \ldots \ldots \ldots \ldots \ldots$

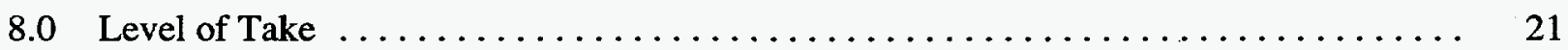

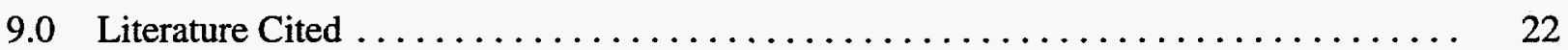

\section{LIST OF FIGURES}

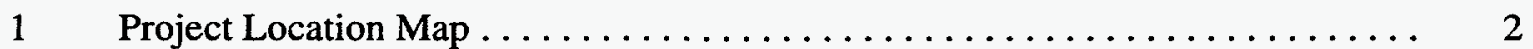

2 Typical Electrical Transmission Line Structure $\ldots \ldots \ldots \ldots \ldots \ldots \ldots \ldots$ 



\subsection{PROPOSED ACTION AND INTRODUCTION}

\section{Proposed Action}

Western and USBR own, operate, and maintain electrical transmission lines connecting McCullough Substation near Henderson, Nevada to the Liberty Substation near Phoenix, Arizona (Figure 1). The request for this action is to replace existing overhead static wire along USBR lines with an optical ground wire (OPGW) (Figure 2). In three locations where power lines cross each other, a static wire is not present for several hundred feet between two or three structures. Alternatives in these areas would involve attaching the OPGW to the existing structures or trenching underground within the existing rightof-way. Safety and tower clearances would dictate the appropriate course of action; however, a pole attachment is preferred to trenching.

This project will require an amendment to the existing right-of-way agreements originally acquired for the Granite Reef Aqueduct transmission system. In addition, a grant of right-of-way would be required from BLM for three regeneration stations and two electrical distribution lines described in detail in the project description as alternatives. The OPGW would use Western and USBR facilities exclusively and connect the substations of McCullough, Davis Dam, Parker Dam, Harcuvar, Hassayampa Tap, and Liberty. In addition to the new OPGW, a total of eight regeneration facilities will be necessary-five would be located at existing substations and three at other locations along the line. A regeneration station is a location where the signal carried by the OPGW is enhanced or amplified. Regeneration stations require an area of 100 by 100 feet bounded by a six-foot chain link fence with a 1,000-square-foot control building. Regeneration stations would be located between 25 to 45 miles apart along the route.

USBR would own the new line and the ancillary facilities including the regeneration stations, but the electronics will be owned and operated by a private commercial company. The project will not change the size of the right-of-way or the way in which it is maintained. New road construction is not necessary as part of this action. New ground disturbance during construction will be limited to eight locations where a maximum 150 -foot by 150 -foot area is prepared for regeneration stations. Permanent new ground disturbance will be limited to the 100 -foot by 100 -foot site for each regeneration station.

\section{Introduction}

Western Area Power Administration (Western) and the Bureau of Reclamation (USBR) jointly propose to install, operate, and maintain an optical ground wire (OPGW) and its ancillary facilities between the Liberty Substation near Phoenix, Arizona and the McCullough Substation near Boulder City, Nevada (see Figure 1).

The evolving deregulation of the utility industry has created unique partnering opportunities, especially within the telecommunication and power transmission market. There has been considerable interest in providing competitive utility services throughout the southwestern United States. Western and USBR recognize the advantages of improving their own systems by installing a telecommunications network and have identified a partner to implement the system. The project would provide high-speed data transfer capabilities for the Western and USBR facilities, allowing them to capitalize on the capabilities 


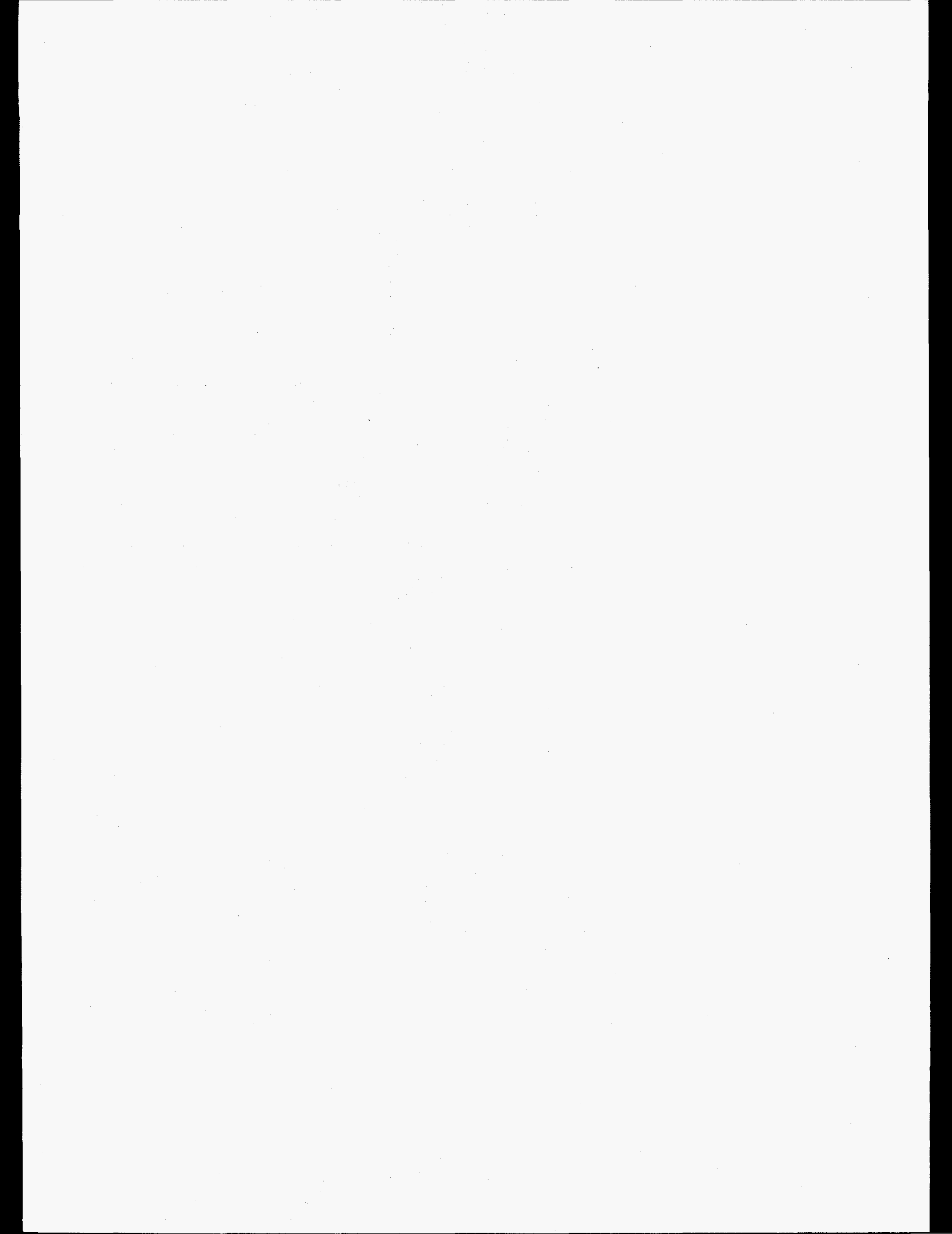




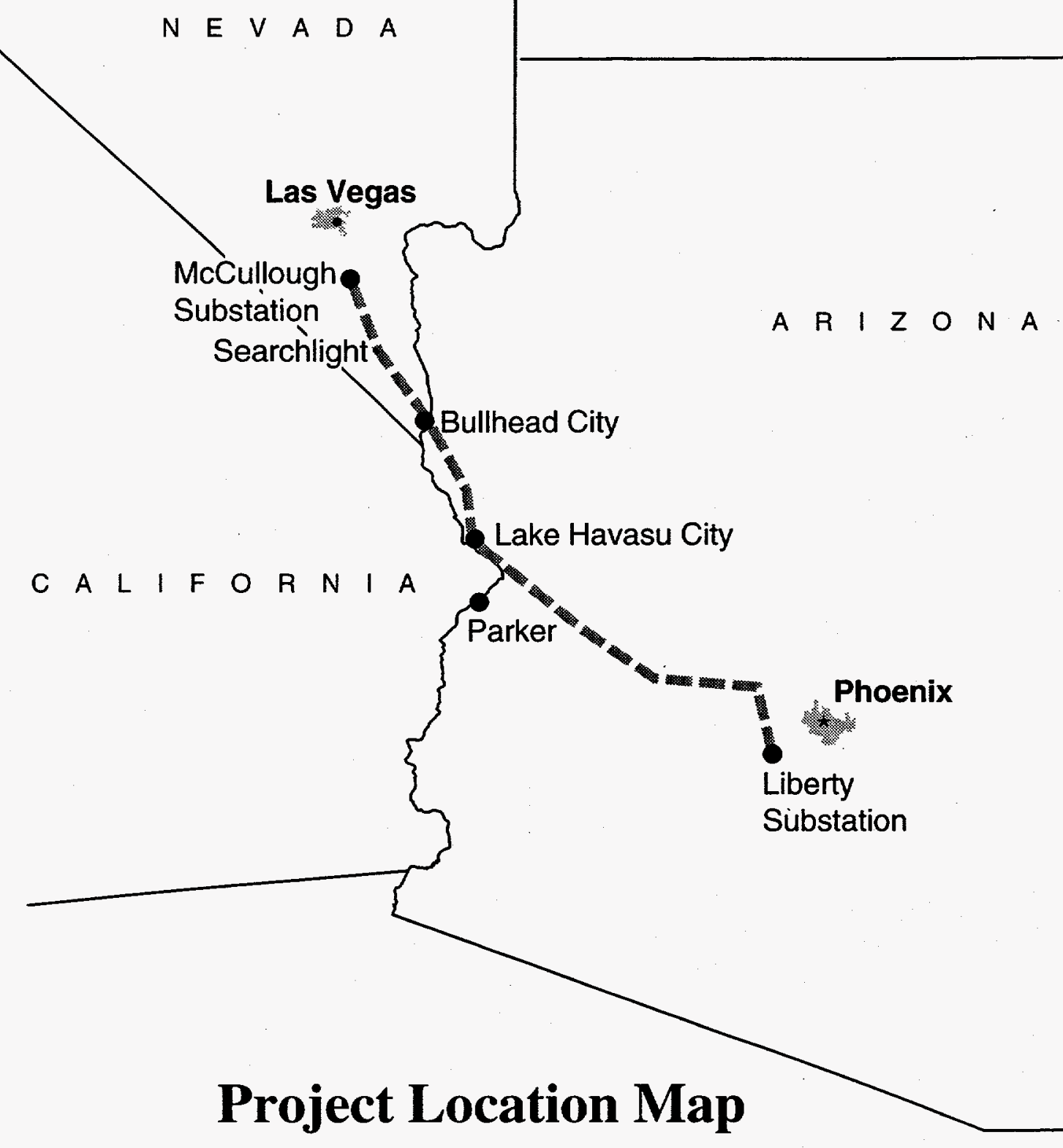

McCullough to Liberty Optical Ground Wire

Figure 1 



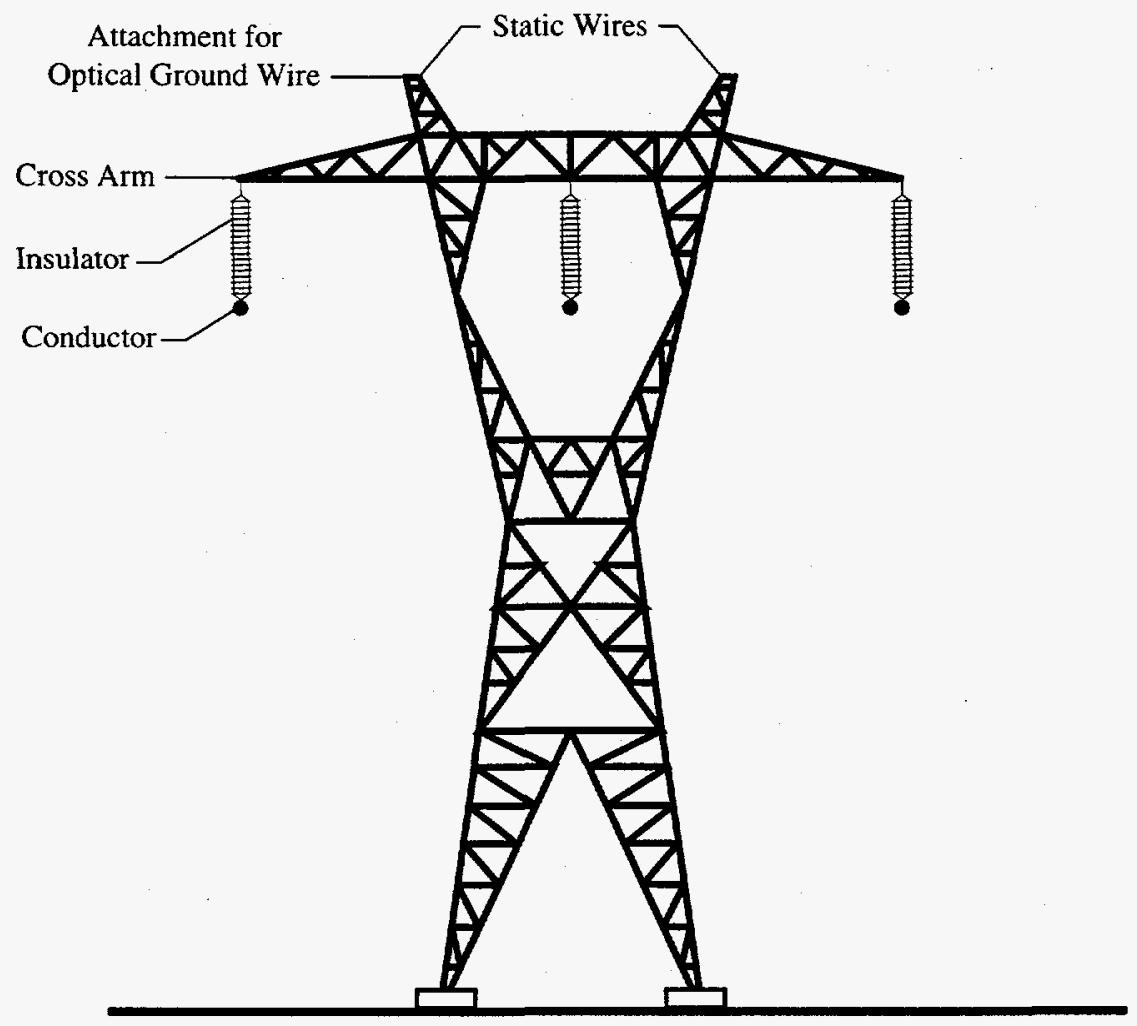

\section{Typical Electrical Transmission Line Structure}

\section{McCullough to Liberty Optical Ground Wire}

Figure 2 

of new technologies supported by fiber optic lines. The project would involve the replacement of an existing overhead static wire on federally owned and operated transmission lines with an overhead static wire containing fiber optics known as OPGW between the McCullough Substation and Liberty Substation. The project area extends from McCullough Substation in southern Nevada to Liberty Substation near Phoenix, Arizona involving the McCullough-Davis, Davis-Parker No. 2, and Parker-Liberty No. 1 transmission lines.

Much of the Nevada portion of the project is situated in critical habitat for the desert tortoise (Gopherus agassizii) (Mohave (=Mojave) population), a species listed as threatened and provided protection under the provisions of the Endangered Species Act (ESA) of 1973, as amended. The project may affect the tortoise. In this circumstance, Section 7 of the ESA requires Western to prepare a biological assessment (BA) to assess the effects of the project on tortoise. This BA contains the information needed by Western to determine if the project will adversely affect the desert tortoise and thereby lead Western to request a formal consultation with the U.S. Fish and Wildlife Service (FWS) pursuant to Section 7 of the ESA. Also considered in this BA are the Yuma clapper rail (Rallus longirostris yumanensis), bald eagle (Haliaeetus leucocephalus), peregrine falcon (Falco peregrinus anatum), southwestern willow flycatcher (Empidonax traillii extimus), razorback sucker (Xyrauchen texanus), and bonytail (Gila elegans). For each of these species there is clearly no potential for adverse affects and the reasons for these conclusions are provided in this BA.

\subsection{PURPOSE AND NEED}

The purpose of the proposed action is to provide Western and USBR with increased data transmission capacity to key components of the communication centers of McCullough, Davis, Parker, Harcuvar, Hassayampa Tap, and Liberty. Additionally, laterals to Havasu, Bouse Hills, and Hassayampa pumping plants would be included in the proposed action. The project will provide uninterrupted, reliable, high-capacity voice and data transfer communication, with backup, to remote locations along Western's transmission lines and USBR's water storage, pumping, and transfer facilities. The project would enhance Western's communication by providing a data link for the Supervisory Control and Data Acquisition (SCADA) microwave system presently used in serving the Phoenix-Mead area. It would provide closer integrated and interregional communication for Western and cooperating utilities as requested by the Western Systems Coordinating Council (WSCC). It would provide primary communication control for USBR's water delivery system. Overall, this project would increase system reliability and reduce the dependence on a single communication path currently provided by microwave systems.

\subsection{PROJECT DESCRIPTION}

Western proposes to conduct all necessary environmental assessments, permitting, design, construction, and rehabilitation/mitigation for the installation of a OPGW and ancillary facilities to be installed on or adjacent to existing electrical transmission line structures.

From end to end the primary or trunk OPGW will be approximately 250 miles, with an additional 32 miles of lateral OPGW (spurs) connecting the trunk line with USBR pumping facilities from three locations-Parker Dam, Harcuvar, and Hassayampa Tap substations. 
The OPGW is comprised of not more than 120 dielectric (does not conduct electricity) fibers and encased in a metal jacket that protects the line and serves the purpose of the static line it replaces. The OPGW with its protective coatings, including the metal jacket, creates a cable approximately one inch in diameter. The cable does not emit any noise or electric or magnetic fields. The OPGW is attached at or near the top of each electrical transmission line structure above the electrical conductors (see Figure 2).

The proposed action would be to construct and operate on property administered by Western and USBR, with the exception of three BLM parcels identified for regeneration stations and two locations where electrical distribution lines are under consideration as alternative power supplies.

The route for the project generally trends southeast from McCullough Substation in Nevada to Liberty Substation near Phoenix. The main trunk of the OPGW will attach to existing $230 \mathrm{kV}$ transmission lines connecting the endpoints and will include the following segments:

- McCullough-Davis $230 \mathrm{kV}$ - 62 miles

- Parker-Davis No. 2 230kV - 68 miles

- Parker-Liberty No. 1 230kV - 113 miles

In addition to the main trunk wire, three lateral wires would connect USBR pumping plants to the system. These laterals also would attach to existing transmission lines. There are eight regeneration stations proposed along the route, five of which are within or adjacent to existing substations. The OPGW would for the most part replace the existing static line on the existing structures. As described earlier, where static wire is not present, an attachment would be built to hold the new OPGW in place below the transmission line conductors near the bridge of the structure. If the attachment was not possible, the line would continue underground between the towers where the static line is missing.

The following paragraphs describe the route in more detail, moving from McCullough to Liberty, in segments from one regeneration station to the next. At each regeneration station the site description includes property ownership, access, and power supply. Where there are alternatives within a segment, they are listed in bullet form for easy reference.

If approved, construction may be initiated anywhere along the route. For descriptive purposes, the project would begin at the McCullough Substation site where a newly constructed regeneration station, McCullough Regeneration Station, would connect existing facilities to the project. There are two alternatives for the location of the regeneration station at McCullough:

- entirely within the fenced yard of the existing substation compound with the OPGW dropping directly into the substation or

- immediately outside the existing substation compound on USBR property with the OPGW entering and exiting the regeneration station underground and connecting with the nearest transmission line structure (within a few hundred feet)

Both alternative locations for the regeneration station have existing access roads and power availability to the site. Power would be supplied by Nevada Power Company. 
Near the McCullough Substation, several high-voltage transmission lines converge and cross over the McCullough-Davis line. In this area, the static line has not been installed and the following alternatives are under consideration:

- attaching to the structures below the existing conductors

- trenching within the existing right-of-way for 3,500 feet between the regeneration station and structure number $0 / 4$

- trenching approximately 6,000 feet along the existing access road from the regeneration station site to structure $1 / 2$ where the existing line crosses the access road

The route then continues southwest from the first regeneration site on the Davis-McCullough $230 \mathrm{kV}$ transmission line structures. Approximately seven miles from the McCullough Substation site, the route turns to the southeast, crossing under another transmission line, making it necessary again to consider undergrounding for about 1,200 feet.

The route continues south and southeast on the McCullough-Davis $230 \mathrm{kV}$ line for approximately 19 miles to the second regeneration station, which is to be located directly west of the city of Searchlight near structure 26/1. The Searchlight Regeneration Station would be constructed adjacent to USBR rightof-way on BLM land. At this location, the OPGW would drop down the transmission line tower and continue underground within the existing right-of-way for approximately 200 feet in order to enter and exit the proposed regeneration station. Construction activities at this site would use existing access roads. The power would be provided at the site by an existing distribution line owned and operated by Nevada Power.

From Searchlight the route continues on the McCullough-Davis $230 \mathrm{kV}$ line southeast for 23 miles, then turns to the east for about 6 miles along the southern boundary of the Lake Mead National Recreation Area, continuing into the Davis Dam Substation. Directly north of the Davis Dam Substation within USBR property, the third regeneration station, Davis Dam Regeneration Station, would be located at an abandoned building site owned by USBR. Power would be supplied by USBR and obtained by tapping into an adjacent distribution line. Approximately three distribution poles would be necessary to span the 1,000 feet between the existing electrical distribution line and the regeneration site. The three new distribution poles would be set on USBR land.

From the Davis Dam area, the route continues on the Davis-Parker No. $2230 \mathrm{kV}$ transmission line southeast for approximately 41 miles. Near the intersection of the Davis-Parker No. 2 line and State Route 95 at structure 41/3, another regeneration station, Topock Regeneration Station, would be constructed on BLM land adjacent to the USBR right-of-way. Power would be obtained by tapping into a distribution line owned by Citizens Utilities Company approximately 250 feet away. Construction of this regeneration station would be accomplished by using existing access.

From the Topock site, the route continues on the Davis-Parker No. $2230 \mathrm{kV}$ transmission line southeast through the Crossman Peak Natural Scenic Area to Parker Dam Substation. The line passes through approximately eight miles of the Crossman Peak Natural Scenic Area. For this segment there are two alternatives for access during the construction: 
- the use of helicopters to supplement construction crews

- the use of existing roads and making limited improvements followed by reclamation

At Parker Dam Substation, the Parker Dam Regeneration Station would be constructed on USBR property. Power would be supplied using existing structures, and there is existing access to the site. In this area the OPGW would cross the lake and river on existing structures. Also from the Parker Dam Substation site there would be a 2-mile, 8-fiber OPGW connecting the main fiber optic wire to the Lake Havasu Pumping Plant. The lateral connection would involve a river crossing on existing structures.

From Parker Dam Substation, the route attaches to the Parker-Liberty No. $1230 \mathrm{kV}$ transmission line structures, continues southeast for approximately 44 miles to the existing Harcuvar Substation, where the sixth regeneration station (Harcuvar Regeneration Station) is proposed. The regeneration station would be built adjacent to the existing substation on the southeast portion on Western property. Power would be obtained in one of two ways:

- by installing a transformer inside the existing substation

- by installing a distribution line from the Alamo Dam Access Road for approximately one mile along the substation access road to the regeneration site

A second 25-mile, 8-fiber OPGW would connect the Bouse Hills Pumping Plant to the main OPGW. The lateral would replace the overhead existing static wire on the Harcuvar-Bouse Hills $115 \mathrm{kV}$ wooden $\mathrm{H}$-frame structures and use existing access.

The route continues from the Harcuvar regeneration site east about 22 miles to Structure No. $66 / 5$ where the Aguila Regeneration Station is proposed. The Aguila Regeneration Station would be built adjacent to USBR right-of-way on property that is currently owned by BLM southwest of Eagle Eye Road. The site is intersected by an existing distribution line that would serve as the power source. The route continues on the existing transmission line structures for approximately 32 miles to the Hassayampa Tap Substation, where the last regeneration station is proposed. The Hassayampa Tap Regeneration Station would be located outside the substation yard on USBR property and would utilize existing access for construction. Power here would be supplied in one of the two following ways:

- locate transformers inside the existing substation

- tap into power from the Hassayampa Pumping Plant, which would require running a distribution line from the regeneration site, paralleling Granite Reef and the Hassayampa River adjacent to Western's existing right-of-way, a distance of 6.7 miles

A 6.7-mile, 8-fiber OPGW would connect the regeneration station to the Hassayampa Pumping Plant by replacing the existing static wire and attaching to the existing Hassayampa Tap 230kV transmission line structures.

The route continues southeast and east for about 17 miles from the Hassayampa Regeneration Station on the Parker-Liberty No. $1230 \mathrm{kV}$ line to the Liberty Substation, which is the termination point for the OPGW. Equipment will be placed inside the existing substation facility. 


\section{Ancillary Facilities}

\section{Cable Splice Cases}

Cable splice cases are small boxes where the OPGWs are joined together. The cases are approximately 24 inches in length and 8 inches in diameter and mounted on the lattice transmission line structures 20 feet above the ground below the conductors. Splice cases are located along the line approximately three miles apart.

\section{Regeneration Stations}

A regeneration station is a location where the signal carried by the OPGW is enhanced or amplified. Regeneration stations require an area of 100 by 100 feet bounded by a six-foot-high chain link security fence with a locking gate. Within the compound, the site would contain one-half inch to three-quarter inch broken aggregate gravel. A 1,000-square-foot single story, flat roofed structure will occupy each site and house the equipment. The buildings are constructed of precast, exposed aggregate concrete. They are constructed on a concrete slab foundation and have precast, tilt-up, concrete walls. Buildings are equipped with electronic equipment, lighting, temperature control systems (heating and air conditioning), and two emergency electrical generators.

There are eight regeneration stations proposed along the route spaced between 20 to 45 miles apart.

The following are the major construction activities for regeneration station sites:

m surveying and staking

- conduct archaeological and threatened and endangered species field investigations

- prepare site

- pour concrete building pad

- assemble pre-manufactured structure

- install security fence

- install regeneration equipment

Electrical Power-Each of the regeneration sites will require 800 amps which will be supplied in the following ways. Where it is necessary to build an electrical distribution line, the equipment used to construct the line will include three separate vehicles—one with an auger, another referred to as a "bucket truck" with the equipment that places the poles, and a pole truck. The auger will drill the holes for the poles to a depth of six feet. The bucket truck will place the poles in the holes. Augured soil will be backfilled and tamped around the pole. Pole height will be approximately 34 feet above ground. Pole spacing will be approximately 300 feet. The area of disturbance will be confined to a few feet immediately around each pole. Once the poles are in place, the conductor will be pulled into place with a rubber tire reel truck and tension truck. Whenever a regeneration station is powered by an existing or proposed distribution line, a pole-mounted transformer will be necessary. 
At all other regeneration locations, electrical power will be provided via the local existing and adjacent electrical distribution system.

Emergency back-up power will be provided by a propane-powered electric generator located on site. These generators would utilize a 500-gallon tank of propane gas capable of sustaining electrical power for 11 hours.

In two of the regeneration stations it may be necessary to build transformers within the substations to accommodate the power needs of the regeneration equipment. In these two cases transformers would convert high-voltage power to a useable voltage.

\section{Project Design and Construction Standards}

\section{Construction Techniques}

Equipment, OPGW, and other construction material will be acquired from various vendors and stockpiled along the route at sites owned by Western and USBR or their contractors. During the construction phase, contractors will obtain material from these sites.

The OPGW will be constructed in spreads consisting of equipment and crews handling various phases of construction for a given line segment. The equipment utilized in the construction will include a tensioner and cable puller. These vehicles are large 10-wheel trucks designed for heavy loads. Tensioners also may be mounted on a trailer.

The process of replacing the static wire with the OPGW will be accomplished by first mounting a traveler or pulley on each structure near the place where existing wire attaches to the structure. Next, the existing static wire is released from its attachment to the structure and placed into the traveler and cut at one end. The OPGW is then tied to the end of the old static line and pulled through the travelers, removing the static line and installing the OPGW in one motion. Linemen then remove the new OPGW from the travelers and attach them to the structures. Wire is typically pulled for about three miles at a time.

\section{Environmental Field Survey}

As described earlier, along most of the route the project will be constructed overhead avoiding new ground disturbance. However, where new ground disturbance is proposed, a field survey will be performed prior to construction. The field survey will involve identifying sensitive or protected plants, species, or cultural resources for avoidance.

\section{Flagging and Staking of Right-of-way}

All activities associated with the construction, operation, and maintenance of the right-of-way will be conducted within the authorized limits of the temporary and permanent disturbance. Disturbance of the regeneration sites is 150 by 150 feet and 100 by 100 feet for temporary and permanent respectively. For 
the undergrounding areas, trenching would displace 18 inches of soil for the length of the trench. The length of the trench depends on the alternative selected.

Sensitive areas as identified by the specialist (e.g., biologist, archaeologist) where construction equipment and vehicles are planned to disturb will be clearly marked for avoidance before any construction or surface disturbing activities begin.

\section{Temporary Construction Areas}

Two to four temporary staging areas for equipment and materials storage, each approximately 50 feet by 100 feet in size, will be required. These marshaling yards will be located on previously disturbed Western or USBR property, avoiding wetlands and other environmentally sensitive areas.

\section{Clearing and Grading of the Right-of-way}

In some areas, the existing access road to the transmission line structures may require improvement in order to accommodate cable trucks or construction vehicles. Improvements would be limited to blading the existing alignment to remove erosion ruts. Road improvements are known to be necessary to access the Aguila Regeneration site.

No construction or routine maintenance activities will be performed during periods when the soil is too wet to adequately support construction equipment. If equipment creates ruts in excess of six inches deep, the soil shall be deemed too wet to adequately support construction equipment.

The width of the disturbance zone along the route will be minimized to the extent practicable. Construction vehicles will be excluded from traveling or turning around in undisturbed areas outside the right-of-way, except for reasons of safety.

\section{Access}

New road construction is not anticipated. Construction-related traffic will be restricted to existing routes approved by the authorized specialist.

\section{Fences and Range Improvements and Existing Land Uses}

All existing improvements will be protected. If damage occurs it will be repaired immediately to the satisfaction of the owner or land manager.

Western will protect all public survey monuments found within or adjacent to the right-of-way. Survey monuments include but are not limited to General Land Office and BLM Cadastral Survey Corners; reference corners; witness points; U.S. Coastal and Geodetic benchmarks and triangulation stations; military control monuments; and recognizable civil (both public and private) survey monuments. If any 
of the above are obliterated or disturbed, Western will report the incident, in writing, to the BLM Field Office Manager and the respective installing authority, if known. Where BLM or General Land Office right-of-way monuments or references are obliterated during operations, Western will secure the service of a registered land surveyor or a staff cadastral surveyor to restore the disturbed monument according to procedures found in the latest edition of the manual of surveying instructions for the survey of the public lands of the United States. Western will record such survey in the appropriate county and send a copy to the authorized specialist.

\section{Work Force}

Each construction spread will require 15 to 20 workers including foremen, equipment operators, general laborers, and environmental monitors and construction inspectors. Each spread will require three to five pieces of equipment and support vehicles. There may be as many as three spreads under construction at any one time over the entire route, accounting for approximately 45 to 60 workers and 15 to 25 pieces of equipment.

Construction workers will not be permitted to camp upon public lands while participating in construction activities. Construction camps will not be necessary.

\section{Vegetation}

Disturbance of vegetated areas will be avoided where possible. In those areas where the development of the regeneration station will disturb previously undisturbed areas, significant or protected species will be avoided.

\section{Safety}

The following measures will be undertaken to ensure the health and safety of agency personnel, contractors, and the general public:

- the existing power line will be de-energized

- adherence to applicable Department of Energy construction and safety standards

- boat traffic control at crossings of navigable waters as approved by Army Corps of Engineers

- traffic control procedures at road crossings, as approved by state highway departments

\section{Hazardous/Toxic Materials}

No hazardous material would be generated by the actions required for the operation and maintenance of the project. To minimize the impact of hazardous materials used during construction activities (fuels and lubricating oils), all equipment would be regularly inspected for leaks. Any significant leaks which are detected would be promptly corrected. Fueling operation would be conducted at commercial filling stations or fuel farms. 


\section{Maintenance and Operation}

Supervisors and field personnel would monitor and control the system by driving throughout the project area inspecting facilities and checking equipment. Periodic reconnaissance of the OPGW right-of-way will be conducted once a month by driving the entire route on the existing roads or an overflight. Improvements and repairs would be conducted as necessary. Maintenance procedures of the right-of-way would remain unchanged with the addition of the OPGW.

Regeneration stations would not be manned, but will be visited every month for inspection and maintenance. Back-up generators at regeneration stations would provide extended service in the case of a power outage.

Once the proposed facilities are in place and functioning, they would remain in continuous operation.

\section{ALTERNATIVES}

The action alternatives considered for the project are minor variations to the proposed action and include locations of regeneration sites, sources of power, and placing the lines overhead versus burying. In addition, the no-action alternative was also considered. There are no routing options remaining that could connect the regeneration stations and pumping facilities described in the purpose and need.

\section{No Action}

The no-action alternative would not meet the stated need for the project.

\section{Alternatives Considered but Eliminated from Further Study}

Two additional regeneration sites were evaluated in the vicinity of the intersection of the Parker-Davis No. 2 line, Interstate Highway 40, and State Highway 95 near Topock, Arizona. These sites were located immediately adjacent to State Highway 95 . They were rejected because of safety concerns, proximity to floodplains, proximity to several high-pressure gas pipelines, and the need for power.

An additional regeneration site was evaluated near Aguila, Arizona immediately adjacent to Eagle Eye Road. The site was rejected because of the need for power on site, visual resources, safety, and security concerns.

An alternative line location was considered near Lake Havasu that would avoid the Crossman Peak Natural Scenic Area and pass through the city. This alternative involved changing from the Parker-Davis No. 2 line to the Parker-Davis No. 1 line near the Topock Regeneration Station and then changing back to the Parker-Davis No. 2 line near the Black Mesa Substation. This alternative was eliminated because of contractual difficulties in accessing the Parker-Davis No. 1 line. 


\subsection{ENVIRONMENTAL SETTING}

The Nevada portion of the project area is within the Mohave desertscrub biome. It is this portion of the project area that supports the desert tortoise (Mohave population). Mohave desertscrub vegetation is shrub-dominated. The principal, dominant shrub species include creosotebush (Larrea tridentata), allscale (Atriplex polycarpa), brittlebush (Encelia farinosa), desert holly (Atriplex hymenelytra), white burrobush (Hymenoclea salsola), and blackbrush (Coleogyne ramosissima) (Turner and Brown 1982). Joshua tree (Yucca brevifolia) "woodlands" (not a true woodland due to the wide spacing of plants) are a diverse vegetation type. Joshua trees form a scattered, open overstory subtended by a wide variety of shrub and succulent (cacti) species. Creosotebush typically dominates on bajadas and well-drained sandy flats, usually at elevations below about 4,000 feet. Creosotebush often occurs in association with white bursage (Ambrosia dumosa) in two-layered stands of uniform sized plants over extensive areas. Such stands often give the appearance of being monotypically dominated by creosotebush owing to the lesser stature of white bursage. In terms of wildlife, Mohave desertscrub habitats support relatively few species of large mammals, numerous small nocturnal mammals, and few bird and reptile species that are not found elsewhere. Amphibians are almost wholly lacking from Mohave desertscrub areas. Other important wildlife habitats transected by the project include wetlands, floodplain woodlands, and aquatic habitats associated with the Colorado River.

\subsection{SPECIES ACCOUNTS AND PROJECT EFFECTS}

\subsection{INTRODUCTION}

The following accounts of the species of concern include information on the protective status, distribution, natural history, populations within the project area, habitat preferences, threats, and the potential effects of the project for each species. Included are all federally listed, or proposed, threatened, and endangered species with a potential to occur within the project area. Information was obtained from the available literature, and contacts with state and federal agencies.

\subsection{DESERT TORTOISE (MOHAVE POPULATION)}

\section{Background Information}

The desert tortoise (Mohave population) is federally listed as a threatened species (55 Federal Register (FR) 12178, April 2, 1990). Critical habitat has been designated for the desert tortoise (59 FR 5820, February 8,1994$)$. The designation of critical habitat is used to identify areas where federal agencies need to exercise special care to avoid damage to a species' habitat. These areas are considered to be essential to the long-term survival and recovery of a species. Critical habitat does not preclude all modification of habitat in the designated area. The Sonoran population of the desert tortoise, not protected under ESA, occurs in the Arizona portion of the project area. The Sonoran population is addressed in the environmental assessment prepared for this project.

The desert tortoise is one of four gopher tortoises in North America. The Mohave population of the desert tortoise is an administrative designation for tortoises that occur north and west of the Colorado 
River. The desert tortoise is distinguished by a high-domed shell with prominent growth rings on both the carapace (upper portion of the shell) and the plastron (lower portion of the shell) (Stebbins 1985). The desert tortoise is completely terrestrial requiring firm, suitable substrates for digging burrows and nest sites or providing other coversites, such as rock crevices for shelter. Throughout the Mohave Region, desert tortoises occur on flats and bajadas with soils ranging from sand to sandy-gravel, and they occur on rocky terrain and slopes (FWS 1994b). They require sufficient suitable plants for forage and cover. Vegetation is usually scattered shrubs and abundant inter-shrub space for growth of herbaceous plants. The most common plant associated with their habitat is creosotebush. Tortoise habitat includes other vegetation such as ocotillo, yucca trees, and microphyll woodland washes. Desert tortoises are primarily herbivores, foraging on grasses, forbs, cacti, and the flowers of annual plants. They live to be 30 to 100 years of age and reach sexual maturity at 12 to 30 years (Woodbury and Hardy 1948). Females lay an average of 4.2 eggs per clutch inside the burrow and have an average of 1.89 clutches per year (Turner and Berry 1984). Their variable reproductive success is correlated with environmental conditions (FWS 1994b).

Activity patterns of the desert tortoise are closely tied to ambient temperatures and forage availability. Desert tortoises spend much of their lives in burrows, emerging to feed and mate during late winter and early spring. They remain active through the spring and portions of the summer through to late fall. Their active season is typically defined as being from March 1 through October 31 .

Threats to this species include direct and indirect human-caused mortality, coupled with the inadequacy of existing regulatory mechanisms to protect desert tortoises and their habitat. Impacts such as destruction, degradation, and fragmentation of their habitat from urbanization, agricultural development, livestock grazing, mining, roads, vehicle-oriented recreational use, and losses from human take and disease have contributed to population declines (FWS 1994b).

In June 1994, the FWS (1994b) published a Desert Tortoise (Mojave population) Recovery Plan. The objective of the Recovery Plan is to recover the species to the point where it can be removed from the list of threatened species. Part of the recovery strategy is to establish Desert Wildlife Management Areas (DWMAs). DWMAs would receive special protective measures to ensure the survival of the species. The establishment and management of DWMAs is to be accomplished by agencies, such as the Bureau of Land Management (BLM), responsible for the management of lands supporting desert tortoises. Management of DWMAs includes securing habitat, developing management to eliminate factors that have caused declines, implementing management decisions, and monitoring recovery (FWS 1994b). The proposed project traverses the Piute-Eldorada DWMA which enncompasses southern Clark County. Population densities in this DWMA, and thus the project area, range from 40 to 90 adult tortoises per square mile (FWS 1994b).

\section{Effects of the Project}

A small area of tortoise habitat would be permanently committed to the project as a result of the construction of the two regeneration sites. One thousand square feet of habitat would be lost as a result of the construction of Searchlight Regeneration Station, and an additional 1,000 square feet adjacent to the McCullough Substation would be lost if this site is located outside of the Substation perimeter fence. An additional 50 feet would be temporarily disturbed on the perimeter of the regeneration station(s). 
Small areas of habitat would be temporarily disturbed at splicing and pulling sites. At these sites, two vehicles would leave the access road and crush vegetation within the existing right-of-way. There would be approximately 20 such locations. Trenching would be required for underground portions of the line, but no more than three miles of the OPGW would be underground causing an insignificant amount of temporarily habitat disturbance. With strict adherence to mitigation measures, tortoise burrows would be avoided.

Stringing the OPGW in the McCullough-Davis (i.e., Nevada) portion of the project would require approximately one week ( 10 miles per day). These activities could kill or injure tortoises as a result of vehicle movement on and off the right-of-way, and in personnel transport to and from work sites. However, the short time frame of construction activities minimizes the potential for vehicle collision with tortoises.

\subsection{YUMA CLAPPER RAIL}

\section{Background Information}

The Yuma clapper rail is listed by the federal government as an endangered species (32 FR 4001, March 11,$1967 ; 48$ FR 34182, July 27, 1983). This species is much larger than the Virginia rail ( $R$. limicola) and somewhat smaller than the king rail (Rallus elegans). Coloring is gray-brown above and bright cinnamon below with brownish-gray cheeks (National Geographic Society 1987). The species' range includes the Colorado River from Needles, California to the delta/Sea of Cortez region of Mexico (USBR 1996). The highest Yuma clapper rail populations in the United States occur along the Colorado River in the Havasu National Wildlife Refuge (NWR), Cibola and Imperial NWR, and the Mittry Lake Arizona State Wildlife Refuge (Tomlinson and Todd 1973). The population that occurs at the northern extreme at Havasu NWR was once thought to winter in Mexico, but studies now indicate that 70 percent of the breeding population remains on the lower Colorado River (Eddleman 1989 in Rosenberg et al. 1991).

The preferred habitat of the Yuma clapper rail is sedimented, shallow water cattail (Typha latifolia) and bulrush (Scirpus acutus) marshes (Tomlinson and Todd 1973). The Yuma clapper rail nests primarily in freshwater marshes in mature cattail-bulrush habitat. Nests are commonly found at or near the water's edge (Ohmart and Smith 1973; Smith 1974). Stands of cattail and bulrush dissected by narrow stream channels apparently support the densest populations of Yuma clapper rails (Tomlinson and Todd 1973). Research conducted along the Colorado River by Anderson and Ohmart (1985) found Yuma clapper rails preferred dense vegetation regardless of whether it was cattail or bulrush. They also found them in other vegetation including reeds.

On the lower Colorado River, populations of clapper rails are associated with marsh habitats within the national wildlife refuges and lakes in the Yuma area. Isolated pockets of marsh habitat are scattered all along the river between the Cibola and Havasu NWRs. These pockets provide potential breeding habitat and may be used by migrating clapper rails in the spring and fall (E. Linwood Smith and Associates 1987). 


\section{Effects of the Project}

The marsh habitats on which the Yuma clapper rail depends would not be affected by the project.

\subsection{BALD EAGLE}

\section{Background Information}

The bald eagle was federally listed as endangered, but has been down-listed to threatened (60 FR 35999, July 12, 1995). There has been no determination of critical habitat for bald eagles. Bald eagles are large birds of prey and adult birds are distinguished by a white head and tail, and a large yellow bill. Because of their large size, bald eagles require a substantial prey base consisting mainly of fish. The breeding habitats of this species include nest sites in large trees within a 0.6 mile of water and free from disturbances (Johnsgard 1990).

In western Arizona, bald eagles nest on the Bill Williams River near Alamo Lake (Busch 1988; FWS 1991). The number of known nest sites has increased, but it is unclear whether this represents an expanding breeding population or more concentrated search efforts for this species (Arizona Game \& Fish Department (AGFD) 1988). Most of the states' major river systems, including the mainstem of the Colorado, support wintering bald eagles (Bush 1988; Rosenberg et al. 1991). On the mainstem of the Colorado, this species is most commonly observed on the three NWRs which provide protected aquatic habitats (Rosenberg et al. 1991). Important habitat characteristics within the project area (i.e., aquatic habitats in conjunction with perch sites) are found in the Colorado River valley in the vicinity of the river crossings. While Rosenberg et al. (1991) described bald eagles as a rare to uncommon winter visitor on the lower Colorado River, more recent counts (1992-1996) conducted by the AGFD indicate they are no longer rare (USBR 1996). The closest nesting bald eagles to the project are two pairs on the Bill Williams River near Alamo Dam (approximately 30 miles east of Parker Dam).

\section{Effects of the Project}

Any possible adverse effect involves the potential for collision with transmission line conductors and static lines along the Colorado River. Research indicates that larger birds with restricted maneuverability and/or flocking behavior (e.g. waterfowl, pelicans, herons, etc.) are at higher risk (Hoover 1978; Williard et al. 1977). Bald eagles are diurnal birds and are not noted for being high speed or clumsy fliers. Moreover, eagles and other birds of prey are noted for their keen vision and would likely be able to see the OPGW and/or electrical conductors far in advance of any possible collision. Consequently, it is unlikely that the transmission line crossings at the Colorado River currently poses a threat to bald eagles or that the OPGW would represent an additional significant threat. Habitats on which nesting and wintering bald eagles depend would not be affected by the project. 


\subsection{PEREGRINE FALCON}

\section{Background Information}

The peregrine falcon is listed by the federal government as endangered (35 Federal Register 16047, October 13, 1970; 35 Federal Register 8495, June 2, 1970) without determination of critical habitat. This species is found across North America from northern Alaska and Canada south to southern Baja California, the coast of Sonora, and into Central and South America (American Ornithologists Union 1983). Peregrines occur on isolated cliff ledges throughout Arizona, but in small numbers (Monson and Phillips 1981). Their principal prey are passerine birds, waterfowl, and shorebirds (Snow 1972). Peregrines may travel up to 17 miles to hunting areas which are often cropland, meadows, riverbottoms, marshes, and lakes, which attract abundant bird life (Ellis 1982). The reason for this species' decline is reproductive failure due to pesticide contamination (FWS 1991). Nationwide population declines in the 1950s and 1960s appear to have been reversed (AGFD 1988). On the lower Colorado River, Rosenberg et al. (1991) described the species as an uncommon transient and winter visitor from September to late March, and a rare but consistent visitor from May through August. Nest sites in Arizona are located in extensive mountain ranges or canyon systems usually near water where prey are abundant (Ellis 1982).

\section{Effects of the Project}

There will be no effects on peregrine falcons from implementation of the project. Peregrine falcons do not nest in electrical transmission towers and would, therefore, not be disturbed by construction. Peregrines, like bald eagles and other birds of prey, are noted for their keen vision and would likely be able to see the OPGW and/or electrical conductors far in advance of any possible collision. Habitats on which peregrines depend would not be affected by the project.

\subsection{SOUTHWESTERN WILLOW FLYCATCHER}

\section{Background Information}

The southwestern willow flycatcher is listed as an endangered species (60 FR 10694, February 27, 1995). It is a small bird with a grayish-green back and wings, whitish throat, light grey-olive breast, and pale yellowish belly. The breeding range of the southwestern willow flycatcher includes Arizona, southern California, New Mexico, the extreme southern parts of Utah and Nevada, southwestern Texas, and extreme northwestern Mexico. The preferred habitat of the species includes riparian habitats along rivers, streams, or other wetlands with dense growth of willows, arrowweed, and tamarisk, often with a scattered overstory of cottonwood (FWS 1995). Breeding usually occurs in swampy thickets with willow and buttonbrush (American Ornithologists Union 1983). During migration, southwestern willow flycatchers use a variety of habitats and may be encountered in all but the most sparse, desert habitats.

The southwestern willow flycatcher was believed to no longer nest along the lower Colorado River (Rosenberg et al. 1991), however, birds have been observed along the lower Colorado River in several locations during the breeding season in recent years. There are currently no reports of this species nesting in the vicinity of either Parker or Davis dams (USBR 1996). 


\section{Effects of the Project}

The project will have no affect on riparian habitats on which the southwestern willow flycatcher depends. Also, this species would not be affected by project construction in that this species is not currently known to nest in the vicinity of the project.

\subsection{RAZORBACK SUCKER}

\section{Background Information}

The razorback sucker is listed by the federal government as an endangered species (56 FR 54957, October 23, 1991) with critical habitat (59 FR 13374, March 21, 1994). The critical habitat on the lower Colorado River extends from Parker Dam to Imperial Dam, and also includes Lakes Mead and Mohave and the reach of river between them (USBR 1996). This species is easily distinguished by a sharp-edged hump behind the head (FWS 1991). It grows to a large size and is found in the Colorado River Basin, and the rivers, streams, and canals in the basin. In Arizona, it has been reduced to natural populations in Mohave, Mead, and Havasu lakes, but other populations exist in the Central Arizona Canal and lower Colorado River (AGFD 1988). This fish feeds on benthic flora and fauna, detritus, and plankton (FWS 1991). It is threatened by habitat alteration and non-native fish predators (AGFD 1988).

\section{Effects of the Project}

Implementation of this project will have no effect on the aquatic habitats of the Colorado River system on which razorbacks depend.

\subsection{BONYTAIL}

\section{Background Information}

The bonytail is listed as an endangered species (45 FR 27710, April 23, 1980) with critical habitat (59 FR 13374, March 21, 1994). Critical habitat for this species includes the Colorado River from Hoover Dam to Davis Dam, and from the northern boundary of Havasu NWR to Parker Dam (USBR 1996). Bonytails are well adapted to the conditions of the Colorado River System prior to dam constructions and other modifications (Minckley 1973). This species, once found throughout the mainstream Colorado River, is close to extinction. Although a few old specimens ( $40+$ years) continue to be been taken, there is no known recruitment in the wild. This fish inhabits warm, swift, turbid rivers and is usually found in eddies and pools (FWS 1991). The only remaining natural population is in Lake Mohave (AGFD 1988). Like the razorback sucker, bonytails are threatened by habitat alteration and non-native fish predators (AGFD 1988; FWS 1991). 


\section{Effects of the Project}

Implementation of this project will have no effect on the aquatic habitats of the Colorado River system on which razorbacks depend.

\subsection{CUMULATIVE EFFECTS}

Cumulative effects under ESA regulations are defined as those of future non-federal (state, local government, or private) activities that are reasonably certain to occur during the course of project activity. Future federal actions are subject to the consultation requirements established in Section 7 of the ESA and, therefore, are not considered cumulative to the proposed action. Cumulative impacts can result from individually minor, but collectively significant, actions taking place over a period of time (40 CFR 1508.7).

Impacts of non-federal actions projects and activities on the desert tortoise continue to occur throughout the range of the species. Off road vehicle use, shooting, and collecting of individuals continue to impact tortoise populations. Impacts to tortoises in the project area are addressed in detail in the Desert Tortoise (Mojave population) Recovery Plan (FWS 1994b). Activities effecting the remaining species associate with the Colorado River are addressed in detail by the USBR (1996).

\subsection{MITIGATION MEASURES FOR THE DESERT TORTOISE}

The following mitigation measures are designed to reduce potential impacts of the proposed project on the desert tortoise. These measures would be implemented to avoid, minimize, correct, reduce, or eliminate impacts. The measures would be applicable to all activities within the Nevada and California portions of the project area. No mitigation measures are recommended for the Yuma clapper rail, bald eagle, peregrine falcon, southwestern willow flycatcher, razorback sucker, or bonytail chub.

Note: In the following measures, the term biologist refers to a qualified biologist. A qualified biologist is a professional biologist who has demonstrated experience with the desert tortoise. This includes experience in techniques to locate tortoises and inventory habitat. These measures are adapted from those approved for other linear projects located in Clark County, Nevada, and are consistent with measures required by the FWS for previous projects.

Listed below are measures that would minimize the potential for mortality or injury of desert tortoises due to construction activity and in operation of heavy equipment.

1. A tortoise biologist would be present during all construction activities where one or more pieces of heavy construction equipment are being used.

2. All construction-vehicle movement outside of the right-of-way would be restricted to predesignated access, or public roads. 
3. The areal limits of construction activities would be predetermined, with activity restricted to and confined within those limits. No paint or permanent discoloring agents would be applied to rocks or vegetation to indicate survey or construction activity limits.

4. Hazardous materials would not be drained onto the ground or into streams or drainage areas. Totally enclosed containment would be provided for all trash. All construction waste including trash and litter, garbage, other solid waste, petroleum products, and other potentially hazardous materials would be removed to a disposal facility authorized to accept such materials.

5. The two regeneration sites and construction activity sites (e.g., pulling and splicing areas) be clearly marked or flagged at the outer limits prior to the onset of any surface-disturbing activity. All personnel would be informed that their activities must be confined to within the marked or flagged areas. All construction and activity sites would be surveyed by qualified tortoise biologists no more than 15 days prior to the initiation of construction. Surveys would provide 100 percent coverage of the entire construction area. Any desert tortoise burrows located would be conspicuously flagged or marked, and avoided.

6. Procedures for handling, holding, or relocating tortoises from the right-of-way would follow the most current procedures established by the FWS and BLM.

Listed below are measures that would minimize predation on tortoises by ravens drawn to construction areas or by unleashed dogs brought to construction areas.

7. To prevent mortality, injury, and harassment of desert tortoises and damage to their burrow and coversite, no pets would be permitted in any project construction area unless confined or leashed.

8. Totally enclosed, raven-proof, containment would be provided for all trash.

Listed below are measures that would minimize disturbance of desert tortoise habitat, such as soil compaction, erosion, or crushed vegetation, due to construction or maintenance activities.

9. No widening or upgrading of existing access roads would be undertaken in the area of construction, except for repairs necessary to make roads passable. There would be no blading of new access roads.

10. A biologist would be assigned to the pre-construction survey team(s). The biologist would be responsible for ensuring that all work areas (e.g. splicing, pulling sites, trenched areas) would also be surveyed by a biologist as construction proceeds. Potential work areas would be flagged several days prior to construction for review by a biologist. All tortoise burrows (or other shelter sites) would be avoided.

11. Overnight parking and storage of equipment and material would be in previously disturbed areas (i.e., lacking vegetation). These areas would also be designated by the pre-construction survey team. 
12. No blading of splicing and tensioning sites would occur. Construction workers would strictly limit their activities and vehicles to construction areas and routes of travel which have been flagged to eliminate adverse impacts to desert tortoises and their habitat. Aside from these areas, workers may not drive cross-country even within the right-of-way. All workers would be instructed that their activities are restricted to flagged and cleared areas.

The following measures would be taken to ensure compliance with measures:

13. Western would designate a field contact representative (FCR). The FCR would be responsible for overseeing compliance with protective stipulations for the desert tortoise and for coordination on compliance with the Western. The FCR would have the authority to halt activities of construction equipment which may be in violation of the stipulations.

14. All construction personnel would participate in a tortoise-education program. The program would be developed by Western prior to the beginning of construction. The program would be submitted to the FWS for review and approval prior to implementation. The program would include, at a minimum, the following topics: (a) the occurrence of desert tortoises, (b) the sensitivity of the species to human activities, $\mathcal{O}$ legal protection for desert tortoises, (d) penalties for violations of federal and state laws, (e) general tortoise activity patterns, (f) reporting requirements, (g) measures to protect tortoises, and (h) personal measures employees can take to promote the conservation of desert tortoises.

15. The FWS would be notified of any tortoise death or injury caused by project activities. Notification would include the date, time, circumstances, and location of any injury or death. Dead animals may be marked and left on site. Injured animals would be transported to a qualified veterinarian. The FWS would furnish direction on the final disposition of tortoises taken to a veterinarian.

16. No later than 90 days after completion of construction within tortoise habitat, the FCR and on-site biologist would prepare a report for Western and FWS. The report would document the effectiveness of the tortoise mitigation measures. The report would include an assessment of the any habitat disturbance.

\subsection{LEVEL OF TAKE}

Based on an analysis of impacts, the proposed mitigation measures, estimates of population densities of tortoises in the Piute-Eldorado DWMA, anticipated project duration in Nevada, and time-of-year of construction, it is anticipated that the following take could occur as a result of the proposed action:

1. One desert tortoise may be accidently injured or killed by vehicles or equipment during development and maintenance of the OPGW.

2. Five desert tortoises may be harassed by removal from the boundaries of the OPGW right-ofway. 


\subsection{LITERATURE CITED}

American Ornithologists Union. 1983. Checklist of the Birds of North America. Sixth Edition. Allen Pres, Lawrence, Kansas. 877 pp.

Anderson, B.W. and R.D. Ohmart. 1985. Habitat Use by Clapper Rails in the Lower Colorado River Valley. Condor 87:116-136.

Arizona Game \& Fish Department (AGFD). 1988. Threatened Native Wildlife in Arizona. Arizona Game \& Fish Department Publication, Phoenix, Arizona. 32 pp.

Berry, K. and L. Humphreys. 1984. The Distribution and Density of Desert Tortoise populations in California in the 1970's. Pp 26-60 In K. Berry, Ed. the Status of the Desert Tortoise (Gopherus agassizi) in the United States. Report to FWS from the Desert Tortoise Council. Order No. 113100083-81.

Busch, D.E. 1988. Bald Eagle. Pages 57-64 in R.L. Glinski et al., eds. Proceedings of the Southwest Raptor Management Symposium and Workshop. National Wildlife Federation, Washington, D.C.

California Department of Fish \& Game (CDFG). 1994. State and federal endangered and threatened animals of California and listing dates. The Resources Agency, California Fish \& Game, Sacramento, California.

1990. 1989 Annual report on the status of California's state listed threatened and endangered plants and animals. The Resources Agency, California Fish \& Game, Sacramento, California. March 1990.

. 1980. At the crossroads-A report on California's endangered and rare fish and wildlife. California Fish \& Game, Sacramento, California.

E. Linwood Smith and Associates. 1987. Biological Assessment, Threatened and Endangered Species, Palo Verde to Devers 500kV Transmission Line 2. Submitted by Bureau of Land Management, Riverside, California.

Ellis, D.H. 1982. The Peregrine Falcon in Arizona: Habitat Utilization and Management Recommendations. Institute for Raptor Studies Research Report No. 1. Oracle, Arizona. 24 pp.

Hoover, K.H. 1978. Introduction to: Impacts of Transmission Lines on Birds in Flight. A proceedings. Oak Ridge Associated Universities. Sponsored by U.S.D.I., Fish and Wildlife Services.

Johnsgard, P. A. 1990. Hawks, Eagles, and Falcons of North America. Smithsonian Institution Press, Washington and London. 403 pp.

Minckley, W.L. 1973. Fishes of Arizona. A publication of the Arizona Game \& Fish Department. Sims Printing Co. Phoenix, Arizona. 293 pp. 
Monson, G. and A. R. Phillips. 1981. Annotated Checklist of the Birds of Arizona. University of Arizona Press, Tucson. $240 \mathrm{pp}$.

National Geographic Society. 1987. Field Guide to the Birds of North America. Second edition. National Geographic Society, Washington D.C. 464 pp.

Ohmart, R.D. and R.W. Smith. 1973. North American Clapper Rail (Rallus longirostris) Literature Survey consideration Being Given to the Past and Current Status of yumanensis. In fulfillment U.S. Bureau of Reclamation contract No. 14-06-300-2409. Yuma, Arizona.

Olson, N. 1996. Letter from Nancy Olson, Project Biologist, Arizona Game and Fish Department, to Karim Dada, Western Area Power Administration, Phoenix, Arizona. October 28.

Phillips, A.R., J. Marshall, and G. Monson. 1964. The Birds of Arizona. The University of Arizona Press, Tucson. $212 \mathrm{pp}$.

Rosenberg, K.V., R.D. Ohmart, W.C. Hunter, and B.W. Anderson. 1991. Birds of the Lower Colorado River Valley. The University of Arizona Press, Tucson. 416 pp.

Smith, P.M. 1974. Yuma Clapper Rail Study, Mohave County, Arizona. California Department of Fish and Game. Wildlife Management Branch Administrative Report No. 75-2.

Stebbins, R.C. 1985. A Field Guide to Western Reptiles and Amphibians. Sponsored by the National Audubon Society. Houghton-Mifflin Co: Boston. 179pp.

Tomlinson, R.E. and R.L. Todd. 1973. Distribution of Two Western Clapper Rail Races as Determined by Responses to Taped Calls. Condor 75:177-183.

Turner, R.M. and D.E. Brown. 1982. Sonoran Desertscrub. Pp. 181-221 in D.E. Brown (ed). Biotic Communities of the American Southwest-United States and Mexico. Desert Plants 4(1-4).

Turner, F. and K. Berry. 1984. Population Ecology of the Desert Tortoise. Report to Southern California Edison Company.

U.S. Bureau of Reclamation (USBR). 1996. Description and Assessment of Operations, Maintenance, and Sensitive Species of the Lower Colorado River; Final Biological Assessment. Prepared for U.S. Fish and Wildlife Service and Lower Colorado River Multi-Species Conservation Program. August.

U.S. Fish and Wildlife Service (FWS). 1995. Endangered and Threatened Wildlife and Plants; Final Rule Determining Endangered Status for the Southwestern Willow Flycatcher. Federal Register 60:10694.

. 1994a. Endangered and Threatened Wildlife and Plants; Determination of Critical habitat for the Mojave Population of the Desert Tortoise. Federal Register 59:5820. 
U.S. Fish and Wildlife Service (FWS). 1994b. Desert tortoise (Mojave population) Recovery Plan. U.S. Fish \& Wildlife Service, Portland, Oregon. 73pp. plus appendices.

1994c. Endangered and Threatened Wildlife and Plants; Determination of Critical Habitat for the Colorado River Endangered Fishes: Razorback Sucker, Colorado Squawfish, Humpback Chub, and Bonytail Chub. Federal Register 59:13374.

1991. Endangered and Threatened Species of Arizona. Phoenix. 102pp.

1990. Endangered and Threatened Wildlife and Plants; Determination of Threatened Status for the Mojave Population of the Desert Tortoise. Federal Register 55:12178.

Willard, D.E., J.T. Harris and M.J. Jaeger. 1977. The Impact of a 500kV Transmission Route on Waterfowl and Other Birds. Public Utility Commission, Salem, Oregon. 89 pp.

Woodbury, A. and R. Hardy. 1948. Studies of the Desert Tortoise (Gopherus agassizii). Ecological Monograph 18:145-200. 



\section{APPENDIX E BIOLOGICAL OPINION}





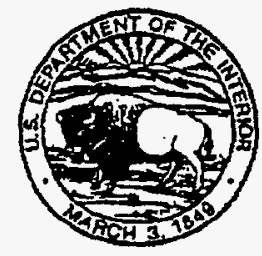

\title{
United States Department of the Interior
}

\author{
FISH AND WILDLIFE SERVICE \\ NEVADA STATE OFFICE \\ 4600 KIETZKE LANE, SUITE $125 \mathrm{C}$ \\ RENO, NEVADA 89502-5055
}

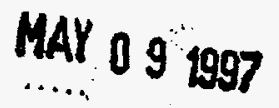

File No. 1-5-97-F-119

J. Tyler Carlson, Regional Manager

Western Area Power Administration

Desert Southwest Customer Service Region

Post Office Box 6457

Phoenix, Arizona 89502-5055

Dear Mr. Carison:

Subject: Biological Opinion for the McCullough to Liberty Fiber Optics Project

The U.S. Fish and Wildlife Service has reviewed your request for initiation of formal consultation on the Western Power Administration's (Western) and the Bureau of Reclamation's

(Reclamation) installation, operation, and maintenance of an optical ground wire and its ancillary facilities between the McCullough Substation near Boulder City, Nevada, and the Liberty Substation near Phoenix, Arizona. Your January 29, 1997, request for formal consultation was received on January 30,1997 . The Service requested additional information necessary to complete consultation on February 21, 1997, and received that information on March 24, 1997. The Service initiated formal consultation on March 24, 1997. This document represents the Service's biological opinion on the effects of the proposed action on the threatened desert tortoise (Gopherus agassizii) and its critical habitat (CH) in accordance with section 7 of the Endangered Species Act of 1973, as amended (Act) (16 U.S.C. 1531 et seq.).

Reclamation has the right-of-way for the transmission lines in which the optic ground wire will be attached, and Western has an interagency agreement with Reclamation to manage the transmission lines. Reclamation has applied to the Bureau of Land Management (Bureau) for a right-of-way amendment to construct three regeneration stations and two electrical distribution lines. Therefore, the Bureau and Reclamation have agreed that Western will be the lead Federal agency for this biological opinion.

Western has determined that the proposed action is not likely to adversely affect the endangered American peregrine falcon (Falco peregrimus anatum), Yuma clapper rail (Rallus longirostris), Southwestern willow flycatcher (Empidonox traillii extimus), razorback sucker (Xyrauchen texanus), bonytail chub (Gila elegans) and threatened bald eagle (Haliaeetus leucocephalus). 
The Service concurs with this finding. Our concurrence is based on the following:

(1) Construction activities will not occur within 0.5 -miles of known or potential peregrine falcon or bald eagle nesting habitat; (2) construction activities will not result in damage to Yuma clapper rail habitat along the Colorado River, (3) construction activities will not result in the damage of Southwestern willow flycatcher habitat along the Colorado or Bill Williams Rivers;

(4) construction activities will not occur adjacent to Southwestem willow flycatcher habitat between April 1 and September 1; and (5) construction activities will not result in the damage of razorback sucker or bonytail chub habitat in the Colorado River. Therefore, these species will not be addressed in this biological opinion.

This biological opinion is based on information provided in Western's correspondence dated January 29, 1997 and March 21, 1997; Reclamation's correspondence dated April 17, 1997; Bureau's correspondence dated April 11, 1997 and April 18, 1997; a biological assessment dated January, 1997; conversations with Western, the Bureau, and Dames and Moore staffs; and our files. A complete administrative record of this consultation is on file in the Las Vegas Office.

\section{Description of the Proposed Action}

Western and Reclamation jointly propose to install, operate, and maintain an optical ground wire and its ancillary facilities between the McCullough Substation near Boulder City, Nevada, and the Liberty Substation near Phoenix, Arizona (Figure 1). Western proposes to replace an existing overhead static wire on Reclamation transmission lines with an overhead static wire containing fiber optics known as an optical ground wire. The main trunk of the optical ground wire will be approximately 243 miles in length, with an additional 32 miles of lateral optic ground wire connecting the trunk line with Reclamation pumping facilities. The optic ground wire will be attached to the following three 230 kilovolt transmission line segments: (1) McCullough-Davis Segment (62 miles); (2) Parker-Davis No. 2 Segment (68 miles); and (3) Parker-Liberty No. 1 Segment (113 miles). Only the 62-mile McCullough-Davis transmission line segment is in desert tortoise habitat ( 45 miles in $\mathrm{CH}$ ) (Figure 2).

Western estimates that a total of 2.05 acres of desert tortoise habitat, including 0.83 -acres of $\mathrm{CH}$ will be disturbed during the installation of the optic ground wire and construction of the Searchlight regeneration station. The burying of 1,650 feet of optic ground wire will result in the disturbance of 0.38 -acres of desert tortoise habitat. Two regeneration stations, the McCullough and Searchlight regeneration stations will be constructed along the McCullough-Davis transmission line segment (Figure 2). The McCullough regeneration station is located in previously disturbed desert tortoise habitat, and construction of the Searchlight regeneration station will result in the disturbance of 0.52 -acres of desert tortoise habitat. Twenty-five splicing 


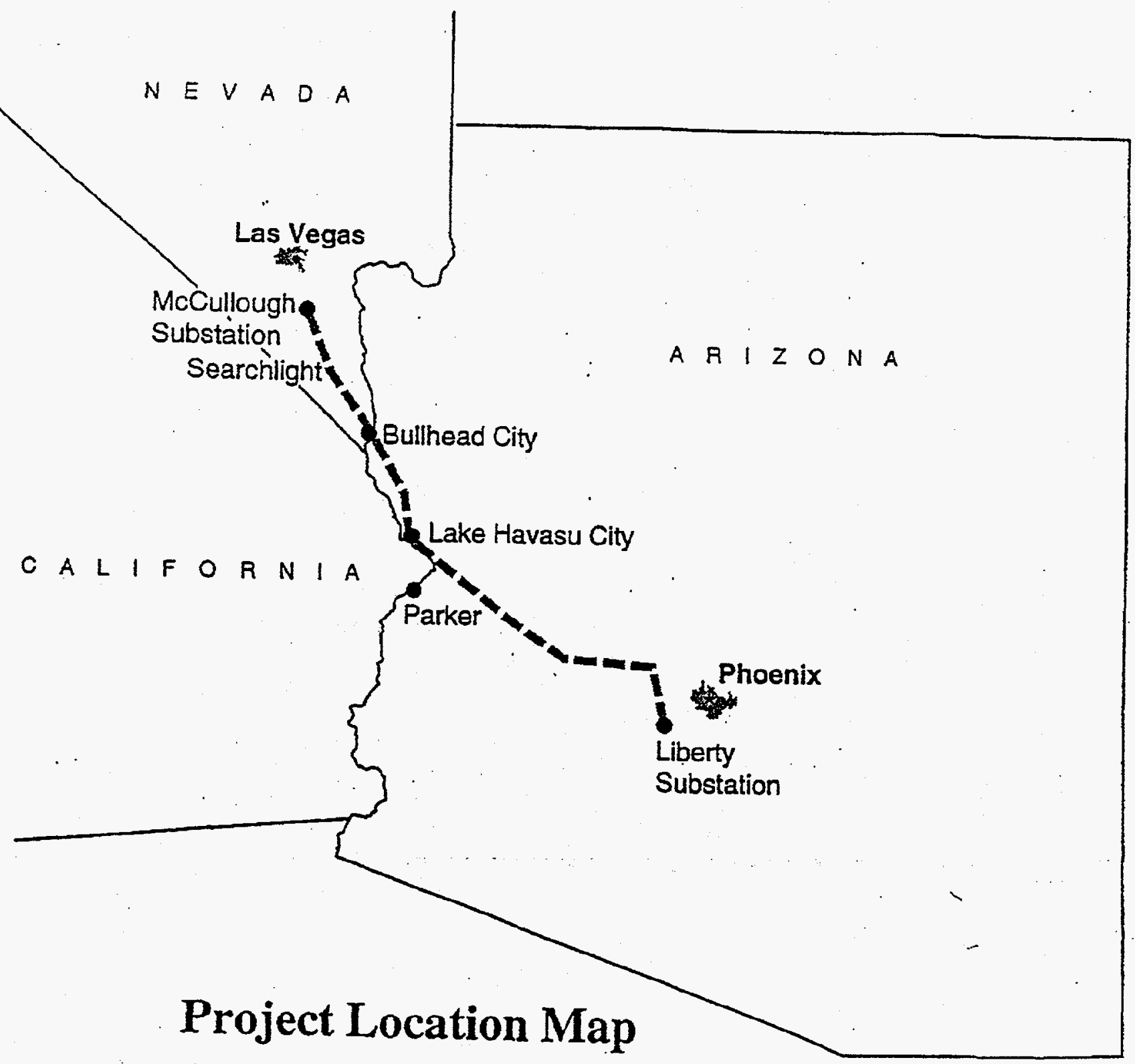

\section{McCullough to Liberty Optical Ground Wire}

Figure 1 



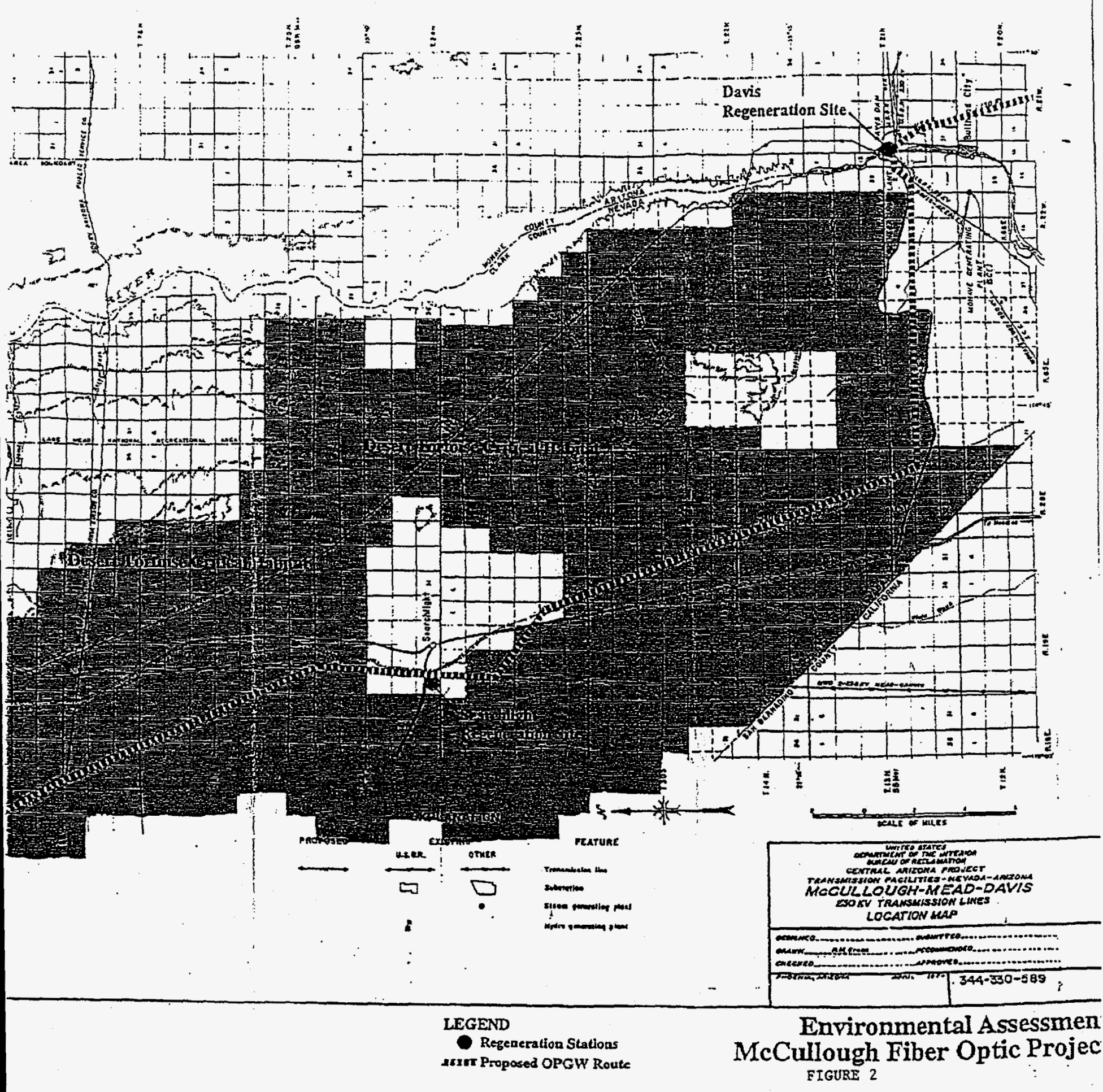



and pulling sites will be established along the transmission line segment. These sites will result in the disturbance of 1.15 acres of desert tortoise habitat (0.83-acres in $\mathrm{CH})$. Each generation station will be connected with the main trunk by a buried optic ground wire.

Western proposes the following measures to minimize effects to desert tortoises from the installation, operation, and maintenance of optical ground wire (Dames and Moore 1997):

1. A tortoise biologist would be present during all construction activities where one or more pieces of heavy construction equipment are being used.

2. All construction-vehicle movement outside of the right-of-way would be restricted to predesignated access, or public roads.

3. The area limits of construction activities would be predetermined, with activity restricted to and confined within those limits. No paint or permanent discoloring agents would be applied to rocks or vegetation to indicate survey or construction activity limits.

4. Hazardous materials would not be drained onto the ground or into streams or drainage areas. Totally enclosed containment would be provided for all trash. All construction waste including trash and litter, garbage, other solid waste, petroleum products, and other potentially hazardous materials would be removed to a disposal facility authorized to accept such materials.

5. The two regeneration sites and construction activity sites (e.g., pulling and splicing areas) would be clearly marked or flagged at the outer limits prior to the onset of any surfacedisturbing activity. All personnel would be informed that their activities must be confined to within the marked or flagged areas. All construction and activity sites would be surveyed by qualified tortoise biologists no more than 15 days prior to the initiation of construction. Surveys would provide 100 -percent coverage of the entire construction area. Any desert tortoise burrows located would be conspicuously flagged or marked, and avoided.

6. Procedures for handling, holding, or relocating tortoises from the right-of-way would follow the most current procedures established by the Service and Bureau.

7. To prevent mortality, injury, and harassment of desert tortoises and damage to their burrows and coversites, no pets would be permitted in any project construction area unless confined or leashed. 
8. Totally enclosed, raven-proof, containment would be provided for all trash.

9. No widening or upgrading of existing access roads would be undertaken in the area of construction, except for repairs necessary to make roads passable. There would be no blading of new access roads.

10. A biologist would be assigned to the pre-construction survey team(s). The biologist would be responsible for ensuring that all work areas (e.g., splicing, pulling sites, trenched areas) would also be surveyed by a biologist as construction proceeds. Potential work areas would be flagged several days prior to construction for review by a biologist. All tortoise burrows (or other shelter sites) would be avoided.

11. Overnight parking and storage of equipment and material would be in previously disturbed areas (i.e., lacking vegetation). These areas would also be designated by the preconstruction survey team.

12. No blading of splicing and tensioning sites would occur. Construction workers would strictly limit their activities and vehicles to construction areas and routes of travel which have been flagged to eliminate adverse impacts to desert tortoises and their habitat. Aside from these areas, workers may not drive cross-country even within the right-of-way. All workers would be instructed that their activities are restricted to flagged and cleared areas.

13. Western would designate a field contact representative (FCR). The FCR would be responsible for overseeing compliance with protective stipulations for the desert tortoise and for coordination on compliance with Western. The FCR would have the authority to halt activities of construction equipment which may be in violation of the stipulations.

14. All construction personnel would participate in a tortoise-education program. The program would be developed by Westem prior to the beginning of construction. The program would be submitted to the Service for review and approval prior to implementation. The program would include, at a minimum, the following topics: (a) The occurrence of desert tortoises; (b) the sensitivity of the species to human activities; (c) legal protection for desert tortoises; (d) penalties for violations of Federal and State laws; (e) general tortoise activity patterns; (f) reporting requirements; (g) measures to protect tortoises; and $(h)$ personal measures employees can take to promote the conservation of desert tortoises. 
15. The Service would be notified of any tortoise death or injury caused by project activities. Notification would include the date, time, circumstances, and location of any injury or death. Dead animals may be marked and left onsite. Injured animals would be transported to a qualified veterinarian. The Service would furnish direction on the final disposition of tortoises taken to a veterinarian.

16. No later than 90 days after completion of construction within tortoise habitat, the FCR and onsite biologist would prepare a report for Western and the Service. The report would document the effectiveness of the tortoise mitigation measures. The report would include an assessment of any habitat disturbance.

\section{Status of the Specier/Environmental Baseline}

The desert tortoise, a large, herbivorous reptile, is generally active when annual plants are most common (spring, early summer, autumn). Desert tortoises usually spend the remainder of the year in sheltered sites, escaping the extreme weather conditions of the desert. Sheltering habits of desert tortoises vary greatly in different geographic locations. Sheiter sites may be located under bushes, in the banks or beds of washes, in rock outcrops, or in caliche caves. The size of desert tortoise home ranges varies with respect to location and year. Females have long-term home ranges that are approximately half that of the average male, which range from 25 to 200 acres (Berry 1986). Further information on the range, biology, and ecology of the desert tortoise can be found in Berry and Burge (1984); Burge (1978); Burge and Bradley (1976); Bury, et al., (1994); Germano, et al., (1994); Hovik and Hardenbrook (1989); and Karl (1981, 1983a, 1983b).

The range of the Mojave population of the desert tortoise includes a portion of the Mojave Desert and the Colorado Desert subdivision of the Sonoran Desert and spans portions of four States. The Mojave Desert is located in southem Califomia, southern Nevada, northwestern Arizona, and southwestern Utah. It is bordered on the north by the Great Basin Desert, on the west by the Sierra Nevada and Tehachapi Ranges, on the south by the San Gabriel and San Bernardino Mountains and the Colorado Desert, and on the east by the Grand Wash Cliffs and Hualapai Mountains of Arizona. In Nevada, the native range of this species is generally restricted to Clark County and those portions of Nye and Lincoln Counties south of 37 degrees North latitude and below approximately 1,330 meters elevation $(4,000$ feet).

The desert tortoise is most commonly found within the desert scrub vegetation type, primarily in creosote bush scrub vegetation, but also in succulent scrub, cheesebush scrub, blackbush scrub, hopsage scrub, shadscale scrub, microphyll woodland, and Mojave saltbush-allscale scrub (Service 1994). Within these vegetation types, desert tortoises potentially can survive and 
reproduce where their basic habitat requirements are met. Throughout most of the Mojave region, tortoises occur most commoniy on gently sloping terrain with soils ranging from sand to sandy-gravel and with scattered shrubs, and where there is abundant inter-shrub space for growth of herbaceous plants. Throughout their range, however, tortoises can be found in steeper, rockier areas. In Nevada, tortoises are considered to be active from March 1 through October 31.

The Desert Tortoise (Mojave population) Recovery Plan (Recovery Plan) (Service 1994) estimates that the proposed Piute-Eldorado Desert Wildlife Management Area (DWMA) supports population densities of 40 to 90 adult tortoises per square mile. The McCullough-Davis transmission line traverses the Piute-Eldorado DWMA.

Vegetation along the McCullough-Davis transmission line is representative of the Mojave Desert. Dominant perennial species are creosote bush (Larrea tridentata) and white bursage (Ambrosia dumosa). Other species include silver cholla (Opuntia echinocarpa), ratany (Krameria spp.), joshua tree (Yucca brevifolia), mohave yucca (Yucca schidigera), and Nevada joint-fir (Ephedra nevadensis). Existing disturbance in the vicinity of the McCullough-Davis transmission line includes a natural gas pipeline, numerous dirt roads, State Route 163, and U.S. Highway 95. The transmission line passes within 1 mile of Searchlight, Nevada.

\section{Programmatic Consultation on the Las Vegas Valley}

On September 26, 1996, the Service issued a programmatic biological opinion (File No. 1-5-91F-1 12) to the Bureau's Las Vegas District for implementation of their Management Framework Plan (MFP) within the boundaries of Clark County's incidental take permit in the Las Vegas Valley. As a result of the action, approximately 42,240 acres of Bureau land were authorized for disposal by sale, exchange, mineral leases, rights-of-way leases, or recreation or public purpose leases. These lands could be developed for residential, industrial, commercial, and public infrastructure projects to accommodate rapid urban development. The biological opinion concluded that the proposed action to implement the Bureau's MFP was not likely to jeopardize the continued existence of the Mojave population of the desert tortoise; no $\mathrm{CH}$ would be destroyed or adversely modified. The Bureau has currently disposed of 5,252 acres out of the 42,240 acres originally identified.

On April 11, 1996, the Service issued a programmatic biological opinion (File No. 1-5-96-F-23R) to the Bureau's Las Vegas District for implementation of their MFP and the land exchange portion of their Stateline Resource Management Plan within the Las Vegas Valley. Implementation of these plans, when finalized, may result in disposal or development of approximately 125,000 acres of land administered by the Bureau by sale, land exchange, or lease. 
Consultation was reinitiated on the 1991 biological opinion to expand the programmatic area from 263,267 acres to 378,978 acres to accommodate the rapid urban development in the Las Vegas Valley and surrounding area. As a result of urban expansion, most Bureau lands within the Las Vegas Valley are highly fragmented and impacted by human activities, particularly a 4,000acre "exclusionary" zone. The Bureau delineated an exclusionary zone within the programmatic boundary which does not contain suitable desert tortoise habitat. Except for lands within the exclusionary zone, the Bureau will collect a fee of $\$ 550.00$ per acre to compensate for the loss of tortoise habitat within the programmatic boundary. The fees will be used to fund management actions which are expected to provide direct and indirect benefits to the desert tortoise over time which will assist in its recovery. The proposed $\mathrm{McCullough}$ regeneration station occurs approximately 10 miles south of the programmatic boundary.

\section{Listing and Recovery Actions}

On April 2, 1990, the Service determined the Mojave population of the desert tortoise to be threatened (55 EB 12178). The Mojave population includes those animals living north and west of the Colorado River in the Mojave Desert of California, Nevada, Arizona, southwestern Utah, and in the Colorado Desert in California (a division of the Sonoran Desert). Reasons for the determination included loss of habitat from construction projects such as roads, housing and energy developments, and conversion of native habitat to agriculture. Grazing and off-highway vehicle activities have degraded additional habitat. Also cited as threatening the desert tortoise's continuing existence were illegal collection, upper respiratory tract disease, and predation on juvenile desert tortoises by common ravens (Corvus corax).

On February 8, 1994, the Service designated approximately 6.4 million acres of $\mathrm{CH}$ for the Mojave population of the desert tortoise ( $59 \mathrm{~EB} 45748$ ), which became effective on March 10, 1994. Critical habitat units (CHUs) are based on recommendations for DWMAs outlined in the Recovery Plan. Because the CHU boundaries were drawn to optimize reserve design, the CHUs may contain both "suitable" and "unsuitable" habitat. Suitable habitat generally can be defined as areas that provide the constituent elements of nesting, sheltering, foraging, dispersal, and/or gene flow. The regulation of activities within $\mathrm{CH}$ through section 7 (of the Act) consultation will be based on recommendations in the Recovery Plan. The proposed project traverses 45 miles of desert tortoise $\mathrm{CH}$.

The Recovery Plan divides the range of the desert tortoise into 6 distinct population segments, or recovery units (RUs), and recommends establishment of 14 DWMAs throughout the RUs. Within each DWMA, the Recovery Plan recommends implementation of reserve-level protection of desert tortoise populations and habitat, while maintaining and protecting other sensitive species 
and ecosystem functions. The design of DWMAs should follow accepted concepts of reserve design. As part of the actions needed to accomplish recovery, land management within all DWMAs should restrict human activities that negatively impact desert tortoises (Service 1994). DWMAs will be designated by the Bureau through the resource management plan. The proposed fiber optic line traverses the Northeastern Mojave and the Eastern Mojave RUs and the proposed Piute-Eldorado DWMA.

The Northeastern Mojave RU occurs primarily in Nevada, but it also extends into California along the Ivanpah Valley and into extreme southwestern Utah and northwestern Arizona. Vegetation within this unit is characterized by creosote bush scrub, big galleta-scrub steppe, desert needlegrass scrub-steppe, and blackbrush scrub (in higher elevations). Topography is varied, with flats, valleys, alluvial fans, washes, and rocky slopes. Much of the northern portion of the RU is characterized as basin and range, with elevations from 2,500 to 12,000 feet. Desert tortoises typically eat summer and winter annuals, cacti, and perennial grasses. Desert tortoises in this RU, the northern portion of which represents the northernmost distribution of the species, are typically found in low densities (approximately 10 to 20 adults per square mile).

The Eastern Mojave RU, located primarily in California, extends into Nevada in the Amargosa, Pahrump, and Piute Valleys. It lies directly to the north of the Northern Colorado RU, with the western bank of the Colorado River as an eastern boundary. This RU is isolated from the Western Mojave RU by the Baker Sink, where desert tortoises do not occur. Vegetation within the eastern portion of this unit is transitional between the Colorado Desert and the Mojave Desert communities and is represented by big galleta-scrub steppe, succulent scrub (Yucca, Opuntia species), creosote bush scrub, cheesebush scrub (east Mojave type), and Indian rice grass scrubsteppe. Desert tortoises are active here in the spring and in late summer/early autumn because this region receives both winter and summer rains, resulting in two distinct annual floras on which tortoises can feed. These desert tortoises occupy a variety of vegetation types and feed on summer and winter annuals, cacti, perennial grasses, and herbaceous perennials. Topography is characterized by flats, valleys, alluvial fans, washes, and rocky slopes. Elevations range from 1,600 to 4,900 feet. Desert tortoises generally den singly in caliche caves, on alluvial fans, and in washes. Current population densities within the RU are patchy and varied, with pockets of high densities ( 5 to 350 tortoises per square mile, with an average density of 25 adult tortoises per square mile). 


\section{Habitat Conservation Plans}

On May 23, 1991, the Service issued a biological opinion on the issuance of incidental take permit PRT-756260 (File No. 1-5-91-FW-40) under section 10(a)(1)(B) of the Act. The Service concluded that incidental take of 3,710 desert tortoises on up to 22,352 acres of habitat within the Las Vegas Valley and Boulder City in Clark County, Nevada, was not likely to jeopardize the continued existence of the desert tortoise. The permit application was accompanied by the ShortTerm Habitat Conservation Plan for the Desert Torioise in the Las Vegas Valley, Clark County, Nevada (Regional Environmental Consultants 1991) (short-term HCP) and an implementation agreement that identified specific measures to minimize and mitigate the effects of the action on desert tortoises.

On July 29, 1994, the Service issued a non-jeopardy biological opinion on the issuance of an amendment to incidental take permit PRT-756260 (File No. 1-5-94-FW-237) to extend the expiration date of the existing permit by 1 year (to July 31,1995 ) and include an additional disturbance of 8,000 acres of desert tortoise habitat within the existing permit area. The amendment did not authorize an increase in the number of desert tortoises allowed to be taken under the existing permit. Additional measures to minimize and mitigate the effects of the amendment were also identified. Approximately 1,300 desert tortoises were taken under the authority of PRT-756260, as amended. In addition, during the short-term HCP, as amended, approximately 541,000 acres of desert tortoise habitat have been conserved in Clark County on lands administered by the Bureau and National Park Service.

On July 11, 1995, the Service issued an incidental take permit (PRT-801045) to Clark County, Nevada, including cities within the county and the Nevada Department of Transportation (NDOT), under the authority of section $10(\mathrm{a})(1)(\mathrm{B})$ of the Act. The permit became effective August 1, 1995, and allows the "incidental take" of desert tortoises for a period of 30 years on 111,000 acres of non-Federal land and approximately 2,900 acres associated with NDOT activities in Clark, Lincoln, Esmeralda, Mineral, and Nye Counties, Nevada. The Clark County Desert Conservation Plan (CCDCP) (Regional Environmental Consultants 1995), serves as the permittees' habitat conservation plan and details their proposed measures to minimize, monitor, and mitigate the effects of the proposed take on the desert tortoise. The permittees will impose, and the NDOT will pay, a fee of $\$ 550.00$ per acre of habitat disturbance to fund these measures. The permittees will expend $\$ 1.35$ million per year, and up to $\$ 1.65$ million per year for the first 10 years, to minimize and mitigate the potential loss of desert tortoise habitat. It is anticipated that the majority of these funds will be used to implement mitigation measures, such as increased law enforcement; construction of highway barriers; road designation, signing, closure, and rehabilitation; and tortoise inventory and monitoring. The benefit to the species as provided by 
the CCDCP should substantially minimize and mitigate those effects which will occur through development within the permit area and aid in recovery of the desert tortoise. The proposed McCullough regeneration station and 1,350 feet of buried fiber optic line would be within the incidental take permit area and within lands owned by Boulder City, but under a Bureau right-ofway issued to Reclamation, therefore, not covered by the section $1 O(a)(1)(B)$ permit.

\section{Effects of the Proposed Action on the Listed Species}

Desert tortoises may be harassed through removal from the project area; killed or injured crossing access roads. Vehicles that stray from the project area and roads may crush desert tortoises above ground or in their burrows. Desert tortoises may become entrapped in trenches if left open. Measures proposed by Western to: (1) Require a desert tortoise biologist onsite during construction; (2) confine vehicle travel to designated areas; (3) confine construction activities to designated areas; (4) flag or mark construction areas; (5) prohibit widening or upgrading of existing access roads; (6) assign a biologist to a pre-construction team; (7) confine overnight parking and storage of equipment to previously disturbed areas; and (8) prohibit blading of splicing and tensioning sites should minimize these effects.

Additional harassment may occur from increased levels of human activity, noise, and ground vibrations produced by vehicles and heavy equipment (Bondello 1976, Bondello, et al. 1979); attraction of ravens to the area if trash is not removed immediately (Berry 1985, Bureau 1990); and capture of tortoises by workers for use as pets. Minimization measures proposed by Western to implement tortoise education and litter-control programs should minimize these effects.

Project-related activities may result in the take of two (2) desert tortoises through death or injury during installation of the optic ground wire and construction of the Searchlight regeneration station. An additional two (2) tortoises may be accidentally killed or injured per year on access roads used for maintenance. In addition, five (5) tortoises may be captured and moved out of harm's way during installation of the optic ground wire and construction of the Searchlight regeneration station, and two (2) tortoises per year may be captured and moved out of harm's way on access roads used for maintenance. Up to 2.05 acres of desert tortoise habitat, including 0.83 -acres of $\mathrm{CH}$, may be disturbed as a result of the installation of the optic ground wire and construction of the Searchlight regeneration station. 


\section{Cumulative Effects}

Cumulative effects are those effects of future non-Federal (State, local government, or private) activities that are reasonably certain to occur in the project area considered in this biological opinion. Future Federal actions that are unrelated to the proposed action are not considered in this section because they require separate consultation pursuant to section 7 of the Act.

The areas surrounding the proposed optic ground wire are administered by the Bureau and Boulder City, Nevada. Actions on the Federal lands will be subject to consultation under section 7 of the Act. It is expected that most future non-Federal actions in Clark County will fall under purview of the CCDCP and the associated incidental take permit until 2025.

\section{Conclusion}

After reviewing the current status of the desert tortoise, the environmental baseline for the project area, the effects of the proposed action and the cumulative effects, it is the Service's biological opinion that the installation, operation, and maintenance of an optic ground wire is not likely to result in jeopardy to the species or destruction or adverse modification of $\mathrm{CH}$.

The Service reached this conclusion for the following reasons:

(1) The proposed Searchlight regeneration station does not occur within any area recommended for recovery of the desert tortoise and is not in $\mathrm{CH}$;

(2) the optic ground wire is being installed on an existing transmission line which has an existing access road; and

(3) effects on desert tortoises within the project area represent a small impact to the Mojave population of the desert tortoise when total desert tortoise population numbers and geographical extent are considered.

\section{Incidental Take}

Section 9 of the Act, as amended, prohibits take (harass, harm, pursue, hunt, shoot, wound, kill, trap, capture or collect, or attempt to engage in any such conduct) of listed species of fish or wildlife without a special exemption. "Harm" is further defined to include significant habitat modification or degradation that results in death or injury to listed species by significantly impairing behavioral patterns such as breeding, feeding, or sheltering (50 CFR $\S 17.3$ ). "Harass" 
is defined as actions that create the likelihood of injury to listed species to such an extent as to significantly disrupt normal behavior patterns which include, but are not limited to, breeding, feeding, or sheltering ( $50 \mathrm{CFR} \S 17.3$ ). Incidental take is any take of listed animal species that results from, but is not the purpose of, carrying out an otherwise lawful activity conducted by the Federal agency or applicant. Under the terms of sections 7(b)(4) and 7(o)(2) of the Act, taking that is incidental to and not intended as part of the agency action is not considered a prohibited taking provided that such taking is in compliance with the terms and conditions of this incidental take statement.

The Service hereby incorporates by reference Western's 16 minimization measures from the Description of the Proposed Action into this incidental take statement as part of these terms and conditions. The following terms and conditions: (1) Restate measures proposed by Western, (2) modify measures proposed by Western, or (3) specify additional measures considered necessary by the Service. Where these terms and conditions vary from or contradict the measures proposed under the Description of the Proposed Action, specifications in these terms and conditions shall apply. The measures described below are nondiscretionary and must be implemented by Wester, so that they become binding conditions of any grant or permit issued to the applicant, as appropriate, in order for the exemption in section 7(0)(2) to apply.

Western has a continuing duty to regulate the activity that is covered by this incidental take statement. If Western fails to require the applicant to adhere to the terms and conditions of the incidental take statement through enforceable terms that are added to the permit or grant document, and/or fails to retain oversight to ensure compliance with these terms and conditions, the protective coverage of section $7(0)(2)$ may lapse.

\section{Amount of Take}

Based on the analysis of impacts provided above, remuneration measures proposed by Western, and anticipated project duration, the Service anticipates that the following take could occur as a result of the proposed action:

1. Two (2) desert tortoises may be accidentally injured or killed during installation of the optic ground wire and construction of the Searchlight regeneration station. In addition, two (2) tortoises may be accidentally injured or killed per year during use of access roads for maintenance. 
2. Five (5) desert tortoises may be taken by capture and movement out of harm's way during installation of the optic ground wire and construction of the Searchlight regeneration station. In addition, two (2) desert tortoises may be taken per year by capture and movement out of harm's way during use of access roads for maintenance.

3. An unknown number of desert tortoises may be taken in the form of indirect mortality through predation by ravens drawn to the project area.

4. An unknown number of desert tortoise eggs may be destroyed during installation of the optic ground wire and construction of the Searchlight regeneration station.

5. An unknown number of desert tortoises may be taken indirectly in the form of harm through increased noise associated with operation of heavy equipment.

In addition, a total of 2.05 acres of desert tortoise habitat, including 0.83 -acres of $\mathrm{CH}$ may be disturbed as a result of the installation of the optic ground wire and construction of the Searchlight regeneration station.

\section{Effect of the Take}

In the accompanying biological opinion, the Service determined that this level of anticipated take will not reduce appreciably the likelihood of survival and recovery of the Mojave population of the desert tortoise in the wild or diminish the value of $\mathrm{CH}$ both for survival and recovery of the desert tortoise.

\section{Reasonable and Prudent Measures}

The Service believes that the following reasonable and prudent measures are necessary and appropriate to minimize take of desert tortoise:

1. Measures shall be taken to minimize take of desert tortoises associated with the installation of the optic ground wire and construction of the Searchlight regeneration station.

2. Measures shall be taken to minimize predation on tortoises by ravens drawn to the proposed project area. 
3. Measures shall be taken to minimize destruction of desert tortoise habitat, such as soil compaction, erosion, or crushed vegetation, due to surface-disturbing activities.

4. Measures shall be taken to ensure compliance with the reasonable and prudent measures, terms and conditions, reporting requirements, and reinitiation requirements contained in this biological opinion.

\section{Terms and Conditions}

In order to be exempt from the prohibitions of section 9 of the Act, Western must comply with the following terms and conditions, which implement the reasonable and prudent measures described above. These terms and conditions are non-discretionary.

1. To implement Reasonable and Prudent Measure Number 1, Western shall fully implement the following measures:

a. A qualified desert tortoise biologist shall clear all areas proposed for disturbance of desert tortoises prior to initial surface disturbance. During the tortoise active season, the preconstruction clearance shall be conducted no more than 24 hours before initiation of construction. During the tortoise inactive season (November 1 through February 28) the preconstruction clearance shall be conducted within 3 days before work begins. All desert tortoise burrows and other species' burrows which may be used by tortoises, shall be examined with a fiber optic scope, if necessary, to determine occupancy of each burrow by desert tortoises.

b. Burrows containing tortoises or nests will be excavated by hand with hand tools to allow removal of the tortoise or eggs. Any desert tortoises or eggs found shall be removed and relocated by a qualified tortoise biologist in accordance with Serviceapproved protocol and Term and Condition 1.c. below. The current Serviceapproved protocol is Desert Tortoise Council (1994, revised 1996). Tortoises shall be purposefully moved only by a qualified tortoise biologist, solely for the purpose of moving them out of harm's way. No tortoise shall be relocated to habitat on lands not administered by Reclamation or the Bureau without the permission of the land owner or management agency. If on private lands, this permission shall be in writing. If on public lands, permission may be verbal initially, but shall be followed up in writing. 
In accordance with Procedures for Endangered Species Act Compliance for the Mojave Desert Tortoise (Service 1992), a biologist should possess a bachelor's or graduate degree in biology, ecology, wildlife biology, herpetology, or related fields. The biologist must have demonstrated prior field experience using accepted resource agency techniques to survey for desert tortoises. Field experience may mean a minimum of 60 days field experience searching for desert tortoises and tortoise sign. In addition, the biologist should have the ability to recognize and accurately identify all types of desert tortoise sign. The Service does not endorse any individual or company with respect to their abilities to conduct satisfactory surveys.

c. Desert tortoises removed from the project area shall be released into undisturbed habitat approximately 1,000 feet from the project boundary and placed in the shade of a shrub or in a natural unoccupied burrow similar to the hibernaculum in which it was found or in an artificially constructed burrow in accordance with Serviceapproved protocol (Desert Tortoise Council 1994, revised 1996). During mild temperature periods in the spring and early fall, tortoises removed from the site will not necessarily be placed in a burrow but will be placed in the shade.

d. Desert tortoises moved in winter (i.e., November 1 through February 28/29) or those in hibernation, regardless of date, must be placed into an adequate burrow; if one is not available, one will be constructed following Service-approved protocol. The current Service-approved protocol is Desert Tortoise Council (1994, revised 1996).

e. A qualified tortoise biologist will be onsite during regeneration station construction and other construction activities (e.g., pulling and splicing and trenching) to insure that desert tortoises are not inadvertently harmed. If a tortoise wanders onto the site, all construction activity in the immediate area will cease until the tortoise leaves the area on its own accord or is removed in accordance with Term and Condition 1.c. and 1.d. above.

f. A qualified desert tortoise biologist will be responsible for informing all foremen, workers, and other employees working on this project abcut the desert tortoise. This will include information on the life history of the desert tortoise, legal protection for desert tortoises, penalties for violations of Federal and State laws, 
general tortoise activity patterns, reporting requirements, measures to protect tortoises, and personal measures employees can take to promote the conservation of desert tortoises. The definition of "take" will also be explained.

The education program shall instruct attendees that the definition of "take" includes capture. Therefore, any unauthorized person who picks up a desert tortoise or restricts the animals' ability to move freely, could be found guilty of illegal "take." The same applies for any individual if the authorized level of incidental take has been reached or exceeded.

g. Western shall insure that all operators and associated personnel receive training described in Term and Condition 1.f. above. Western shall require circulation of an acknowledgment form to all those who received training. As part of the education program, all workers will also be instructed to check underneath all vehicles before moving such vehicles. Tortoises often take cover under vehicles.

h. A maximum speed limit of 25 miles per hour will be required for all vehicles on the project site and unposted dirt roads.

i. The chain-link fencing around each regeneration station shall be constructed to maintain zero clearance between the ground and the bottom edge of the fence.

j. During construction, if trenches are to remain open overnight during the period from March 1 through October 31, they shall be checked for desert tortoises. The trenches shall be checked at least twice a day, immediately before work in the morning and at the end of the work day. The trenches shall also be checked immediately before backfilling.

k. To prevent mortality, injury, and harassment of desert tortoises and damage to their burrows and coversites, no pets shall be permitted in any project construction area unless confined or leashed.

1. If a tortoise encountered during the use of access roads for maintenance activities is in imminent danger with immediate death or injury likely (such as from an approaching vehicle or equipment), and the tortoise has been given the opportunity to move but has withdrawn in its shell and is not moving, maintenance personnel that have had the training described in 1.f. above may move the tortoise off the access road if it is not possible to safely drive around the tortoise without 
damaging vegetation. The tortoise must be moved in the same direction of travel. The tortoise shall be picked up gently with two hands, kept level, and carried close to the ground. The tortoise shall be placed in the shade of a shrub approximately 25 feet from the road edge.

2. To implement Reasonable and Prudent Measure Number 2, Western shall fully implement the following measure:

The optic ground wire contractor shall implement a litter-control program that will include the use of covered, raven-proof trash receptacles; removal of trash from the construction site to the trash receptacles following the close of each work day; and proper disposal of trash in a landfill or transfer facility on an as-needed basis.

3. To implement Reasonable and Prudent Measure Number 3, Western shall fully implement the following measures:

a. The two regeneration sites and construction activity sites (e.g., pulling and splicing areas and trenching areas) shall be clearly marked or flagged at the outer limits prior to the onset of any surface-disturbing activity. All personnel shall be informed that their activities must be confined to within the marked or flagged areas.

b. No widening or upgrading of existing access roads shall be undertaken in the area of construction, except for repairs necessary to make roads passable. There shall be no blading of new access roads.

c. A biologist shall be assigned to the pre-construction survey team(s). The biologist shall be responsible for ensuring that all work areas (e.g., splicing and pulling sites, trenching sites) shall also be surveyed by a biologist as constnuction proceeds. Potential work areas shall be flagged several days prior to construction for review by a biologist. All tortoise burrows (or other shelter sites) shall be avoided.

d. Ovemight parking and storage of equipment and material shall be in previously disturbed areas (i.e., lacking vegetation). These areas shall also be designated and clearly flagged by the pre-construction survey team. 
e. No blading of splicing and pulling sites shall occur. Construction workers shall strictly limit their activities and vehicles to construction areas (e.g., splicing and pulling sites, trenching sites, regeneration sites) which have been flagged to eliminate adverse impacts to desert tortoises and their habitat. Aside from these areas, workers may not drive cross-country even within the right-of-way. All workers would be instructed that their activities are restricted to flagged and cleared areas.

f. All construction-vehicle movement outside of the right-of-way shall be restricted to existing access roads.

g. The area limits of construction activities shall be clearly flagged, with activity restricted to and confined within those limits. No paint or permanent discoloring agents would be applied to rocks or vegetation to indicate survey or construction activity limits.

h. Hazardous materials shall not be drained onto the ground or into streams or drainage areas. Petroleum products, and other potentially hazardous materials shall be removed to a disposal facility authorized to accept such materials.

i. Prior to any surface-disturbing activity associated with this proposed project, Reclamation shall pay a fee of $\$ 2,200.00$ per acre for each acre of surface disturbance in desert tortoise $\mathrm{CH}$ and $\$ 550.00$ per acre for each acre of surface disturbance in other desert tortoise habitat. A total of $\$ 2,497.00$ in fees shall be collected to remunerate for the loss of 2.05 acres of desert tortoise habitat. ( 1.22 acres of desert tortoise habitat plus 0.83 -acres of desert tortoise $\mathrm{CH}$ ) as a result of construction of the Searchlight regeneration station, burying of 1,650 feet of optic ground wire, and pulling and splicing of the optic ground wire at 25 sites [ $(\$ 550.00 \times 1.22$ acres $)$ plus $(\$ 550.00 \times 0.83$ acres $\times 4$ for compensation rate)]. This fee will be paid to the Desert Tortoise Habitat Conservation Fund Number 730-9999 administered by Clark County, for the purpose of securing tortoise management areas, habitat enhancement, and tortoise research. This rate will be indexed for inflation based on the Bureau of Labor Statistics Consumer Price Index beginning January 1, 1998. These funds are independent of any other fees collected by the county for desert tortoise conservation planning. Clark County serves as the banker of these funds and receives no benefit from administering these funds. This fee will be paid to the Desert Tortoise Habitat Conservation Fund prior to surface-disturbing activity. 
Payment shall be by certified check or money order payable to Clark County and delivered to:

\author{
Clark County \\ Department of Administrative Services \\ 500 South Grand Central Parkway \\ Post Office Box 551712 \\ Las Vegas, Nevada 89155-1712
}

The payment shall be accompanied by a cover letter from the payee that identifies the following information:

(1) The project name, biological opinion number, and payee's name, address, and phone number.

(2) The amount of payment enclosed and the number of the check or money order.

The project proponent or applicant may receive credit for the payment of such fees and deduct such costs from desert tortoise impact fees charged by local government entities.

[Note: The compensation rate is based on the offsite compensation formula developed and approved by the Desert Tortoise Management Oversight Group (Hastey, et al. 1991). A compensation rate of 4 was determined by the following formula: Compensation rate of $4=C(3)+T(1)+E(0)+G(0)+A(0)]$. For additional information regarding the formula see Appendix $A$.

4. To implement Reasonable and Prudent Measure Number 4, Western shall fully implement the following measures:

a. Western will designate an FCR. The FCR will be responsible for overseeing compliance with protective stipulations for the desert tortoise and for coordinating compliance with this biological opinion. The FCR will have authority to halt activities or equipment which may be in violation with the stipulations.

b. Prior to handling any desert tortoise, carcass, or egg, appropriate State permits will be acquired from the Nevada Division of Wildlife. 
c. No later than 90 days after completion of construction within tortoise habitat, the FCR and onsite biologist shall prepare a report for Western and the Service. The report shall document the effectiveness of the tortoise minimization measures. The report shall include an assessment of the number of acres of desert tortoise habitat disturbed by the project. An annual report of any tortoise encounters during use of access roads for maintenance activities shall be provided to the Service in January.

The reasonable and prudent measures, with their implementing terms and conditions, are designed to minimize the anticipated incidental take that may result from the proposed action. With implementation of these measures, the Service believes that no more than two (2) desert tortoises may be killed or injured during installation of the optic ground wire and the construction of the Searchlight regeneration station, and an additional two (2) tortoises may be accidentally killed or injured per year on access roads used for maintenance; five (5) tortoises may be captured and moved out of harm's way during installation of the optic ground wire and construction of the Searchlight regeneration station, and an additional two (2) tortoises per year may be captured and moved out of harm's way during use of access roads for maintenance. Up to 2.05 acres of desert tortoise habitat, including 0.83 -acres of $\mathrm{CH}$ may be disturbed as a result of the installation of the optic ground wire and the construction of the Searchlight regeneration station. If during the course of the action, the level of incidental take identified is exceeded, reinitiation of consultation will be required. Western must immediately provide an explanation of the causes of the taking and review with the Service the need for possible modification of the reasonable and prudent measures.

\section{Reporting Requirements}

Upon locating a dead, injured, or sick endangered or threatened species, initial notification must be made to the Service's Division of Law Enforcement in Las Vegas, Nevada, at (702) 388-6380. Care should be taken in handling sick or injured desert tortoises to ensure effective treatment and care or the handling of dead specimens to preserve biological material in the best possible state for later analysis of cause of death. In conjunction with the care of sick or injured desert tortoises or preservation of biological materials from a dead animal, the finder has the responsibility to carry out instructions provided by the Service's Division of Law Enforcement to ensure that evidence intrinsic to the specimen is not unnecessarily disturbed.

Sick or injured desert tortoises shall be delivered to any qualified veterinarian for appropriate treatment or disposal. Dead desert tortoises suitable for preparation as museum specimens shall be frozen immediately and provided to an institution holding appropriate Federal and State 
permits per their instructions. Should no institutions want the desert tortoise specimens, or if it is determined that they are too damaged (crushed, spoiled, etc.) for preparation as a museum specimen, then they may be buried away from the project area or cremated, upon authorization by the Service's Division of Law Enforcement. Reclamation or the project proponent shall bear the cost of any required treatment of injured desert tortoises, euthanasia of sick desert tortoises, or cremation of dead desert tortoises. Should sick or injured desert tortoises be treated by a veterinarian and survive, they may be transferred as directed by the Service.

\section{Censervation Recommendations}

Section 7(a)(1) of the Act directs Federal agencies to use their authorities to further the purposes of the Act by carrying out conservation programs for the benefit of endangered and threatened species. Conservation recommendations are discretionary agency activities to minimize or avoid adverse effects of a proposed action on listed species or CH, to help implement recovery plans, or to develop information.

As a conservation recommendation, Western should rehabilitate a disturbed area or closed road within the proposed Piute-Eldorado DWMA.

In order for the Service to be kept informed of actions that either minimize or avoid adverse effects or that benefit listed species or their habitats, the Service requests notification of the implementation of any conservation recommendations.

\section{Beinitiation Notice}

This concludes formal consultation on the actions outlined in your January 29,1997 , request. As required by 50 CFR $\$ 402.16$, reinitiation of formal consultation is required where discretionary Federal agency involvement or control over an action has been retained (or is authorized by law) and if: (1) The amount or extent of incidental take is exceeded; (2) new information reveals effects of the agency action that may affect listed species or $\mathrm{CH}$ in a manner or to an extent not considered in this opinion; (3) the agency action is subsequently modified in a manner that causes an effect to the listed species or $\mathrm{CH}$ that was not considered in this opinion; or (4) a new species is listed or $\mathrm{CH}$ designated that may be affected by the action. In instances where the amount or extent of incidental take is exceeded, any operations causing such take must cease pending reinitiation. 
We appreciate the assistance and cooperation of your staff throughout this consultation process. If we can be of any further assistance, please contact Dolores Savignano, in the Las Vegas Office, at (702) 646-3499, or me at (702) 784-5227.

$$
\begin{aligned}
& \text { Ollu R.Pfisten } \\
& \text { fo Carlos H. Mendoza }
\end{aligned}
$$

cc:

Director of Public Lands, The Nature Conservancy, Las Vegas, Nevada

Desert Conservation Plan Administrator, Administrative Services, Clark County, Las Vegas, Nevada

Administrator, Nevada Division of Wildlife, Reno, Nevada

Regional Manager, Nevada Division of Wildlife, Las Vegas, Nevada

Deputy State Director, Resources, Land Use, and Planning, Bureau of Land Management, Reno, Nevada

District Manager, Las Vegas District, Bureau of Land Management, Las Vegas, Nevada (Attn: ADM--Renewable Resources; ADM-Recreation and Wilderness; and ADM-NonRenewable Resources)

Manager, Environmental Compliance Group, Lower Colorado River Regional Office, Bureau of Reclamation, Boulder City, Nevada

Assistant Regional Director, Interior Basin Ecoregion, Fish and Wildlife Service, Portland, Oregon

Assistant Regional Director, Klamath and Califomia Ecoregions, Fish and Wildlife Service, Portland, Oregon (Attn: Larry Salata)

State Supervisor, Phoenix State Office, Fish and Wildlife Service, Phoenix, Arizona

Senior Resident Agent, Division of Law Enforcement, Fish and Wildlife Service, Boise, Idaho 


\section{Literature Cited}

Berry, K. H. 1985. Avian predation on the desert tortoise (Gopherus agassizii) in California. U.S. Bureau of Land Management, Riverside, California. Report to Southern California Edison Company, Rosemead, Califomia.

Berry, K. H. 1986. Desert tortoise (Gopherus agassizii) research in California, 1976-1985. Herpetologica 42:62-67.

Berry, K. H. and B. L. Burge. 1984. The desert tortoise in Nevada. Chapter 8 In: The status of the desert tortoise (Gopherus agassizii) in the United States. Report to U.S. Fish and Wildlife Service from the Desert Tortoise Council. Order No. 11310-0083-81.

Bondello, M. C. 1976. The effects of high-intensity motorcycle sounds on the acoustical sensitivity of the desert iguana (Dipsosaurus dorsalis). M.A. Thesis, Biology Department, California State University, Fullerton. 37 pp.

Bondello, M. C., A. C. Huntley, H. B. Cohen, and B. H. Brattstrom. 1979. The effects of dune buggy sounds on the telencephalic auditory evoked response in the Mojave fringe-toed lizards (Uma scoparia). Unpublished report, Contract No. CA-060-CT7-2737, Bureau of Land Management, Riverside, California. 31 pp.

Bureau of Land Management. 1990. Draft Raven Management Plan for the California Desert Conservation Area. Prepared by Bureau of Land Management, Califormia Desert District, Riverside, California. April 1990.

Burge, B. L. 1978. Physical characteristics and patterns of utilization of cover sites by Gopherus agassizii in southern Nevada. Proceedings of the 1978 Desert Tortoise Council Symposium. pp. 80-111.

Burge, B. L., and W. G. Bradley. 1976. Population density, structure and feeding habits of the desert tortoise (Gopherus agassizii), in a low desert study area in southern Nevada. Proceedings of the 1976 Desert Tortoise Council Symposium. pp. 51-74. 
Bury, R. B., T. C. Esque, L. A. DeFalco, and P. A. Medica. 1994. Distribution, habitat use, and protection of the desert tortoise in the Eastern Mojave Desert. In: R. B. Bury and D. J. Germano, editors. Biology of the North American tortoises. National Biological Survey, Fish and Wildlife Research 13:57-72.

Dames and Moore. 1997. Biological assessment for the proposed McCullough to Liberty fiber optics project. Unpublished report prepared by Dames and Moore for Western Area Power Administration. January 1997.

Desert Tortoise Council. 1994. Guidelines for handling desert tortoises during construction projects. Edward L. LaRue, Jr., editor. San Bernardino, California. Revised 1996.

Fish and Wildlife Service. 1992. Procedures for Endangered Species Act compliance for the Mojave desert tortoise. Regions 1, 2, and 6. October 1992. 18 pp. plus appendices.

Fish and Wildlife Service. 1994. Desert tortoise (Mojave population) recovery plan. Portland, Oregon. 73 pp. plus appendices.

Germano, D.J., R.B. Bury, T.C. Esque, T.H. Fritts, and P.A. Medica. 1994. Range and habitat of the desert tortoise. In: R. B. Bury and D. J. Germano, editors. Biology of the North American tortoises. National Biological Survey, Fish and Wildlife Research 13:7384.

Hastey, E., L. K. Rosenkrance, B. R. Templeton, J. M. Parker, W. H. Radtkey, D. L. Harlow, B. D. Taubert, F. Worthley, W. A. Molini, R D. Radantris. 1991. Compensation for the desert tortoise. A report prepared for the Desert Tortoise Management Oversight Group. November 1991. $16 \mathrm{pp}$.

Hovik, D. C. and D. B. Hardenbrook. 1989. Summer and fall activity and movements of desert tortoise in Pahrump Valley, Nevada. Abstract of paper presented at the Fourteenth Annual Meeting of the Desert Tortoise Council.

Karl. A. 1981. The distribution and relative densities of the desert tortoise (Gopherus agassizii) in Lincoln and Nye Counties, Nevada. Proceedings of the 1981 Desert Tortoise Council Symposium. pp. 76-92. 
Karl, A. E. 1983a. The distribution and relative densities of the desert tortoise (Gopherus agassizi) in Clark County, Nevada. Unpublished Report to Bureau of Land Management, Denver, Colorado. Contract No. YA-512-CT9-90. 46 pp.

Karl, A. E. 1983b. The distribution, relative densities, and habitat associations of the desert tortoise (Gopherus agassizii) in Nevada. MS Thesis, California State University, Northridge. $111 \mathrm{pp}$.

Regional Environmental Consultants. 1991. Short term habitat conservation plan for the desert tortoise in Las Vegas Valley, Clark County, Nevada. Prepared for Clark County, 225 Bridger Avenue, Las Vegas, Nevada 89155. January 1991. 143 pp.

Regional Environmental Consultants. 1995. Clark County desert conservation plan. Prepared for Clark County, 500 Grand Central Parkway, Las Vegas, Nevada 89155. 129 pp. plus appendices. 
Appendix A

Description of factors used to compute compensation rates.

EACTOR

$\mathrm{C}=$ Category of habitat:

a) the lands are in Category III desert tortoise habitat

b) the lands are in Category II desert tortoise habitat

c) the lands are in Category I desert tortoise habitat or critical habitat

$T=$ Term of effect:

a) the effects of the proposed action are expected to be short term ( $<10$ years)

b) the effects of the proposed action are expected to be long term

( 10 years)

$E=$ Existing disturbance on site:

a) there is moderate to heavy existing habitat disturbance

b) there is little or no existing habitat disturbance

$G=$ Growth inducing effects:

a) the proposed action will have no growth inducing effects

b) the proposed action will have growth inducing effects

$A=$ Adjacent habitat impacts:

a) adjacent habitat will not be affected

b) adjacent habitat will receive direct or indirect deleterious impacts

Compensation Rate $=\mathrm{C}+\mathrm{T}+\mathrm{E}+\mathrm{G}+\mathrm{A}$ 